CO-TEACHING AS A CLINICAL MODEL OF STUDENT TEACHING: PERCEPTIONS OF PREPAREDNESS FOR FIRST YEAR TEACHING

\author{
A Dissertation \\ presented to \\ the Faculty of the Graduate School \\ at the University of Missouri-Columbia \\ In Partial Fulfillment \\ of the Requirements for the Degree \\ Doctor of Educational Leadership and Policy Analysis \\ by \\ ABBY VOLMER \\ May 2018
}


The undersigned, appointed by the dean of the Graduate School, have examined the dissertation entitled

\section{CO-TEACHING AS A CLINICAL MODEL OF STUDENT TEACHING: PERCEPTIONS OF PREPAREDNESS FOR FIRST YEAR TEACHING}

presented by Abby Volmer, a candidate for the degree of doctor of Educational Leadership and Policy Analysis, and hereby certify that, in their opinion, it is worthy of acceptance.

\begin{tabular}{c}
\hline Dr. Sandy Hutchinson \\
\hline Dr. Barbara Martin \\
\hline Dr. Steve Ritter \\
\hline Dr. Doug Thomas
\end{tabular}




\section{DEDICATIONS}

I would like to thank the Cohort Nine group of women who provided me with guidance, support, and laughter throughout our doctoral program. Most importantly, however, I would like to thank my husband Lynn Volmer for his patience and encouragement in my crazy and amazing endeavor during this autumnal season of our lives. 


\section{ACKNOWLEDGEMENTS}

I would like to thank Dr. Sandy Hutchinson for her unfailing support and guidance throughout my doctoral process. I would also like to thank Dr. Michael Wright, the Dean of the College of Education at the University of Central Missouri (UCM), for his open communications regarding the history and implementation of the co-teaching model of student teaching at UCM. Additionally, I would like to thank Dr. Joanie Hartnett for her insight and research in the implementation process of the co-teaching model for student teachers. Finally, I would like to thank all the student teachers, cooperating teachers, and supervising teachers who took their time to reflect upon the use of the co-teaching model of student teaching and share their perceptions of how well the co-teaching model prepares teachers for their first year of teaching. 


\section{TABLE OF CONTENTS}

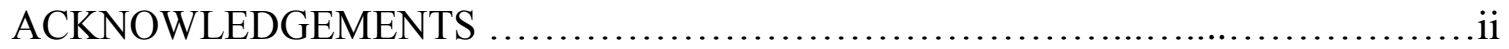

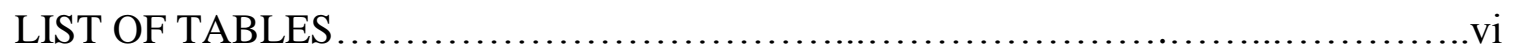

LIST OF JOURNAL ARTICLE TABLES .....................................vii

LIST OF APPENDIX ARTICLE TABLES ........................................viii

LIST OF ABBREVIATIONS ..................................................

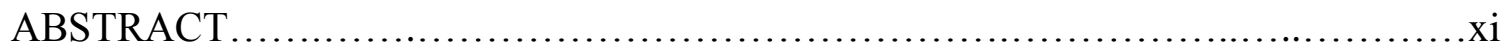

SECTION 1: INTRODUCTION TO DISSERTATION ............................

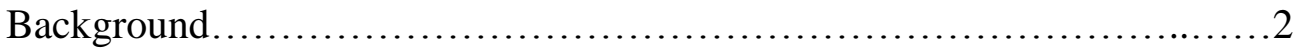

Statement of the Problem..........................................4

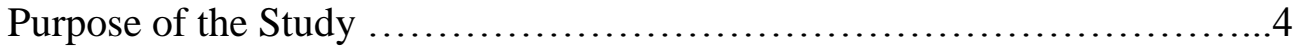

Research Questions..................................................5

Definition of Terms...............................................6

Conceptual/Theoretical Frameworks...................................7

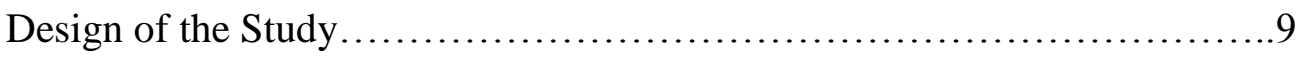

Data Analysis................................................... 17

Limitations, Assumptions, and Design Controls.......................22

Significance of the Study .......................................22

Summary ......................................................24

SECTION 2: PRACTITIONER SETTING FOR THE STUDY $\ldots \ldots \ldots \ldots \ldots \ldots \ldots \ldots \ldots . . . . . . .28$

History of Organization..........................................29 
Organizational Analysis.................................................... 31

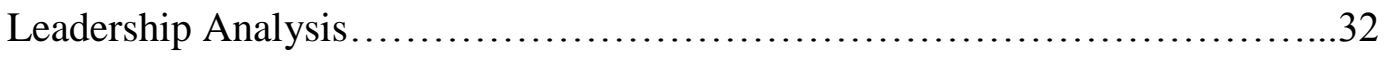

Implications of Research in the Practitioner Setting ............................36

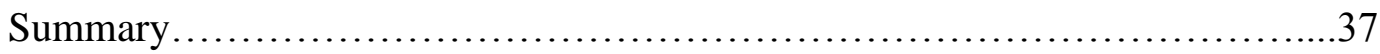

SECTION 3: SCHOLARLY REVIEW FOR THE STUDY ............................

Introduction ................................................................ 40

Models of Co-Teaching ..................................................... 41

Co-Teaching Skill Sets and Roles........................................43

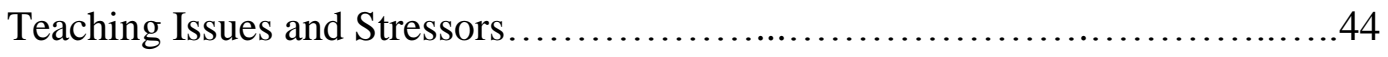

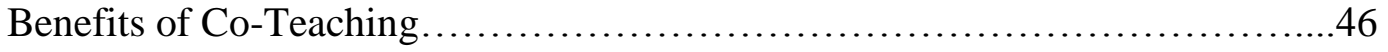

History of Student Teaching ..............................................48

Scholarship Research in Relation to Research Questions........................52

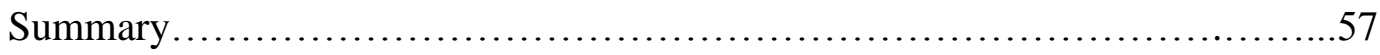

SECTION 4: CONTRIBUTION TO PRACTICE .................................60

Plan for Dissemination of Practitioner Contribution...........................61

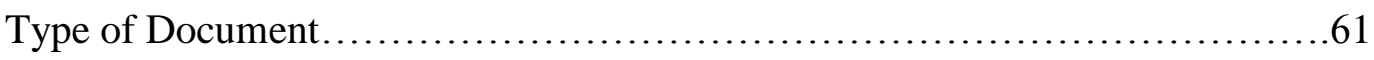

Rationale for Contribution Type........................................61

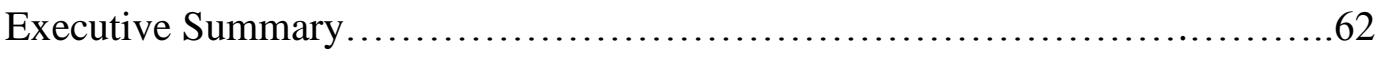

Practitioner Presentation.................................................65

SECTION 5: CONTRIBUTION TO SCHOLARSHIP ............................116

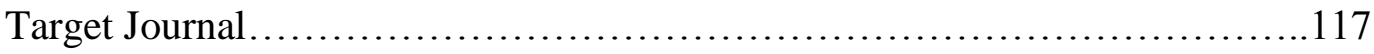

Rationale for This Target................................................ 117 
Plan for Submission..............................................117

Journal Submission..................................................117

SECTION 6: SCHOLARLY PRACTIONER REFLECTION ....................... 150

REFERENCES ........................................................... 156

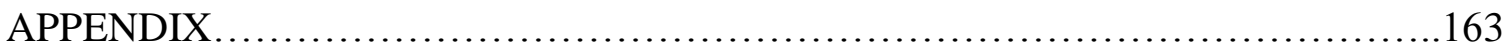

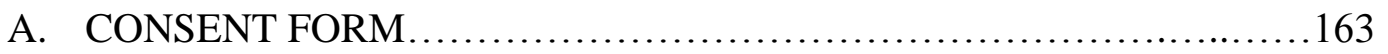

B. SURVEY AND INTERVIEW QUESTIONS AND PROMPTS RELATE TO

RESEARCH QUESTIONS.......................................... 165

C. QUANTITATIVE SURVEYS ...................................... 167

D. QUALITATIVE INTERVIEW PROMPTS/QUESTIONS: STUDENT

TEACHER ........................................................ 184

E. QUALITATIVE INTERVIEW PROMPTS/QUESTIONS: COOPERATING TEACHERS.............................................................. 186

F. QUALITATIVE INTERVIEW PROMPTS/QUESTIONS: UNIVERSITY

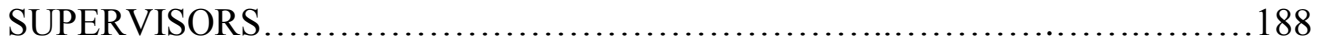

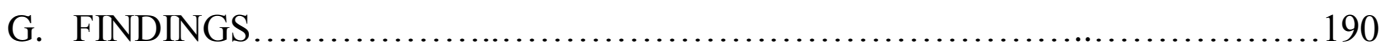

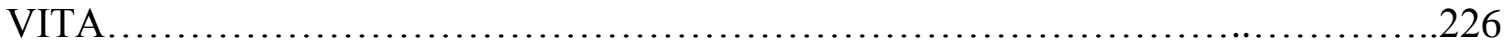




\section{LIST OF TABLES}

Table

Page

1. Quantitative Survey Participants..................................................

2. Qualitative Interview Participants: Current and Former Student Teachers...................13

3. Qualitative Interview Participants: Cooperating Teachers..............................13

4. Qualitative Interview Participants: University Supervisors........................... 14

5. Respondent Groups' Perceptions of Effectiveness of Co-Teaching Model of Student

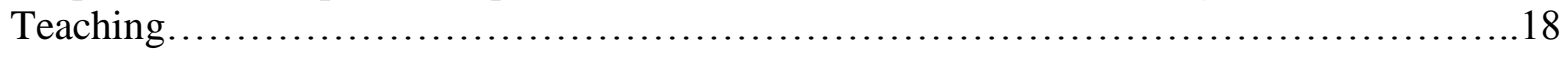




\section{LIST OF JOURNAL ARTICLE TABLES}

Table

Page

1. Quantitative Survey Participants.............................................. 126

2. Respondent Groups' Perceptions of Effectiveness of Co-Teaching Model of Student Teaching ......................................................................

3. Student Teachers/Cooperating Teachers Group Perceptions $t$-Test Descriptive Table......132

4. Student Teachers/University Supervisors Group Perceptions $t$-Test Descriptive Table.......132

5. Cooperating Teachers/University Supervisors Group Perceptions t-Test Descriptive

Table............................................................................ 133 


\section{LIST OF APPENDIX TABLES}

Table

Page

G1. Respondent Groups’ Perceptions of Effectiveness of Co-Teaching Model of Student Teaching.

G2. Respondent Group (Roles) Perceptions One-Way ANOVA Descriptives Table.

G3. Respondent Group (Roles) Perceptions One-Way ANOVA Result Details Table.

G4. Student Teachers/Cooperating Teachers Group Perceptions t-Test Descriptive Table.

G5. Student Teachers/University Supervisors Group Perceptions t-Test Descriptive Table

G6. Cooperating Teachers/University Supervisors Group Perceptions t-Test Descriptive Table. .194

G7. Respondents' Perceptions by Grade Level One-Way ANOVA Descriptives Table....

G8. Respondents' Perceptions by Grade Level One-Way ANOVA Result Details Table. ... 196

G9. Grades K-8/K-12 Respondents t-Test Descriptive Table.

G10. Grades K-8/9-12 Respondents t-Test Descriptive Table.

G11. Grades 9-12/K-12 t-Test Three Descriptive Table. .198

G12. Respondents' Perceptions by Educational Concepts Summary of Data.

G13. Respondents' Perceptions by Educational Concepts: One-Way Repeated Measures ANOVA

Results Details .199

G14. Respondents' Perceptions by Educational Concepts Means. .200 


\section{LIST OF ABBREVIATIONS}

AACTE.......The American Association of Colleges for Teacher Education ANOVA......Analysis of Variance

CK/IS..........Content Knowledge/Instructional Strategies

CM.............Classroom Management

COE........... College of Education

CR/LP.........Curriculum/Lesson Planning

DESE..........Department of Elementary and Secondary Education

ELL............English Language Learner

GRR...........Gradual Release of Responsibility

IDEIA..........Individuals with Disabilities Education Improvement Act

INTASC........Interstate New Teacher and Assessment Support Consortium

JTE.............Journal of Teacher Education

LEA..............ocal Education Agency

LSD ............Least Squared Differences

MKO............More Knowledgeable Other

NCATE.........National Council for Accreditation of Teacher Education

NCLB...........No Child Left Behind

PR.............Professionalism

SLG............Student Learning Goals

SPSS...........Statistical Package for the Social Sciences

TQE.............Teacher Quality Enhancement 
UCM...........University of Central Missouri YMCA......Y Young Men's Christian Association ZPD..........Zone of Proximal Development 


\title{
CO-TEACHING AS A CLINICAL MODEL OF STUDENT TEACHING: PERCEPTIONS OF PREPAREDNESS FOR FIRST YEAR TEACHING
}

\begin{abstract}
College of Education faculty members at the University of Central Missouri found that public school teachers and administrators from surrounding schools were reluctant to hand over classrooms of students to novice teachers for student teaching. With high stakes accountability for test scores, teachers voiced their need to be present in the classroom, particularly during spring semester of statewide testing (Diana, 2014). The university adopted a co-teaching model of student teaching to prepare its teaching candidates for the first year of teaching while allowing the cooperating teacher to stay in the classroom throughout the student teaching term. The problem-of-practice addressed in this study focuses on the need to determine if a co-teaching student teacher model provides university students an adequate amount of clinical experience and preparation to support a successful first year of teaching.

The purpose of this study is two-fold: 1) analyze the perceptions of former and current student teachers, cooperating teachers, and university supervisors on the coteaching model of student teaching and 2) assess the model's effectiveness in preparing student teachers for their first year of teaching. To this end, the research questions are as follows:
\end{abstract}

Research Question 1. What are the perceptions of University of Central Missouri current and former student teachers on the co-teaching student-teaching model's ability to prepare student teachers for their first year of teaching?

Research Question 2. What are the perceptions of University of Central Missouri 
university supervisors on the co-teaching student-teaching model's ability to prepare student teachers for their first year of teaching?

Research Question 3. What are the perceptions of cooperating teachers on the coteaching student- teaching model's ability to prepare student teachers for their first year of teaching?

The research questions were answered through an analysis of the data collected via a quantitative survey followed by a qualitative interview. The quantitative survey asked respondents to rate items on a Likert-type scale (Fink, 2013) as to how well they perceived the co-teaching model of student teaching prepares student teachers to meet Missouri Teaching Standards. The qualitative survey asked respondents to discuss their perceptions of how well the co-teaching model of student teaching prepares student teachers for their first year of teaching based on their personal experience.

The responses indicated that the co-teaching model scored higher in first year teacher preparation by elementary teachers and elementary supervisors than by secondary teachers and supervisors. Responses also indicated that student teachers and cooperating teachers perceived the co-teaching model as more positively preparing student teachers for their first year of teaching than do university supervisors. Additionally, responses indicated that the co-teaching model of student teaching closely aligns to the Gradual Release of Responsibility theory of learning (Pearson \& Gallagher, 1983) with the coteaching model of student teaching strengths as follows: extensive modeling by a More Knowledgeable Other (Vygotsky, 1978), extensive professional reflection and immediate feedback, a narrowing of focus, professional collaboration, and building of confidence in the student teacher. Due to the student teacher never solely taking over the classroom 
responsibilities in a co-teaching model of student teaching, the model's barrier for preparing student teachers for their first year of teaching centers on the student teacher not receiving a fully realistic teaching experience in a classroom without a co-teacher.

On this basis, it is recommended that universities and school districts adopt the co-teaching model of student teaching to provide a strong base of teaching background for the student teacher through the Gradual Release of Responsibility. The student teacher should also receive two to three weeks of sole classroom responsibility and all the duties in that role as to provide a realistic experience of teaching without a co-teacher present. Further research could synthesize the perceptions of the same group of participants in this study regarding a model similar to the one recommended. 


\section{SECTION ONE}

\section{INTRODUCTION TO DISSERTATION-IN-PRACTICE}




\section{Background}

The University of Central Missouri's teacher preparation program was struggling to find enough school districts to participate in the student teaching program. Upon informal investigation, the university's College of Education found local public school teachers and their administrators were reluctant to hand over classrooms of students to novice teachers. With high stakes accountability for test scores, teachers voiced their need to be present in the classroom, particularly during spring semester statewide testing (Diana, 2014). Within this same time of struggling to find cooperating teachers, the Blue Ribbon Panel of the National Council for Accreditation of Teacher Education (NCATE, 2010) published a national report calling for PK-12 teachers and teacher preparation programs to see teacher preparation as a shared responsibility. So began a study by the university's College of Education leaders in the use of a co-teaching model for clinical practice for student teachers.

\section{Introduction to Co-Teaching Applications and Context}

Co-teaching, also called team-teaching or collaborative teaching, became a viable method of inclusive instruction in the special education discipline to access the regular classroom setting and curriculum. Co-teaching, as defined by Villa, Thousand, and Nevin (2008), is an instructional model whereby two or more people of equal status share the responsibility of planning for, instructing, and assessing some or all of the students in a classroom. Higher education teacher preparation programs followed suit by implementing the co-teaching model in teacher preparation programs to prepare their student teachers to meet the needs of diverse student populations by modeling the coteaching partnership (Nevin, 2009). Finally, in a lesser-researched application, the co- 
teaching model was implemented into clinical practices of regular education teacher preparation programs whereby regular education student teachers team-taught with their mentor teachers throughout their student teaching experience.

\section{University of Central Missouri Student Teaching Background}

The University of Central Missouri (UCM) currently offers the co-teaching clinical model as their student teaching model in the College of Education. Hartnett, Weed, McCoy, Theiss and Nickens (2013) note that UCM developed this clinical model, in part, as a response to a call to university institutions by the Blue Ribbon Panel of the National Council for Accreditation of Teacher Education (NCATE). The NCATE report called for clinical experiences of student teachers that would increase the learning and achievement of students and empower "teachers to meet the urgent needs of schools and the challenges of the 21 st Century Classroom," (2010, p. ii). The report recommended universities view the clinical experience of student teachers as a shared experience (Harnett et al., 2013). Additionally, the state of Missouri’s Department of Elementary and Secondary Education was asking universities to clearly articulate the clinical practices of their institution. Finally, a local challenge was emerging for UCM's College of Education. Partnering school districts accepting student teachers were exhibiting concern with leaving classrooms in full control of student teachers in lieu of the accountability of high stakes testing. Having the mentor teacher and student teacher team-teach seemed a positive solution for both the partnering school districts and the National Council of Accreditation of Teacher Education (NCATE). A co-teaching clinical model from St. Cloud State University in Minnesota was closely researched by UCM staff (Hartnett et al., 2013) and a strategic action plan was set in place to educate UCM stakeholders and 
facilitate the piloting and implementation of a co-teaching model in partnering districts.

\section{Statement of the Problem}

The problem-of-practice in this study addressed in this study lies in the need to determine if a co-teaching student teacher model provides university students an appropriate amount of clinical experience and preparation necessary to support a successful first year of teaching. Public school teachers are held accountable for the success of their students, and thus are somewhat reluctant to release instructional time to a student teacher. Student teaching is generally the last opportunity universities have to help prepare students for teaching. Does the use of a co-teaching clinical model support both parties' needs?

A gap in the research literature exists regarding the level of readiness the coteaching student teaching model provides student teachers and first- year classroom teachers. The research available on co-teaching as a model of student teaching generally focuses on the co-teaching process, professional development of co- teachers, and the benefits of co-teaching partnerships to stakeholders.

\section{Purpose of the Study}

The purpose of this study is to determine and analyze the perceptions of current and former student teachers, cooperating teachers, and university supervisors on the coteaching model of student teaching and its ability to prepare student teachers for their first year of teaching. Analyzing the perceptions of current and former student teachers, cooperating teachers who have experienced the co-teaching model, and university supervisors who have overseen the co-teaching clinical experience determined this level of readiness. 
The state of Missouri provides Missouri Teacher Standards that outline the qualities of best practices in the field of teaching (Missouri Department of Elementary and Secondary Education, 2013). The Missouri Teacher Standards guide the quantitative criteria for this study when determining levels of readiness for teaching by both current and former student teachers. The Missouri Teacher Standard categories are as follows: content knowledge aligned with appropriate instruction; student learning growth and development; curriculum implementation; critical thinking; positive classroom environment; effective communication; student assessment and data analysis; professionalism; and professional collaboration. Quantitative and qualitative data were collected from both current and former student teachers who have experienced the coteaching student teaching model and each sample's perceptions of how well their student teacher experience prepared them for their first year of teaching. Cooperating teachers and supervising teachers also provided quantitative and qualitative data on their perceptions of how well their mentees or subordinates from the co-teaching student teacher models appear prepared to teach.

\section{Research Questions}

The research questions guiding this study are as follows:

1. What are the perceptions of University of Central Missouri current and former student teachers on the co-teaching student-teaching model's ability to prepare student teachers for their first year of teaching?

2. What are the perceptions of University of Central Missouri university supervisors on the co-teaching student-teaching model's ability to prepare student teachers for their first year of teaching? 
3. What are the perceptions of cooperating teachers who work with University of Central Missouri student teachers on the co-teaching student-teaching model's ability to prepare student teachers for their first year of teaching?

\section{Definition of Terms}

The following terms were defined to help in understanding the constructs of this inquiry:

Cooperating Teacher: The cooperating teacher is a veteran teacher employed in a school district who receives a student teacher assignment. He or she works as a mentor in the clinical setting. Cooperating teachers have typically been teaching at least three years.

Co-teaching Student Teaching Model: A student teaching model in which the student teacher and the cooperating teacher plan and teach in tandem. The cooperating teacher does not leave the classroom for extended periods, but rather works collaboratively with the student teacher in both planning and implementing instruction throughout the student teaching experience.

Gradual Release of Responsibility (GRR): A model of instruction theorizing that a more skilled peer leads a learner through explicit instruction and, with guidance, gradually releases the responsibility of the determined skill or strategy until the learner is capable of independently applying the skill to new situations.

More Knowledgeable Other (MKO): A more skilled peer or mentor who works to support a learner in mastering a skill or strategy.

Preservice teacher: The preservice teacher is a teacher candidate who is currently enrolled in university course work to become a certificated teacher. The preservice teacher could be a student teacher but could also be a student accepted into the College of 
Education as a sophomore. junior, or senior who has not yet entered into the student teaching experience.

Student teacher: The student teacher is a university senior student. He or she is in the final clinical stage of teacher preparation whereby he or she is assigned a position in a neighboring school district with a veteran teacher, typically for a semester.

Traditional Student Teaching Model: A student teaching model in which the student teacher observes the cooperating teacher for approximately two weeks, teaches the class for approximately one week while being observed by the cooperating teacher, teaches without the cooperating teacher's presence for the rest of the clinical experience, and gradually gives the responsibility back to the teacher.

University Supervisor: The university supervisor is an employee of the university from which a student teacher is enrolled. His or her responsibility is to oversee the clinical practice of the student teacher.

Zone of Proximal Development (ZPD): The Zone of Proximal Development is a theory first produced by Vygotsky (1978) that describes a range in learning that occurs when a learner is unable to accomplish a skill or task without the support of a more skilled or knowledgeable other.

\section{Conceptual/Theoretical Frameworks}

The theoretical framework guiding this study is the Gradual Release of Responsibility (GRR), first coined by Pearson and Gallagher (1983) and based upon the work of Vygotsky (1978). The GRR model of instruction theorizes that the more skilled peer or, as Vygotsky termed, More Knowledgeable Other (MKO), leads the learner through explicit instruction and guidance. The MKO gradually releases the responsibility 
of the determined skill or strategy until the learner is capable of independently applying the skill to new situations. Fisher and Frey (2008) define four phases of the GRR model based upon Vygotsky's theory. The first phase provides the learner with explicit instruction from the MKO. Fisher and Frey (2008) refer to this stage as a Focused Lesson or the "I do it" portion of instruction in which "I" refers to the MKO. The next stage of GGR is Guided Instruction or the "We do" phase of learning. This stage is based heavily on Vygotsky's idea of instructional scaffolding in which the lesson provides adult and peer support for performing the skill or strategy. During instructional scaffolding, the MKO works with the learner/s in a place of learning in which the novice must rely on support from the MKO or collaboration with peers to perform the targeted skill.

Vygotsky refers to this place of learning as the Zone of Proximal Development (ZPD). The next phase of the GRR model is the collaborative phase or "You do it together" phase. This stage is the beginning of the transfer of learning in which the MKO pulls away from a central role and becomes an observer of the learning. The learner must independently apply the skill or strategy while still engaged with peers. The last phase of the GRR model is the independent phase in which the learner applies his or her new learning to a new situation. The role of the MKO is to observe the independent work of the learner.

The GGR model is applicable to the co-teaching model of student teaching if applied appropriately for independence. In the co-teaching model of student teaching, the senior teacher does not leave the room. Rather, the goal of the co-teaching student teacher model is to reach the GRR Independent Phase in a Teaming or Collaborative Model. The teaming or collaborative model as defined by Easterby-Smith and Olve 
(1984) and Pugach and Blanton (2009) means sharing the responsibility of teaching equitably in lesson planning, instruction, and assessment. The Teaming or Collaborative Model assumes the independent application of needed skills and strategies by junior teachers within a teaming setting and the novice teacher is an equal partner with the expert teacher.

Experts in the field of co-teaching have defined various models of co-teaching in the fields of special education and higher education. These models can be applied to the stages of GRR and the co-teaching model of student teaching. For instance, Friend and Cook (2010) and Bessette (2008) define various co-teaching models as follows: (1) one teach, one observe; (2) one teach, one drift; (3) alternative teaching; (4) parallel teaching: (5) station teaching; and (6) team teaching. The "one teach, one observe" and "one teach, one drift" models can be used in the Focused Lesson phase of GRR during the coteaching student teaching. The "alternative teaching" and "parallel teaching" models are used in the collaborative phase of GRR in student teaching. The "station teaching" is used in the guided practice phase of GRR and the "team teaching" is the independent phase of GRR in the co-teaching student teaching model. Team Teaching in this instance is defined as the independent application of skills or strategies in which both the senior and junior teacher share all responsibility equitably.

\section{Design of the Study}

\section{Setting/Context}

The College of Education at the University of Central Missouri produces approximately 250 Bachelor of Science in Education degrees per year in various educational disciplines (University of Central Missouri Fact Book, 2014). The University 
of Central Missouri as a whole has an enrollment count of approximately 12,500 with $54 \%$ female and $66 \%$ white non-Hispanic students. The average age of the UCM undergraduate is 22.9 and the student/faculty ratio is 16.8 .

The University of Central Missouri's (UCM) College of Education fully implements the co-teaching model of student teaching. By enlisting participants involved in this one university, the researcher was able to identify the perceptions of the level of teaching readiness based more distinctly upon the student teaching experience rather than on background knowledge from previous university work varying universities might have provided. Participants for each group were purposefully selected based upon preset criteria. Ultimately, being able to use one university helped to eliminate other background experiences students from varying universities might have received. Because of this unique ability to more closely cue into the influence of the student teaching experience, the researcher solicited student teaching participants solely from the University of Central Missouri.

The current or former student teacher participants experienced the co-teaching model of clinical practice while a student at the University of Central Missouri. The current student teacher participants completed a full semester of student teaching but have not yet experienced a first year of teaching. The former student teacher participants are all currently employed in a school district and have experienced at least one full year of teaching. The size and demographics of the employing school districts were randomly based upon the employment of the UCM students. The University supervisors are employed by UCM, but the district cooperating teachers come from various Central and Western Missouri school districts where student teachers have been assigned to complete 
their student teaching.

\section{Participants}

The current and former student teacher participants enlisted for this study are K12 UCM regular education classroom current or former student teachers. The researcher received names and emails of student teachers from the UCM College of Education and independently contacted the students via email requesting permission for the study by way of an electronic consent form. The consent form (Appendix A) outlined the purpose of the study, the involvement required of the participants, the voluntary nature of the study, and the confidentiality of identifiable data from the university, cooperating teachers, university supervisors, and employers. The current or former student teachers consented participation via an electronic consent form sent by the researcher. A total of 296 consent forms were sent to current and former student teachers who experienced the co-teaching clinical model of student teachers. There were 23 responses.

The university supervisors were employed by UCM. They were contacted by the researcher via email. The researcher outlined the purpose of the study, the involvement of the supervising teachers, the voluntary nature of the study, and the confidentiality of identifiable data from the students, university, cooperating teachers, and school districts. University supervisors either gave consent to or refuse participation via an electronic consent form sent by researcher. Twenty-eight University of Central Missouri (UCM) student teaching supervisors were sent a survey with 5 responding.

The cooperating teachers came from various assigned school districts located in

Central and Western Missouri. The researcher received names and emails from the UCM College of Education and independently contacted 128 cooperating teachers via email 
requesting permission for the study by way of an electronic consent form. The consent form outlined the purpose of the study, the involvement required of the participants, the voluntary nature of the study, and the confidentiality of identifiable data from the student teachers, the university, the supervising teachers, the school district in which they work, and future employers of the students. Fourteen cooperating teachers responded.

\begin{tabular}{|lccc|}
\hline \multicolumn{2}{|l|}{ Table 1 } & & \\
\hline Quantitative Survey & Participants & & \\
\hline Participant groups & $\begin{array}{c}\text { Total number } \\
\text { participants }\end{array}$ & $\begin{array}{c}\text { Participant grade } \\
\text { level ranges }\end{array}$ & Number of participants \\
\hline $\begin{array}{l}\text { Current or former } \\
\text { student teachers }\end{array}$ & 22 & K-8 & 13 \\
& K-12 & 3 \\
& $9-12$ & 5 \\
Cooperating & Unknown & 1 \\
Teachers & 14 & K-8 & 9 \\
& & K-12 & 0 \\
University & $9-12$ & 5 \\
Supervisors & & K-8 & 1 \\
& 5 & K-12 & 2 \\
\hline
\end{tabular}




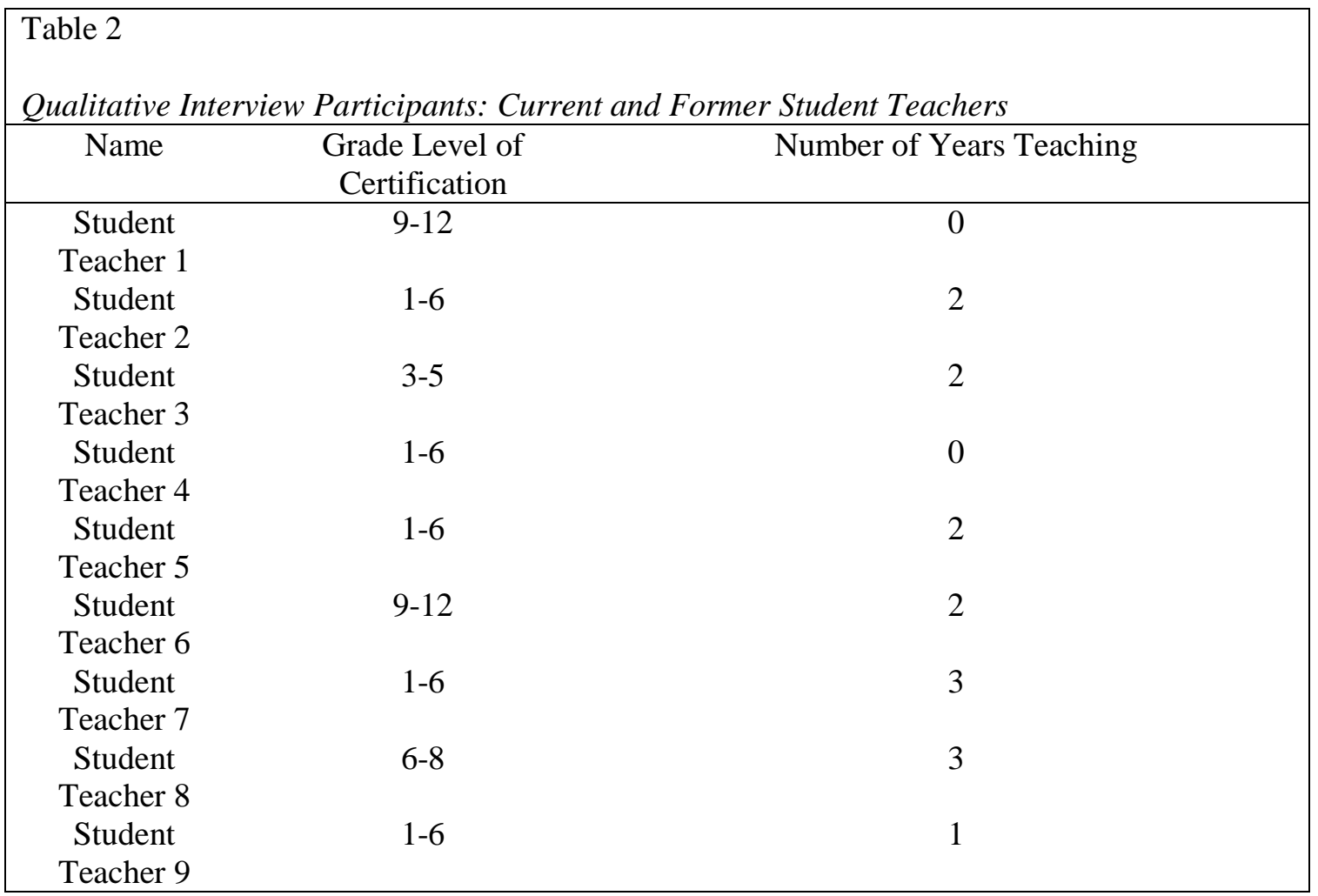

Table 3

Qualitative Interview Participants: Cooperating Teachers

\begin{tabular}{|cccc|}
\hline Name & $\begin{array}{c}\text { Grade Level } \\
\text { Teaching }\end{array}$ & \multicolumn{2}{c|}{ Student Teaching Models Supervised } \\
\hline $\begin{array}{c}\text { Cooperating } \\
\text { Teacher 1 } \\
\text { Cooperating } \\
\text { Teacher 2 }\end{array}$ & $1-6$ & $\frac{\text { Traditional }}{\text { No }}$ & Co-teaching \\
Cooperating & $1-6$ & No & Yes \\
Teacher 3 & $3-5$ & Yes & Yes \\
$\begin{array}{c}\text { Cooperating } \\
\text { Teacher 4 } \\
\text { Cooperating }\end{array}$ & $1-6$ & Yes & Yes \\
Teacher 5 & $1-6$ & Yes & Yes \\
Cooperating & $9-12$ & No & Yes
\end{tabular}




\begin{tabular}{|c|c|c|c|}
\hline \multicolumn{4}{|c|}{$\begin{array}{l}\text { Table } 4 \\
\text { Qualitative Interview Participants: University Supervisors }\end{array}$} \\
\hline Name & $\begin{array}{c}\text { Grade Level } \\
\text { Teaching } \\
\end{array}$ & Student Te & upervised \\
\hline University & $\mathrm{K}-8$ & $\frac{\text { Traditional }}{\text { Yes }}$ & $\frac{\text { Co-teaching }}{\text { Yes }}$ \\
\hline Supervisor 1 & & & \\
\hline $\begin{array}{c}\text { University } \\
\text { Supervisor } 2\end{array}$ & $9-12$ & Yes & Yes \\
\hline $\begin{array}{c}\text { University } \\
\text { Supervisor } 3\end{array}$ & $9-12$ & Yes & Yes \\
\hline
\end{tabular}

\section{Data Collection Tools}

Quantitative Data Collection. The purpose of this study is to derive an understanding of the perceptions of current and former student teachers, university supervisors, and cooperating teachers on the co-teaching model of student teaching and its ability to prepare student teachers for their first year of teaching. The researcher used a mixed method approach to research. By combining descriptive statistics, using an analysis of variance on SPSS, ANOVA data, and $t$-Test data from survey responses and open-ended participant responses from interview questions, the research results reflect the perceptions and belief systems of the participants. Each survey item and interview question or prompt was used to answer particular research questions (Appendix B).

Prior to survey administration, each survey was reviewed by people who met participant qualifications but were not participating in the research study. These persons took the survey and provided feedback to the researcher on question clarity. The mean and mode were determined for each item and for categorical groups of items. The survey was then given as a retest and again the mean and mode were determined for each item and for categorical groups of items. Items showing a large variance from test to retest were eliminated or revised. 
All research participants $(n=44)$ completed an anonymous survey (Appendix C) consisting of 25 belief statements regarding the perceived level of readiness the coteaching experience provided or provides new teachers. Each survey was specific to the participant group (current or former student teachers, cooperating teachers, and university supervisors). Catego1-6rical rating scales (Fink, 2013) included identifying the role of the participant and the level at which he/she works; however, names and locations were excluded to ensure confidentiality of participants.

Fink (2103) noted that the terms or concepts measured by the survey must be clearly defined. She recommends consulting with experts in the field to clearly define those terms. To define the concept of "level of readiness for first year of teaching," the survey belief statements were based upon the Missouri Teacher Standards (DESE, 2013), the rationale being standards for teachers serve as benchmarks for teacher quality, thus are representative of a well-prepared teacher. To develop the survey, each standard was tied to a lead-in statement or item stem that asked the participant to note how well he or she perceives the co-teaching model prepares the first year teacher for his or her first year of teaching. For example, one Missouri Teacher Standard states the effective teacher will engage in reflective practice in order to modify future instruction (Department of Elementary and Secondary Education, 2013). For current and former student teachers, this standard was phrased in a belief statement to be scored on a Likert-type scale as follows. The co-teaching model positively prepared me for my first year of teaching in the following way: to engage in reflective practice in order to modify future instruction. The survey participant then marked his or her level of belief on a scale of 1 (Not at all) to 9 (A good deal). For supervising and cooperating teachers, the same standard was 
phrased as follows. The co-teaching model positively prepares student teachers for their first year of teaching in the following way: to engage in reflective practice in order to modify future instruction. The participant from this group then marked his or her level of belief on a scale of 1 (Not at all) to 9 (A great deal).

Participants marked their perceived level of readiness for each standard on an ordinal, Likert-type (Fink, 2013) one-to-nine scaled survey formatted to resemble that of the Teachers' Sense of Efficacy Scale developed by Tschannen-Moran and Woolfolk Hoy (2001). A (1) represents the answer "Not At All," a (3) represents "Very Little," a (5)"Some," a (7) “Quite A Bit," and a (9) represents the answer "A Great Deal." Since the ranking of (5) was considered "Some," the researcher used that mean number as the cutoff for perceiving the model as "effective" on that item and when means were averaged.

Qualitative Data Collection. Following the quantitative survey, eighteen qualitative neo-positive interviews (Merriam, 2009) were conducted on the perceived level of preparedness the co-teaching model provides first year teachers in relation to the Missouri Teacher Standards. Participating groups consisted of current or former student teacher (Appendix D), cooperating teacher (Appendix E), and university supervisor (Appendix F) agreeing to an interview. Patton (2002) noted a person's feelings, thoughts, and perspectives cannot be observed. Thus, open-ended interviews are a means of providing this information. Open-ended questions in a semi-structured interview structure (Merriam, 2009) allowed for insight and feedback and focused on the student teaching process and experience and its perceived impact on the student teachers' readiness for his or her first year of teaching. The questions were largely guided by a preset list of 
questions but included a mix of less structured questions. The order of the questioning was dependent upon the data received from respondents.

\section{Data Analysis}

\section{IRB and Ethics}

Each interview participant read and signed a consent form (Appendix A) explaining the purpose of the study and participants' rights. Survey participants received an electronic consent form. The consent form identified the researcher and institutions from which the research comes: University of Missouri in conjunction with the University of Central Missouri. The form provided the purpose of the study and a request for participation. The participant was ensured that not participating would in no way penalize him or her and he or she can choose to stop, not answer particular questions, or withdraw their data at any time. No participants were under the age of 18 and a brief description of the research methods was provided. Interview data were audio recorded and transcribed (Krueger \& Casey, 2009). Any participant or K-12 institution names were changed during transcription and data analysis so as to protect participant privacy (Creswell, 2012; Merriam, 2009). The risks associated with participating in this study were similar to the risks of everyday life (Merriam, 2009) and benefits of participating were to add to the body of research on co-teaching as a student teaching model.

\section{Quantitative Data Analysis}

Descriptive statistics, One-Way-ANOVA, One-Way Repeated measures ANOVA, and $t$-Tests were used to analyze the quantitative survey results (Appendix G). The Likert-type responses were treated as continuous (Fink, 2013) and each participant group's (current and former student teachers, cooperating teachers, university 
supervisors) set of data was entered into a spreadsheet. The median, mode, and mean were determined in the frequency distribution of the data (Field, 2013).

To determine if the respondent groups of student teachers, cooperating teaches, university supervisors, and the total response group perceived the co-teaching model as effective in preparing the student teacher for first year teaching, the researcher ran a Single Sample t-Test. Each respondent's overall mean value was compared in this test to a rating of five or above on the Likert-type scale. The labeling of the Likert-type scale named a (5) as "somewhat effective." A (5) and above was considered the range for perceiving the co-teaching model as effective. The (5) mean was then compared to each group member's overall mean. If the test found the results Significant, the group results were determined to be high enough to perceive the co-teaching model of student teaching as effective in preparing student teachers for their first year teaching. The results determined that University Supervisors did not perceive it as effective; however, the coteaching model of all respondent groups was perceived as effective.

\begin{tabular}{|lcccc|}
\hline $\begin{array}{l}\text { Table } 5 \\
\text { Respondent Groups' Perceptions of Effectiveness of Co-Teaching Model of Student } \\
\text { Teaching }\end{array}$ & & & \\
\hline \multicolumn{1}{|c|}{ Respondent Group } & $\mathrm{t}$-Value & $\mathrm{p}$-Value & Significant & Effective \\
\hline Student Teachers & 4.80 & $9.6 \mathrm{E}-05$ & YES & YES \\
Cooperating Teachers & 8.57 & .00001 & YES & YES \\
University Supervisors & -0.12 & 0.91 & NO & NO \\
Total Respondent Group & 5.64 & .00001 & YES & YES \\
\end{tabular}

To compare the overall perceptions between three independent respondent groups 
concerning how well the co-teaching model of student teaching prepares student teaching candidates for their first year of teaching, the One-Way ANOVA statistical analysis was used. The overall survey mean values for all respondents in each of the three separate participant groups were calculated. Each participant group's overall mean values were entered in the One-Way ANOVA calculator for comparison to determine if there was a significant difference in how respondents in each participant group perceived the coteaching model as preparing the new teacher for first year of teaching. A significant difference between participant group's perceptions was determined.

Because a significant difference was determined, the researcher wanted to determine between which participant groups there was a significant difference, so three tTests were run. The t-Tests compared two participant group results at a time: Student Teachers to Cooperating Teachers, Cooperating Teachers to University Supervisors, University Supervisors to Student Teachers. A significant difference was found in two of the t-Tests: University Supervisors to Student Teachers and University Supervisors to Student Teachers. There was no significant difference in perceptions between Student Teachers and Cooperating Teachers.

To compare the overall perceptions between participant groups divided into the grade levels with which they work, the One-Way ANOVA statistical analysis was used again. The respondents were divided into three grade range groups with which they work: K-8, 9-12, and K-12. A significant difference between the three groups was again determined.

Because a significant difference was determined, the researcher ran three new tTests. The respondents' group results were compared in sets of two: K-8 to 9-12, K-8 to 
K-12, K-12 to 9-12. There was significant difference in perceptions of how well the coteaching model prepared first year teachers between those who worked with K-8 and those who worked with 9-12, as well as those who worked with K-8 and those who worked with K-12. There was no significant difference between the perceptions of those who worked with 9-12 and those who worked with K-12.

Finally, in relation to the Missouri Learning Standards educational categories of professionalism and collaboration, classroom management, content knowledge and instructional strategies, student learning goals, and curriculum and lesson planning a One-Way Repeated measures ANOVA test was performed to compare the participant means in each educational concept category. It was determined that there was no significant difference between educational concept category scores.

In summary, the quantitative data revealed that the total respondent group perceived the co-teaching model to be an effective model of student teaching. The data also provided evidence that student teachers and cooperating teachers perceived the coteaching model as supporting first year teachers significantly more than did university teachers. The quantitative data revealed a significant difference in $\mathrm{K}-8$ perceptions of the co-teaching model's ability to more positively support first year teachers than did K-12 or 9-12 respondents. A more detailed narrative of the qualitative data analysis and findings can be found in Appendix G.

\section{Qualitative Data Analysis}

Qualitative interviews were conducted with 18 participants: nine current or former student teachers; six cooperating teachers; and three university supervisors. The qualitative data were coded for patterns, generalizations, and themes (Creswell, 2014). 
The researcher followed the six step coding process for qualitative data (Creswell, 2014). Step 1: The researcher organized and prepared the notes. Step 2: The researcher looked for data consistency within and across the groups. Step 3: The researcher began to group common observations into generalization categories. Step 4: The researcher generated a descriptive theme or themes based on generalizations. Step 5: The researcher created a narrative passage to describe the themes represented in the data (Appendix G). Step 6: The researcher interpreted the qualitative data couched in personal understandings and comparison to literature and known theories.

In summary, the qualitative research data unfolded three findings. First, the coteaching model of student teaching highly supports the growth of student teachers in preparation for their first year of teaching. General categories that supported this finding were that the co-teaching model provided the following components of the Gradual Release of Responsibility (Pearson \& Gallagher, 1983) model of instruction and learning for the student teacher: extensive modeling, immediate feedback and professional reflection, the ability to have a singular foci, and collaboration. Another finding emerged reflecting the strength of the co-teaching student teaching model's ability to build the student teacher's self-confidence. A third and final finding was the common perception that the co-teaching model does not provide the student teacher with a realistic teaching experience in a classroom that does not employ another co-teacher. A more detailed narrative of the qualitative data analysis and findings can be found in Appendix G.

\section{Recommendations}

Based upon the research data collected and findings presented, the researcher recommends that colleges of education implement the co-teaching model of student 
teaching. The researcher also recommends that the student teacher be allotted an extended period of time of two-three weeks in which the student teacher fully takes over the classroom planning, instruction, and management. The co-teacher should meet daily with the student teacher for reflection and feedback; however, the student teacher proceeds as the sole instructor for the allotted period of time.

\section{Limitations, Assumptions, and Design Controls}

Limitations of this study relate to the survey instrument as well as the study's design and setting. The researcher created surveys to collect quantitative data (Appendix C). The instruments' reliability and validity have not been empirically tested.

Additionally, transferability of findings across other institutions will be limited as this study specifically explores UCM's co-teaching clinical model and students who have attended UCM's pre-service courses.

Finally, the present research proceeds under the assumption that each pre-service student teacher is at a somewhat equal level of preparedness as other student teachers before the co-teaching clinical experience begins. This assumption stems from the application of common coursework of all pre-service education students within the UCM College of Education.

\section{Significance of the Study}

This study provides empirical evidence of the perceptions of current and former student teachers, cooperating teachers, and university supervisors on the co-teaching model's ability to prepare student teachers for their first year of teaching. The findings in this study reveal that critical stakeholders in the student teaching experience find the coteaching model of student teaching highly effective for preparing student teachers for 
their first year of teaching.

The findings of this study will benefit university colleges of education by providing key stake holder perceptions of the effectiveness of the co-teaching student teaching model in preparing first year teachers for their first year of teaching. The findings can be a component in determining whether the co-teaching model of student teaching is implementing in the university's teacher preparation program.

Cooperating school districts supporting university students will also benefit from this study. If the co-teaching model of student teaching is incorporated into the student teaching experience, cooperating teachers will not need to relinquish their classrooms to novice teachers for extended periods of time. This may support student achievement on standardized testing since veteran teachers will continue to be a part of instruction.

Cooperating teachers themselves will benefit from the results of the study. Findings show that cooperating teachers begin to see the student teacher as an equal in the classroom. The qualitative findings show that the cooperating teacher and student teacher gain more collaboration time together to learn from one another.

Students in cooperating teacher classrooms will also benefit from the study. With the cooperating teacher not relinquishing the classroom to a novice teacher for an extended period of time, the students will receive instruction from their veteran teacher as well as the student teacher. This may affect student achievement.

Additionally, first year teachers will benefit from this study. Findings show that first year teachers perceive the co-teaching model of student teaching as a highly effective teacher preparation model. It might be inferred that the more highly prepared for teaching the first year teacher is, the more likely the first year will be a positive 
experience for the teachers.

Finally, students of the prepared first year teacher will benefit from this study. Findings show that the first year teaching who experienced the co-teaching model of student teaching highly rate the model as preparing them for classroom management and instruction. This may, in turn, benefit the students of their first year classroom in both classroom behaviors and achievement.

\section{Summary}

Many universities struggle to place student teachers in local districts due to teachers' apprehension in relinquishing their classrooms to a novice teacher while high stakes testing occurs each spring (Ellis \& Bogle, 2008). The Blue Ribbon Panel of the National Council for Accreditation of Teacher Education (NCATE, 2010) published a national report calling for PK-12 teachers and teacher preparation programs to see teacher preparation as a shared responsibility. With these two factors in mind, the University of Central Missouri (UCM) began the study and implementation of coteaching as a student teaching clinical model.

Co-teaching was originally an instructional model most frequently applied to PK12 settings involving a general and special educator. Co-teaching also became an instructional model in higher education courses whereby the faculty would model the coteaching process with their students. A few universities began to explore co-teaching as a student-teaching model. UCM became one such university.

Experts in the field of co-teaching have defined various models of co-teaching in the contexts of special education and higher education. These models can be applied to the stages of Gradual Release of Responsibility (GRR) and the co-teaching model of 
student teaching. For instance, Friend and Cook (2003) and Bessette (2008) defined various co-teaching models as follows: (1) one teach, one observe; (2) one teach, one drift; (3) alternative teaching; (4) parallel teaching: (5) station teaching; and (6) team teaching. The "one teach, one observe" and "one teach, one drift" models can be used in the Focused Lesson phase of GRR during co-teaching student teaching. The "alternative teaching" and "parallel teaching" models are used in the collaborative phase of GRR in student teaching. The "station teaching" is used in the guided practice phase of GRR and the "team teaching" is the independent phase of GRR in the co-teaching student teaching model. Team Teaching in this instance is defined as the independent application of skills or strategies in which both the senior and junior teacher share all responsibility equitably.

The purpose of this study was to determine and analyze the perceptions of current and former student teachers, cooperating teachers, and university supervisors on the coteaching model of student teaching and its ability to prepare student teachers for their first year of teaching. This study used a mixed-methods research approach. Participants included current and former student teachers, cooperating teachers, and university supervisors from the University of Central Missouri. Quantitative data from surveys administered to student teachers, cooperating teachers, and university supervisors who experienced the co-teaching model eliciting perceptions of the level of preparedness the co-teaching model provides student teachers for their first year of teaching. The quantitative surveys provided data on each participant group's perception of the benefits and/or weaknesses of the co-teaching models of student teaching. Qualitative data from one-on-one interviews were collected from each participant group. Participant data were analyzed to determine the overall perceived impact of the co-teaching model of student 
teaching on the level of preparedness for the first year teacher. Participant group data were cross-analyzed to determine any similarities or disparities in perceptions between participant groups.

The quantitative data revealed that the total respondent group perceived the coteaching model to be an effective model of student teaching. The data also showed that student teachers and cooperating teachers perceived the co-teaching model as supporting first year teachers significantly more than did university teachers. The quantitative data revealed a significant difference in K-8 perceptions of the co-teaching model's ability to more positively support first year teachers than did K-12 or 9-12 respondents.

Qualitative research data unfolded three main findings. First, the co-teaching model of student teaching highly supports the growth of student teachers in preparation for their first year of teaching. General categories that supported this finding were that the co-teaching model provided the following components of the Gradual Release of Responsibility (Pearson \& Gallagher) for the student teacher: extensive modeling, immediate feedback and professional reflection, the ability to have singular foci, collaboration. Another finding emerged reflecting the strength of the co-teaching student teaching model's ability to build the student teacher's self-confidence. A third and final finding was the common perception that the co-teaching model does not provide the student teacher with a realistic teaching experience in a classroom that does not employ another co-teacher.

Based on the research data, it is the recommendation of the researcher that the coteaching model be implemented by universities due to the strength in its learning structure. The student teacher should, however, be allotted two-three weeks of sole 
classroom responsibility without the cooperating teacher in the classroom. 
SECTION TWO

PRACTITIONER SETTING FOR THE STUDY 


\section{History of the Organization}

The University of Central Missouri (UCM) is located in Warrensburg, Missouri, approximately 50 miles from the Kansas City metro area (University of Central Missouri Fact Book, 2017). UCM offers 150 undergraduate and graduate areas of studies. The fall of 2017 enrollment notes 12,333 students. The undergraduate student body is composed of 9801 students who are $44 \%$ male, $56 \%$ female, $14 \%$ minority, and $27 \%$ international students. There are approximately 944 undergraduate and graduate international students, with $79 \%$ of the graduate students coming from India. UCM employees approximately 494 full-time faculty and has an 18:1 student-to-faculty ratio.

The University of Central Missouri began as the two-year State Normal School for the Second Normal District in Missouri when it was founded in 1871; originally created for teacher preparation, the university has evolved into a multi-programmatic, multi-college institution. The name of the institution has changed four times in its 136 year history; each name change signified a change in the mission and service of the University. The first name change occurred in 1916 when the State Normal School became Central Missouri State Teachers College. In 1946 it became Central Missouri State College, and became authorized to offer Master of Science in Education degrees beginning in 1947 and Master of Arts and Education Specialist degrees a few years later. In recognition of the changing role and importance of the college, the General Assembly granted permission in August 1972 for university status to be adopted and the name of the college was changed to Central Missouri State University. In 2006 the university changed its name once more, to University of Central Missouri (UCM), to reflect the newly defined mission of becoming a nationally recognized university that delivers a 
world-class education. However, throughout this evolution, teacher education has remained one of UCM's primary academic functions; it continues to be recognized as a cornerstone of UCM, contributing to the mission and vision of the University. University of Central Missouri has an excellent reputation as a teacher education institution and is the longest continuously NCATE-accredited public institution in the State of Missouri.

\section{University of Central Missouri College of Education}

The UCM College of Education ("College of Education," 2015) has been in place for more than 140 years. It offers over 39 undergraduate and 16 graduate degrees. As with all Missouri teacher candidates, education students must pass a content area exam prior to certification. Additionally, candidates must hold a cumulative GPA of 2.9 or higher and a Content GPA of 3.0 or higher with no Professional Education course grade lower than a C. As of August, 2014 co-teaching is the mandatory student teaching model for all teacher candidates.

\section{University of Central Missouri College of Education Co-Teaching Model}

In the spring of 2011, the Dean of the College of Education sent five individuals to the St. Cloud State University co-teaching model training (Harnett, et al., 2013). The group of professors included two faculty from elementary education, one faculty member from art education, one faculty from middle school education, and one faculty member from mathematics education. As a follow-up, the attending faculty group presented training information to the Professional Education Faculty and potential school district members in the fall of 2011. Additionally, they completed visits with faculty from various teacher education programs on campus. From October 2011 to February 2012, group members identified school districts, cooperating teachers, university supervisors, 
and teacher candidates for participation in the fall 2012 pilot of the co-teaching model.

By May of 2012, training for pilot programs began and in August of 2012 the first pilot began with 18 students and six school districts. Various trainings, presentations, and pilot options followed at state, university, and district levels and by November of 2013 the Campus Teacher Education Council voted to make the co-teaching model the official model of student teaching for all teacher candidates effective the fall of 2014. By January of 2015, 180 student teachers were placed in 44 school districts.

\section{Organizational Analysis}

The UCM College of Education (COE) is structured according to a combination of a Professional Bureaucracy organizational model and a Divisionalized Form organizational model (Bolman \& Deal, 2008). As in the Professional Bureaucracy model, the Dean of the COE represents the strategic apex. Supporting technostructures are small by comparison to the operating core of faculty. These technostructures include departments such as Information Technology and administrative staff. There are few managerial positions between the Dean and faculty, thus creating a decentralized system. Control of curriculum lies heavily on faculty expertise. While this free application of expertise allows for individualized creativity, giving the professionals space to do what they do best, it also makes quality control and coordination difficult.

The UCM COE is unique to the other UCM colleges in that it is also a Divisionalized Form structure. While the Dean oversees the COE, many education students' coursework is provided outside the COE within their colleges of content specialty (M. Wright, Personal Communication, November 3, 2015). For example, education students of art, music, PE, math, and science are housed in the college of that 
discipline. Thus, the Dean of COE must work closely with the Deans and faculty of those colleges to coordinate curriculum and clinical practices. So while each college is its own separate division, a tight coupling of the Deans and faculty is necessary to provide a unified program for UCM education students.

\section{Leadership Analysis}

Dr. Michael Wright, UCM Dean of the College of Education, came into his position eight years ago with a single focus: to improve the teacher education process (M. Wright, Personal Communication, November 3, 2015). He strongly believed more field experience was necessary to improve teacher candidates' abilities and began to focus on the clinical experience of the preservice teachers. After two years as Dean, he proposed a clinical experience plan that included more field experiences during a preservice teacher's sophomore, junior, and finally senior years. Each field experience would be a progressive step that built upon each other yearly. The drawback, however, was that by implementing more field experience, the number of courses offered would need to be cut. The proposal was rejected by course professors. This first rejection, however, did not deter Dr. Wright from continuing to seek improvements in the overall good of the teacher education process.

While attending a conference in Washington D.C, Dr. Wright saw a presentation by faculty members of St. Cloud State University in Minnesota. St. Cloud's researchers presented data on how the implementation of the co-teaching model in student teaching not only increased the performance of the student teacher, but also increased the achievement of the K-12 students with whom they worked. There was significant credibility to their program. 
Dr. Wright returned to UCM excited about what he had seen. He gathered a group of faculty he believed were open to new ideas and concepts. Because the Dean of the College of Education not only oversees elementary majors, but also oversees education students in the Department of Computer Science and Math, College of Arts, Humanities, and Social Science, and the Department of Music, Dr. Wright appointed to his committee two faculty from elementary education, one faculty member from art education, one faculty from middle school education, and one faculty member from mathematics education. This group traveled to St. Cloud State University and attended training in the use of the co-teaching model for student teaching.

The co-teaching training committee returned to UCM excited and full of ideas for the COE. They wanted to design a pilot project using co-teaching as the clinical experience, and Dr. Wright was willing. However, Dr. Wright knew a larger vision was necessary to effect authentic change and improved outcomes. Dr. Wright knew that it was from his faculty that real change would occur. He enlisted the support of his staff in creating a program that would blend classroom experiences with field experiences.

Together they built a pilot program that began a student's sophomore year and progressed through his or her senior year. The faculty worked on a sequenced, unified curriculum that balanced coursework and field experiences to bring deeper meaning to the learning process.

Along with a change in curriculum and field experience, Dr. Wright enlisted the support and advice of the cooperating public school districts. Instead of continuing student placement in the $100+$ school districts used previously, he decided the COE would concentrate on 13 primary districts. An advisory board included a representative 
from each partnering district as well as the COE staff of clinical services and certification. From this advisory board, problems and issues of clinical practice and services were discussed and decisions are made.

As with most new initiatives, roadblocks occurred. Although there were to be higher costs for transportation for increased field experiences, no more money was being placed in the COE budget. Dr. Wright was told by a source that the changes he was enacting would not be possible without the $\$ 10,000,000$ grant that was provided to St. Cloud State University for their initial work. Dr. Wright did not believe that to be true. It has taken creativity and critical thinking of various stakeholders, but the co-teaching clinical experience blended with progressive field experiences have now been fully implemented since Fall semester of 2014. Dr. Wright's single focus, to improve the teacher education process, is in action.

Through this change process, Dr. Wright exhibited characteristics of a transformational leader (Northouse, 2013). According to Northouse, a transformational leader is concerned with emotions, values, standards, and long-term goals. The vision "emerges from the collective interests of various individuals and units in an organization" (p. 200). Dr. Wright held to a vision that embraced the "collective good" (p. 187) of the teacher education program by looking beyond the walls of the COE and enlisting support and resources outside the university campus. By his drive to balance coursework and field experience, he held to a high level of standards and made sure that group actions were directly tied to long-term goals and achievements.

Northouse (2013) also noted a transformational leader engages with others and creates a connection that raises the level of motivation and morality in both the leader 
and the follower. This type of leader is attentive to the needs and motives of followers and tries to help followers reach their fullest potential.

Dr. Wright engaged with his faculty committee around training on the co-teaching clinical experience. He not only engaged with the COE building faculty, but intentionally enlisted professors involved with education students from the areas of art, music, and math. Dr. Wright, through his own enthusiasm, inspired and motivated this group of teachers, but allowed them to reach their full potential through the united efforts of creating a pilot project and allowing them to lead the charge of developing training timelines. Additionally, Dr. Wright inspired the work of his followers by developing a diverse advisory board including stakeholders outside the university, allowing for a gain in the sense self-efficacy.

While there was an initial roadblock of self-interest by several professors who hesitated about losing coursework to field experience, Dr. Wright motivated them to respond to the greater good of the student education process. Bass (1985) believed followers are motivated to do more than expected when transformational leaders are able to raise the level of awareness about the importance and value of goals. This happens when followers can set aside self-interest to see the greater good of the organization and when followers personally gain a higher-level of needs. Through motivation and allowing faculty a sense of ownership to new ideas, Dr. Wright was able to accomplish a transformation in the belief system of the staff regarding high quality clinical experiences. Dr. Wright encouraged his faculty to be "creative and innovative and to challenge their own beliefs and values as well as those of the leader and the organization" (Northouse, 2013). Through vision, goal setting, and inspiration, the UCM teacher 
education program was transformed from a traditional format to its more current leveled field experience and co-teaching clinical model.

\section{Implications for Research in the Practitioner Setting}

There are seven distinct groups of stakeholders within the practitioner's setting affected by the level of preparation the co-teaching model provides first year teachers: (a) university teacher education faculty and staff, (b) student teachers, (c) cooperating teachers and districts, (d) students of student teachers, (e) first-year teachers, (f) districts of first-year teachers, and (g) students of first-year teachers. The research within this study can be used to determine the perceptions of how deeply the co-teaching model prepares first-year teachers, thus affecting all stakeholders.

Using this research at the university level, universities can determine whether the co-teaching model is a viable model for clinical experience. School districts and cooperating teachers can understand the perceptions of whether or not the co-teaching model is an effective model for teacher preparation in which cooperating teachers should participate. Districts hiring first year teachers who have come from a co-teaching model of clinical practice can have background on the level of perceived preparation the coteaching clinical model provided potential employees. Finally, while this study does not measure the effect of the co-teaching model on students of student teachers and first year teachers, it does provide perceptions of the level of preparation the model provides the

first year teacher in relation to the current Missouri Teacher Standards (Department of Elementary and Secondary Education, 2013) which will hopefully in turn translate to student achievement. 


\section{Summary}

In summary, the research study of co-teaching as a clinical model of student teaching and perceptions of preparedness it provides first year teachers is deeply embedded in a practitioner's setting. The University of Central Missouri, the single university used within this study, was founded as a teachers' college. It has a rich history of supporting a variety of undergraduate and graduate degrees within the College of Education (COE). The COE offers over 39 undergraduate and 16 graduate degrees. As of August 2014, co-teaching is the mandatory student teaching model for all teacher candidates.

The University of Central Missouri's organizational structure combines both the Professional Bureaucracy and the Divisionalized Form organizational models (Bolman \& Deal, 2008). In the Professional Bureaucracy the Dean of the COE serves as the strategic apex and the faculty of the COE serve directly below without managerial positions inbetween. The Dean, however, must also work with other various colleges within the university since they also prepare future teachers, thus creating a Divisionalized Form organizational model.

The leadership of the UCM College of Education has proven to be transformational in nature. Its former Dean, Dr. Michael Wright, stayed true to a vision of betterment for the collective good of the institution and has inspired, not dictated, his faculty to move forward in that same pursuit. His leadership continues to involve various stakeholders by use of a panel of advisors from a diverse pool of district partnerships.

The co-teaching program from UCM grew from the practitioners' need for a stronger teacher candidate experience and from the local districts' need to not relinquish 
classes to student teachers prior to state testing. The University of Central Missouri's College of Education, its leadership, its primary participating school districts, and its teacher candidates will benefit from the results of this study. School districts will have validation in their decision to either participate or not participate in the co-teaching model of student teaching. Districts hiring from UCM will know if there were benefits to the graduates having participated in co-teaching. The university will be able to use the study as a part of their evaluative process within the student teaching program. 


\section{SECTION THREE}

SCHOLARLY REVIEW FOR THE STUDY 


\section{Introduction}

With authorization of the federal legislation No Child Left Behind (US

Department of Education, 2002), public schools became accountable on state and federal levels for the academic achievement and growth of diverse student populations. Local education agencies' (LEA's) achievement scores on standardized tests were disaggregated by various subgroups including economically disadvantaged students, students from major ethnic and racial groups, students with disabilities as defined by the Individuals With Disabilities Education Improvement Act (IDEIA, 2004), and students with limited English language proficiencies (ELL). Sanctions were imposed upon LEAs not reaching standards set by the law. An important element of NCLB was the IDEIA mandating students with disabilities have access to the general curriculum in the least restrictive environment needed for success. This law required students with disabilities not be pulled from the regular classroom or taught a separate curriculum without strong evidence that such a practice is the least restrictive environment needed to learn. LEA's began searching for alternative structures and strategies that would meet the needs of their diverse subgroups of students. Co-teaching, also called team-teaching or collaborative teaching, became a viable method of inclusive instruction in the special education discipline to access the regular classroom setting and curriculum.

Co-teaching, as defined by Villa, Thousand, and Nevin (2008), is an instructional model where two or more people of equal status share the responsibility of planning for, instructing, and assessing some or all of the students in a classroom. It consists of educators working together to examine student work and find alternative ways of meeting the needs of students (Desimone, 2009). Higher education teacher preparation programs 
followed the lead of special educators by implementing the co-teaching model in the teacher preparation programs to prepare their pre-service students to meet the needs of diverse student populations (Nevin, Thousand \& Villa, 2009). Finally, in a lesser researched application, the co-teaching model was implemented into clinical practices of regular education teacher preparation programs whereby regular education student teachers team-taught with their mentor teachers throughout their student-teaching experience.

\section{Models of Co-Teaching}

Experts in the field of co-teaching have defined various models of co-teaching that are implemented in the inclusive classroom and higher education programs. In their foundational, Easterby-Smith and Olve (1984) describe five co-teaching models still referenced in current literature. The Star model maintains one co-teacher holds the majority of the responsibility while the other co-teacher functions as a guest lecturer and collaborator. In the Hierarchical model, a senior teacher holds most of the responsibility of teaching while junior assistants assist students in need of support. The Specialist model has the co-teachers collaboratively design curriculum. The role of each teacher is dependent upon his or her specialty and both work together to lead discussion. The Generalist model is similar to the Specialist model in that the co-teachers collectively create curriculum; however, practicalities rather than areas of specialty define duties and roles. Finally, the Interactive model also includes a collective design of curriculum;

however, teaching roles are flexible and spontaneous. The teaching roles arise within the need of teaching rather than being planned.

Fishbaugh (1997) defined similar co-teaching models used in the field of special 
education. The Consultant Model, like the Star model of Easterby-Smith and Olve, uses the special educator as a consultant to the general educator in areas of curriculum modification and accommodations. The Coaching Model enlists both the general educator and special educator as coaches to each other based on their areas of specialty in curriculum and pedagogy. The Teaming or Collaborative model, comparable to the Interactive model, equally utilizes both the special and general educator in curriculum planning, instruction, and assessment.

Friend and Cook (2010) introduced six approaches to co-teaching: one teach, one observe; one teach, one drift; alternative teaching; parallel teaching; station teaching; and team teaching. The one teach, one observe approach provides an opportunity for the observing teacher to note student response to pedagogy and to analyze student work. The one teach, one drift approach is perhaps more common in special and general education teaming. This approach holds one teacher responsible for whole group instruction while the other aids students who need assistance. When students need small group attention, the alternative teaching approach is often enlisted. In this approach, the co-teacher addresses the large group while the other co-teacher meets with small groups for specialized instruction. Parallel teaching is similar to alternative teaching; however, the co-teachers divide the class in half and teach the same material simultaneously. Station teaching again divides the class in groups, however the co-teachers teach different content and the students rotate between teachers. Finally, the team teaching approach enlists both co-teachers to flow in and out of instruction inside a single lesson. In the team teaching approach, it is important the co-teachers must depend upon and respect each other's experiences, teaching styles, and management skills. 
St. Cloud State University Department of Teacher Development began a coteaching model of student teaching as a part of their St. Cloud Teacher Quality Enhancement (TQE) (Bacharach, Heck, \& Dahlberg, 2010). Their co-teaching model includes the use of seven strategies of co-teaching in student teaching: One Teach, One

Observe; One Teach, One Assist: Station Teaching; Parallel Teaching; Supplemental Teaching; Alternative (Differentiated) Teaching; and Team Teaching.

\section{Co-Teaching Skill Sets and Roles}

A wide range of research is available defining the skill sets and roles needed to create a successful co-teaching culture and program. While the research is based upon the special education and higher education contexts of co-teaching, the same skill sets and roles can be anticipated to fit the context of student teaching in a co-teaching situation.

Additionally, these skill sets and roles could be used to create a positive culture in the student-teaching co-teaching partnership. For example, Vaughn, Schumm, and Arguelles (1997) proposed co-teachers should answer practical questions prior to coteaching: (1) Whose students are these? (2) Who gives grades and how is it done? (3) Whose classroom management rules do we use? (4) What space does each co-teacher receive? (4) What do we tell students and parents about the teaching arrangement? (5) How can we get time to co-plan? When these roles are defined prior to instructional delivery, the foundation for a successful co-teaching culture and program has been laid. In the field of teacher education, Darling-Hammond $(1996,2005)$ argued future teachers must be provided instruction and opportunities to share in decision-making processes, communications, and planning. When provided these co-teaching skill opportunities, a positive co-teaching program and culture can be established in a student-teacher clinical 
context. Brinkman and Twiford (2012) identified skill sets perceived by special and general educators to be needed for a successful co-teaching program. The skills perceived to be most important for collaboration and co-teaching were communication, data collection/diagnostic testing, interpersonal skills, differentiation, self-advocacy, writing effective lesson plans, organization in providing accommodations, and classroom management strategies and skills. In a student-teacher clinical context, these skills could be defined prior to the work and formatively reviewed and assessed throughout the clinical practice. Diana (2014) purported, along with shared responsibilities and communication skills, co-teachers must establish trust and be able to work together to problem solve.

\section{Co-Teaching Issues and Stressors}

Research on co-teaching has revealed issues, sensitivities, and stressors common to the co-teaching experience. Such effects, if identified prior to the co-teaching studentteacher experience, might be assessed and possibly avoided in the context of the clinical practice. Chanmugan and Gerlach (2013) found it is important to address specific issues at the onset of the co-teaching practice: power sharing, communication, roles, appropriate matching of co-teachers, methods for exchanging feedback, responsibility sharing, and scheduling. They also recommend co-teachers assess their personal level of comfort in sharing their learning process. They note that sometimes lessons will fail and educators must have a self-awareness regarding their comfort level in discussing such failures with their colleague.

Bessette (2007) posited sharing of direct instruction is a major issue to be addressed within the co-teaching practice. Often the special educator is underutilized in 
this capacity. Austin's (2001) research found that both the special educator and general educator co-teachers believe that the general education co-teacher does more than the special education partner.

Bessette's (2007) study proposed a possible remedy. "In this investigation, the findings suggest that role reassignment---from the general educator as the instructional leader (or "authority"), and the special educator as support person (or "helper," "adjunct," "assistant")---to both teachers planning and implementing instruction may be a critical factor in achieving parity between co-teachers" (p. 1392).

Co-teaching at the collegiate levels presents unique issues. Graziano and Navarrete (2012) described barriers to using the co-teaching model at a collegiate level. Co-teaching requires additional plan time. Budget crises do not necessarily allow for extra pay for such time as well as the extra course load required of professors if there are to be two per course. Additionally, a large barrier lies in system policy regarding promotion, tenure, and merit reviews. There may be no policies in place on how these traditional practices align with the implementation of a co-teaching model. Finally, although the overall conclusion was that students preferred co-taught courses, some students reported communication and organizational problems which affected their understanding of course grading expectations. When Vogler and Long (2003) surveyed collegiate students on how they felt about someday co-teaching, concerns included the anticipation of possible conflicts including grading and classroom policies. York-Barr, Bacharach, Salk, Frank, and Benick (2004) found concerns from faculty about content being reduced or eliminated and workload increasedDugan and Letterman (2008) found when college students were surveyed and interviewed about their experiences as students 
of co-taught courses, there was no significant difference in students' preferences for coteaching over traditional classroom instruction. They did find, however, significant differences in the model of co-teaching students preferred. Students preferred co-teaching dyads (simultaneous teaching) over alternate-teaching (sequential teaching) and collaborative panel (classes with three or more instructors). Dugan and Letterman (2004) offered advice on meeting the demands and pitfalls of co-teaching at the collegiate level. They suggest that plans be created for interjecting and turn-taking, power differentials, and conflicts of ideas. If university staff can then explain their processes to studentteachers, the student-teachers may come away with a deeper understanding of coteaching. Perhaps identifying and addressing issues and stressors before, during, and after the co-teaching student-teaching experience might minimize them.

\section{Benefits of Co-Teaching}

Many benefits to the inclusive classroom and higher education teacher preparation programs have emerged from co-teaching research. In a case study of university professors co-teaching in the teacher education department of the university, Albrecht (2003) found benefits from co-teaching included the co-teachers learning from each other and elevating their teaching strategies because of the collaboration. VasquezMontilla, Spillman, Elliott, and McGonney (2007) reported that university faculty who participated in co-teaching found value in the creative process of the experience and had a sense of fulfillment they had not experienced in solitary course instruction. Similarly, in a qualitative case study of university faculty participating in co-teaching at the University of North Dakota, Bass (2005) noted four positive themes that emerged: opportunity to be creative, positive outcomes, open communications, and a sense of fulfillment. In a mixed 
methods study on special educators and general educators' beliefs around co-teaching, Austin (2001) found that both special educators and general educators believed the coteaching experience to be a positive one. Special educators cited growth in content knowledge while general educators cited growth in management and curriculum adaptation. Both co-teaching groups noted benefits of co-teaching such as a lower student-teacher ratio, the benefit of another expert and viewpoint, having a teacher available for immediate remediation for all students, and the opportunity for general education students to gain an understanding of differences and acceptance. Additionally, the co-teaching model provided an opportunity for peer modeling for students with disabilities.

The co-teachers interviewed believed that the students positively benefited academically and socially from the co-teaching experiences. They noted an increase in student participation, acceptance of differences, and greater cooperation between peers. Garaziano and Navareete (2012) described co-teaching benefits of increased student opportunities such as varying the presentation of content, individualizing instruction, scaffolding learning experiences, monitoring students' understanding, and promoting equitable learning opportunities. They noted that benefits to higher education professors who co-teach include the opportunity to reflect on their teaching practices, themselves as individuals, and on student understanding.

York-Barr, Bacharach, Salk, Hinz Frank, and Benick (2004) described the positive effects of co-teaching at the collegiate level between regular education and special education faculty. They found students benefited by understanding multiple perspectives, providing a sense of ownership to both general and special education 
students, and learning about team teaching through example. Faculty found value in an increased sense of professional growth, awareness of perspective from other disciplines, and a deeper understanding of the negotiations that must be considered during team teaching. Chanmugam and Gerlach's (2013) case study of two doctoral students coteaching an undergraduate class found two main benefits for future educators: personal development in novice teachers, and development of teacher effectiveness. As coteachers, they had each other as valued peers to provide ongoing feedback throughout the course. They were able to support each other in reviewing the effectiveness of strategies and identifying strengths and weaknesses in their instructional delivery or curriculum development. In developing teaching effectiveness, the collaboration provided growth in conceptualizing and structuring the course, management and mastery of the content, clerical tasks, brainstorming of learning activities, assignments, and projects, and grading and providing feedback. Bacharach, Heck, and Dahlberg (2008) revealed collegiate level co-teaching benefits such as a fostering of collaborative skills, an increasing student participation, and an opportunity for professional growth. Will these same benefits emerge from the co-teaching student-teaching experience?

\section{History of Student Teaching}

Many current struggles in the field of student teaching have been recurring problems since the student teaching experience became part of the college curricula of potential teachers (Andrews, 1964). The challenge of finding available and quality cooperating teachers for placement has been a persistent problem. The diversity in student teaching programs across the nation, while allowing for creativity and ingenuity, fosters considerable inconsistency of quality in field experiences provided. 
Before the 1930s student teaching required a preservice elementary teacher to teach one hour a day for all or most of a semester and a secondary preservice teacher was assigned one period a day for all or most of the semester (Andrews, 1964). The first standards set in 1926 by The American Association of Teachers Colleges set a minimum of 90 clock hours of student teaching. These assignments were usually in campus laboratory schools with very few in local public schools. Following World War II the number of potential teachers grew, exposing a lack of space for student teachers in campus laboratory schools. Additionally, a greater desire by institution leaders grew for a more authentic student teaching experience reflecting a more realistic simulation of teaching. Research on child development and growth flourished and for the first time the country had an abundance of certificated teachers, although this included high school teachers only. Colleges began to devise a wide variety of field experiences and studies, and both pre- and post- student teaching programs were developing. It was during this time between 1920-1940 many states adopted laws or regulations requiring universities and colleges offer professional teaching courses, student teaching, and a degree of certification for educators.

One program developed was a course that included classroom observation in the campus laboratory schools. Within these courses, the education professors partnered with the laboratory school teachers to develop observation-participation experiences for the preservice teacher as a part of the course work. The college students were to increase their participation as their knowledge base grew and the laboratory schools were to reflect the instructional methods taught in courses. Some were able to mimic these same experiences using public school placements, although it was found that reflecting the 
instructional methods taught in courses was much more difficult to accomplish in the public school placements. Several universities, such as The Ohio State University and the University of Wisconsin, incorporated observation hours outside of the campus. The Ohio State University had its students serve as public school classroom volunteer assistants during the month of September. The University of Wisconsin wanted its potential teachers to understand the nature of a child and what needs that child exhibits. They began a program in which their students would observe children in outside community agencies such as settlement houses, YMCAs, scout troops, day nurseries, and Sunday schools.

It was also during this time that internships emerged. With the abundance of certificated teachers graduating from colleges, an internship program provided the graduate with part time employment in a school district. The graduate received a salary based upon his or her employment hours and was generally supervised by the school district. The university or college, however, continued a relationship with the graduate and together they followed a program designed to develop a competent professional teacher. In 1948 the American Association of Teachers Colleges published what is known as the Flowers Report (Flowers, Patterson, Stratemeyer, \& Lindsey, 1948). This report outlined common principles, issues, and practices for student teaching, provided suggested standards, and also described an example of a quality student teaching program. While the report is credited as seminal in bringing forth vibrant and dynamic discussion in colleges of education, it is not touted for an equal change in action. Many believe the practicalities behind application of the suggestions were too extensive or costly in nature. 
In the late 1950s the Association for Student Teaching's subcommittee, Committee on Terminology, provided a list of common terminology and a definition of terms through which universities and colleges could find common concepts (Andrews, 1964). These terms included the following: professional laboratory experiences; student teaching; directed observation; participation; student teacher; supervising or cooperating teacher; college supervisor; other members of the supervising team; laboratory school; cooperating school and cooperating school district; internship; and clinical experience; apprenticeship or apprentice teaching; and clinical experience.

By the early 1960s most colleges offered teacher-educator curricula and provided credit courses in student teaching. Students could earn 2-20 or more semester hours from the student teaching experience. Few, by this point, used campus schools exclusively.

Most offered a combination of on and off campus laboratory schools, nearby public schools, and even some school districts quite a distance from the university. Universities began assigning college staff members to supervise the student teaching experiences.

The student teaching experiences in the early 1960s were as varied then as they are now. Some cooperating school systems limited the amount of time student teachers could teach. Others required the cooperating teacher to be in class at all times. Still others completely turned over the classroom to the student teachers and virtually left all teaching in their hands.

As is still an issue in current field experiences, the number of potential teachers needing placement in student teaching positions in the early 1960s outnumbered the availability of quality classroom teachers. Particularly in highly populated areas, districts 
were resigned to placing student teachers with any available cooperating teacher regardless of the quality of educator they were. Where once it was common for two student teachers to work together with a cooperating teacher, it now was custom for one student teacher to be matched with one cooperating teacher.

Following Sputnik, the National Commission on Teacher Education and Professional Standards (University of Kansas, 1968) pushed for a Bachelor's Degree to be the minimum requirement for teacher certification. Many states adopted a five-year program in which preservice teachers were required to take two years of general education and a three year professional education plan.

\section{Scholarship Research in Relation to Research Questions}

Research studies on co-teaching with special education and higher education is not new. However, available research on the use of co-teaching as a student teaching clinical model is quite current and limited. This research most directly focuses on the coteaching process, professional development of co-teachers, and the benefits of the partnership to co-teachers and students. The available research can be used to correlate perceived benefits and drawbacks of the co-teaching student teaching model with this study's participant groups.

Available research provides data on the benefits and drawbacks student teachers perceive the co-teaching model provides. For instance, Bacharach and Washut Heck (2012) showed that teacher candidates using the co-teaching model had equal or higher average ratings on the ten Interstate New Teacher and Assessment Support Consortium (INTASC) standards than those candidates in the traditional student teaching setting. Coteaching model responses showed a significantly higher difference in standard ratings 
relating to reflection, professional development, and partnerships in comparison to traditional student teaching models. Co-teaching candidates also out-performed candidates from traditional settings in the area of professional disposition, which includes such qualities as enthusiasm, reliability, responsibility, sensitivity, and responsiveness to the needs of students and staff. Finally, co-teaching candidates reported benefits of the co-teaching model as increased classroom management skills, heightened collaboration, and a deeper understanding of the curriculum. When asked the pros and cons of the coteaching model, co-teaching candidates repeatedly noted that they were seen by the students as "real teachers" from the first day of practice. Areas in which they particularly felt equal were in sharing and managing resources, mutual support and learning in which the teacher candidate and cooperating teacher equally share ideas and strategies, and in feeling they were part of an equal partnership in leadership and responsibility. Morton and Birky (2015) found that co-teaching student teachers perceived an increase in their ability to differentiate learning and believed their quality of teaching was elevated with fully developed lessons. Hartigan (2014) found benefits to co-teaching student teachers in the amount and quality of planning time they were able to spend with both their cooperating teacher and their university supervisor. Hartigan also found that co-teacher candidates benefited greatly in their own reflections on teaching. Bacharach, Washut Heck, and Dahlberg (2008) added that student teachers benefited from shared ideas and materials and noted their feeling of importance in the co-teaching process. DelColle and Keenan (2015) found significantly higher scores in co-teaching candidates than traditional candidates in professional development, the introduction to various instructional strategies, and encouragement to develop a personal teaching style. 
Co-teaching student teachers did note a drawback in the area of classroom management. Some perceived the cooperating teacher as the lead in behavior and wished the student teachers could use time to practice management and discipline. One noted that, while the modeling of classroom management was important, the time for candidates to practice it on their own is important as well.

University supervisors have also provided data on the benefits and drawbacks of the co-teaching model of student teaching. Bacharach and Washut Heck (2012) found that a positive impact on the university itself lies in the area of placement. Finding placements with cooperating teachers increased dramatically. Harnett, McCoy, Weed, and Hickens (2014) found university supervisors observed that P-12 students experienced the highest benefits of co-teaching student teachers versus traditional student teachers by receiving more individual attention, having more engaged teachers, hearing two perspectives, and benefiting from teachers building off each other. University supervisors observed co-teaching benefits to the classroom teacher as receiving more help for students with special needs, building better relationships with teacher candidates, and being able to stay with the classroom during the student teaching experience. University supervisors rated high benefits to co-teaching student teachers themselves as having more exposure to modeling, collaboration of skills, and building of student teacher confidence. Morton and Birky (2015) and DelColle and Keenana (2015) noted that university supervisors observed fewer classroom management problems in co-teaching settings with an increase in student teacher confidence in management procedures. Hartigan (2014) found the professional development between student teachers, cooperating teachers, and university supervisors invaluable in the emphasis placed on collaboration and 
cooperation. DelColle and Keenan (2015) found that university supervisors observed higher mastery of co-teaching candidates than traditional candidates in knowledge of content and pedagogy and the designing of coherent instruction. The most significant difference noted by supervisors, however, was that co-teaching candidates exhibited higher professionalism as defined by ethical conduct, service to students, advocacy, decision-making, and compliance to school and district regulations.

Available research data suggest that cooperating teachers find more benefits than drawbacks using the co-teaching model. Bacharach and Washut Heck (2012) note that cooperating teachers found the model provided more help for students with high needs, helped build a better relationship with their teacher candidates, experienced their own professional growth through co-planning, found enhanced energy for teaching, and enjoyed hosting the candidate without giving up their classrooms. Cooperating teachers also expressed that they perceived the candidates as having a richer learning experience. Finally, cooperating teachers in a focus group agreed that classroom projects were completed more successfully, classroom time was more productive, and candidates became competent more quickly. Murawski (2010) and DelColle and Keenan (2014) also found a positive effect in cooperating teachers' attitudes, noting that there was an increase in job satisfaction.

Cooperating teachers noted benefits in shared responsibilities, ability to one-onone conference with students, and having more time to connect to students. Morton and Birky (2015) found that cooperating teachers expressed a benefit in the increased ability to differentiate learning for students. Bacharach, Washut Heck, and Dahlberg (2008) noted that cooperating teachers found the five critical elements and benefits to co- 
teaching were as follows: sharing classroom leadership, planning together, respecting and trusting each other, communicating openly and honestly, and allowing the cooperating teacher to take the lead in planning and teaching. Diana (2014), however, found that one of the largest challenges to co-teaching at the student teaching level was cooperating teacher resistance. He suggests that many may find the model another educational fad.

P-12 building administrators have provided data on the co-teaching model of student teaching as well. Hartnett, McCoy, Weed, and Nickens (2014) found that building administrators considered the highest benefits the co-teaching model provided P-12 students was teachers were able to build off each other. The largest benefit to cooperating teachers, according to building administrators, was the cooperating teacher did not have to give up his or her classroom completely to the student teacher.

Administrators gave the highest benefits to student teachers. Administration observed an increase in collaboration skills, classroom management, more exposure to modeling, an increase in confidence, and an opportunity to ask questions and reflect. Morton and Birky (2015) found principals observed more student engagement and dynamic learning. Principals also found value in the collaborative nature of the co-teaching relationships. Additionally, Diana (2014) noted that school districts who have difficulty hiring qualified teacher assistants may find co-teaching at the student teacher level beneficial in supporting their teachers and students. Building principals, however, also gave the largest scores in drawbacks of the co- teaching model. They noted the largest drawbacks in the following areas: the co-teaching model takes too much time and the forced partnership was often uncomfortable for the cooperating teaching. 


\section{Summary}

With authorization of the federal legislation No Child Left Behind (US

Department of Education, 2002), public schools became accountable on state and federal levels for the academic achievement and growth of diverse student populations. Coteaching became a viable method of inclusive instruction in the special education discipline to access the regular classroom setting and curriculum. Co-teaching, as defined by Villa, Thousand, and Nevin (2008), is an instructional model where two or more people of equal status share the responsibility of planning for, instructing, and assessing some or all of the students in a classroom. It consists of educators working together to examine student work and find alternative ways of meeting the needs of students (Desimone, 2009). It first appeared as a model of inclusive instruction for special education, moved to the university level by which instructors co-taught, and finally became a model for student teaching.

Experts in the field of co-teaching have defined various models of co-teaching that are implemented in the inclusive classroom and higher education programs. Friend and Cook (2010) introduce six approaches to co-teaching: one teach, one observe; one teach, one drift; alternative teaching; parallel teaching; station teaching; and team teaching. These are the models most commonly found in student teaching research.

A wide range of research is available defining the skill sets and roles needed to create a successful co-teaching culture and program. The skills perceived to be most important for collaboration and co-teaching were communication, data collection/diagnostic testing, interpersonal skills, differentiation, self-advocacy, writing effective lesson plans, organization in providing accommodations, and classroom 
management strategies and skills. Diana (2014) purported along with shared responsibilities and communication skills, co-teachers must establish trust and be able to work together to problem solve.

Research on co-teaching has revealed issues, sensitivities, and stressors common to the co-teaching experience. Chanmugan and Gerlach (2013) found it is important to address specific issues at the onset of the co-teaching practice: power sharing, communication, roles, appropriate matching of co-teachers, methods for exchanging feedback, responsibility sharing, and scheduling. Graziano and Navarrete (2012) described barriers to using the co-teaching model at a collegiate level. Co-teaching requires additional plan time. Budget crises do not necessarily allow for extra pay for such time, as well as the extra course load required of professors if there are to be two per course. Additionally, a large barrier lies in system policy regarding promotion, tenure, and merit reviews. Dugan and Letterman (2004) offered advice on meeting the demands and pitfalls of co-teaching at the collegiate level. They suggest that plans be created for interjecting and turn-taking, power differentials, and conflicts of ideas.

Many benefits to the inclusive classroom and higher education teacher preparation programs have emerged from co-teaching research. Albrecht (2003) noted benefits from co-teaching included the co-teachers learning from each other and elevating their teaching strategies because of the collaboration. Vasquez-Montilla, Spillman, Elliott, and McGonney, (2007) found that university faculty who participated in coteaching found value in the creative process of the experience and had a sense of fulfillment they had not experienced in solitary course instruction. Similarly, in a qualitative case study of university faculty participating in co-teaching at the University 
of North Dakota, Bass (2005) noted four positive themes that emerged: opportunity to be creative, positive outcomes, open communications, and a sense of fulfillment. University supervisors observed co-teaching benefits to the classroom teacher as receiving more help for students with special needs, building better relationships with teacher candidates, and being able to stay with the classroom during the student teaching experience. University supervisors rated high benefits to co-teaching student teachers themselves as having more exposure to modeling, collaboration of skills, and building of student teacher confidence. Cooperating teachers find more benefits than drawbacks using the co-teaching model.

Bacharach and Washut Heck (2012) noted cooperating teachers found the model provided more help for students with high needs, helped build a better relationship with their teacher candidates, experienced their own professional growth through co-planning, found enhanced energy for teaching, and enjoyed hosting the candidate without giving up their classrooms. Cooperating teachers also expressed that they perceived the candidates as having a richer learning experience. Finally, cooperating teachers inside a focus group agreed that classroom projects were completed more successfully, classroom time was more productive, and candidates became competent more quickly.

Current research noted many benefits of the co-teaching model of student teaching such as the positive nature of professional development, the collaborative nature of the co-teaching relationship in planning and instruction, and the benefit of an abundance of expert modeling in a variety of situations. This study will expand on the research field to include the level of preparation the model is perceived to provide the first year teacher. 


\section{SECTION FOUR}

CONTRIBUTION TO PRACTICE 


\section{Plan for Dissemination of Practitioner Contribution}

I will present the co-teaching model of student teaching findings in the form of a PowerPoint presentation and executive summary to the UCM Dean of the College of Education, UCM staff of clinical services, and UCM co-teaching research committee. This format will allow for open dialogue between the UCM stakeholders and the researcher. Additionally, a presentation proposal will be sent to the Missouri Association of Colleges of Teacher Education in the fall of 2018. Follow-up study ideas on the coteaching clinical model will be discussed. An executive summary of findings will also be provided to the study participant group members as follow-up information to their participation in the study.

\section{Type of Document}

I will present a PowerPoint presentation and executive summary to the UCM Dean of the College of Education, the UCM staff of clinical services, and the UCM coteaching research study committee.

\section{Rationale for Contribution Type}

The study aims to provide the UCM College of Education feedback on the use of co-teaching as a clinical model for student teaching. An executive summary will highlight and summarize the findings of the study in a format that is easily followed and can be referenced again if needed. 


\author{
Executive Summary \\ Co-Teaching as a Clinical Model of Student Teaching: \\ Perceptions of Preparedness of First Year Teaching
}

\title{
ORGANIZATION BACKGROUND
}

- The University of Central Missouri (UCM) College of Education has been in place for more than 140 years.

- UCM College of Education offers over 39 undergraduate and 16 graduate degrees.

- In the spring of 2011, the Dean of the College of Education sent five university faculty members to the St. Cloud State University co-teaching model training.

- From October 2011 to February 2012, group members identified school districts, cooperating teachers, university supervisors, and teacher candidates for participation in the fall 2012 pilot of the co-teaching model.

- November of 2013 the Campus Teacher Education Council voted to make the coteaching model the official model of student teaching for all teacher candidates effective the fall of 2014.

- $\quad$ By January of 2015, 180 student teacher co-teachers were placed in 44 school districts.

\section{PROBLEM OF PRACTICE}

- Public school teachers are held accountable for the success of their students on high stakes state tests.

- Does a co-teaching student teacher model provide university students an appropriate amount of clinical experience and preparation necessary to support a successful first year of teaching?

- $\quad$ Does the use of a co-teaching clinical model support both local district and university needs?

- The purpose of this study is to determine and analyze the perceptions of current and former student teachers, cooperating teachers, and university supervisors on the co-teaching model of student teaching and its ability to prepare student teachers for their first year of teaching.

\section{RESEARCH QUESTIONS}

- What are the perceptions of University of Central Missouri current and former student teachers on the co-teaching student-teaching model's ability to prepare student teachers for their first year of teaching?

- What are the perceptions of University of Central Missouri university supervisors on the co-teaching student-teaching model's ability to prepare student teachers for their first year of teaching?

- What are the perceptions of cooperating teachers who work with University of Central Missouri student teachers on the co-teaching student-teaching model's ability to prepare student teachers for their first year of teaching? 


\section{RESEARCH METHODS AND METHODOLOGY}

- A mixed method approach to research was used in this study.

- Qualitative Methodology: One-on-one neo-positive interviews

- $\quad$ Quantitative Methodology: Online survey with Likert-type scale numeric values with item stems based on the Missouri Teacher Standards

\section{THEORETICAL FRAMEWORK}

- $\quad$ Gradual Release of Responsibility and Social Learning Theory

- $\quad$ Co-Teaching

\section{DATA ANALYSIS}

- $\quad$ Quantitative Data: Analyzed through two One-Way ANOVA tests; six t-Tests; and one One-Way Repeated Measures ANOVA test

- Qualitative Data: Coded for patterns, generalizations, and themes using the Six Step Coding Process: Organized and prepared the noted; looked for data consistency within and across the groups; grouped common observations into generalization categories; generated a descriptive theme or themes based on generalizations; created a narrative passage to describe the themes represented in the data; interpreted the qualitative data couched in personal understandings and comparisons to literature and known theories.

- Qualitative and quantitative data were triangulated to identify overarching themes between the qualitative and quantitative data. The researcher interpreted the overall data within the context of personal understandings and comparisons to literature and known theories

\section{FINDINGS}

- The overall participant group perceive the co-teaching student teaching model to be an effective model for preparing new teachers for their first year of teaching.

- $\quad$ Student teachers and cooperating teachers perceive the co-teaching model as preparing first year teachers significantly more than do university supervisors.

- $\quad$ K-8 participant perceptions of the co-teaching model's ability to prepare first year teachers is significantly higher than K-12 or 9-12 respondents.

- $\quad$ The co-teaching model of student teaching highly supports the growth of student teachers in preparation for their first year of teaching.

- The co-teaching student teaching model builds the student teacher's selfconfidence.

- $\quad$ One weakness noted by participants was that, by not completely and independently taking over the classroom, the student teacher does not get a fully realistic experience of teaching. 


\section{LIMITATIONS, ASSUMPTIONS, AND DESIGN CONTROL}

- Transferability of findings across other institutions will be limited as this study specifically explores UCM's co-teaching clinical model and students who have attended UCM's pre-service courses.

- $\quad$ The present research proceeds under the assumption that each pre-service student teacher is at a somewhat equal level of preparedness as other student teachers at the onset of the co-teaching clinical experience. This assumption stems from the application of common coursework of all pre-service education students within the UCM College of Education.

\section{CONCLUSIONS/DISCUSSIONS/RECOMMENDATIONS/FUTURE RESEARCH}

- $\quad$ Current and former student teachers and cooperating teachers perceived the coteaching model of student teaching as strongly preparing student teachers for their first year of teaching.

- Strengths of the co-teaching student teaching model included extensive modeling, immediate feedback, professional reflection, collaboration, singular foci, and building the confidence of the student teacher.

- A barrier noted was without the student teacher spending two to three weeks of being solely responsible for the duties of the classroom teacher without the cooperating teacher in the room, a realistic experience of most classroom teachers is not provided.

- The recommendation of the researcher is to continue the use of the co-teaching model as a student teaching clinical model but provide two-three weeks of student teaching whereby the student teacher is solely responsible for all classroom duties of the cooperating teacher while the cooperating teacher is out of the room.

- $\quad$ Future research using the same methodology and participant groups could be done on a co-teaching model that also incorporates extended time alone in the classroom by the student teacher. 


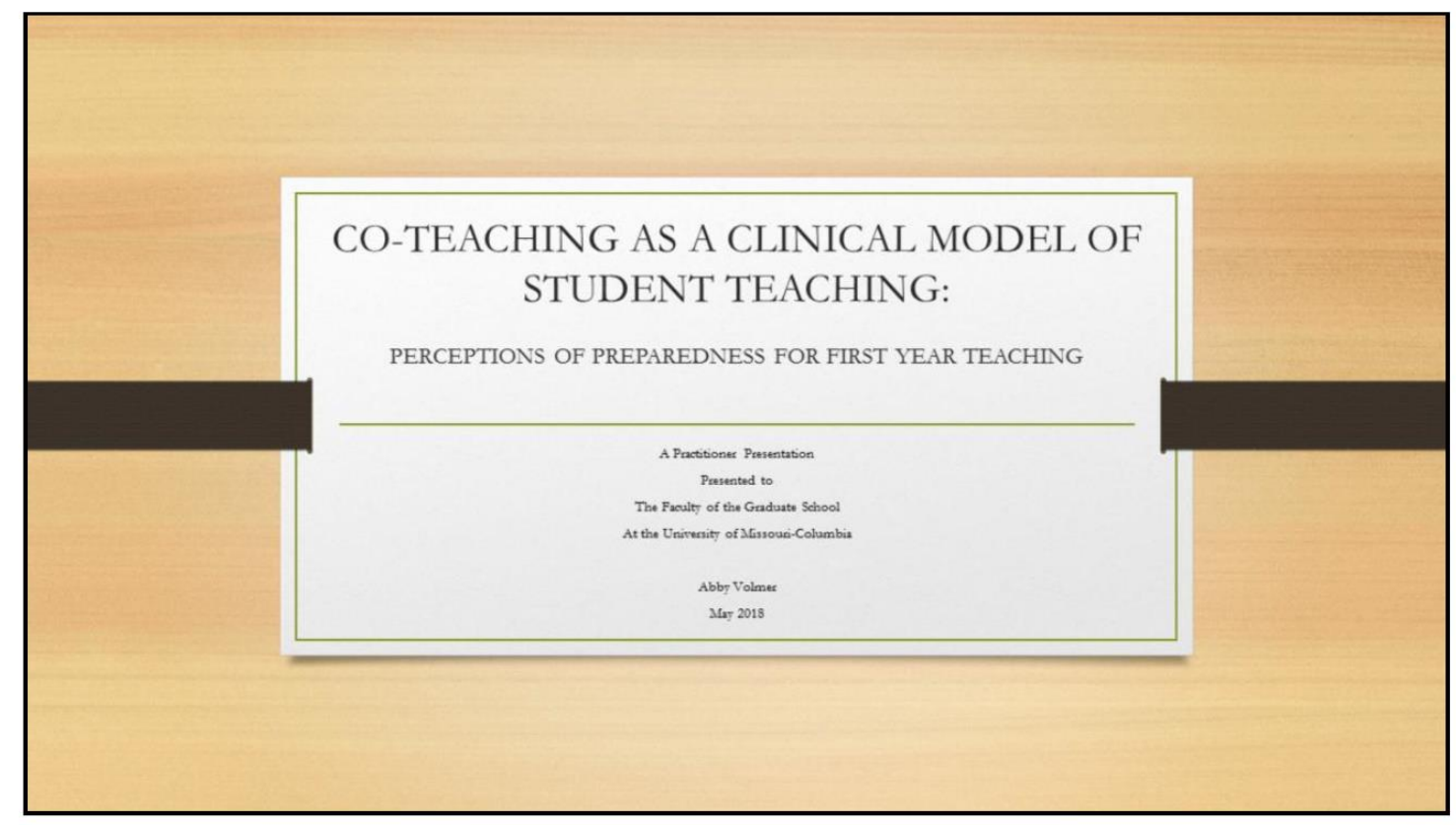




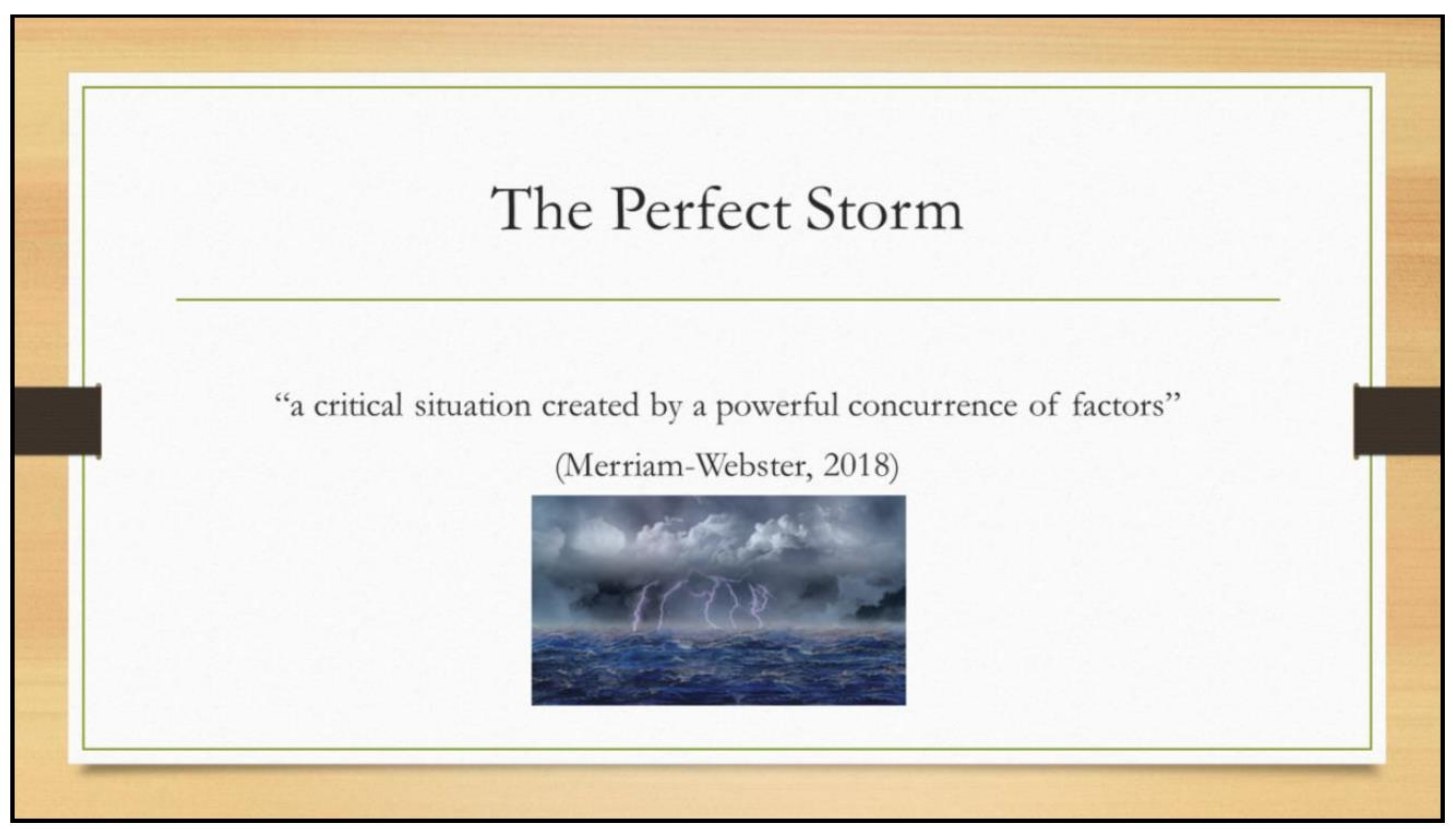

Talking Points

- Perfect storm brewing UCM College of Education 


\section{BACKGROUND}

- Blue Ribbon Panel of the National Council for Accreditation of Teacher Education (NCATE, 2010) call for teacher preparation as a shared responsibility and experience

- Department of Elementary and Secondary Education (DESE) asked universities to articulate the clinical practices of their institution (Harnett, Wee, McCoy, Theiss and Nickens, 2013)

- Teachers voiced concerns about accepting student teachers due to the accountability of high stakes state-wide testing (Diana, 2014)

- University of Central Missouri Dean of the College of Education sought out research on the use of co-teaching as a model of student teaching (M. Wright, Personal Communication, November 3, 2015)

Talking Points

- Discuss the four "powerful factors" creating a critical situation at UCM College of Education teacher preparation program 


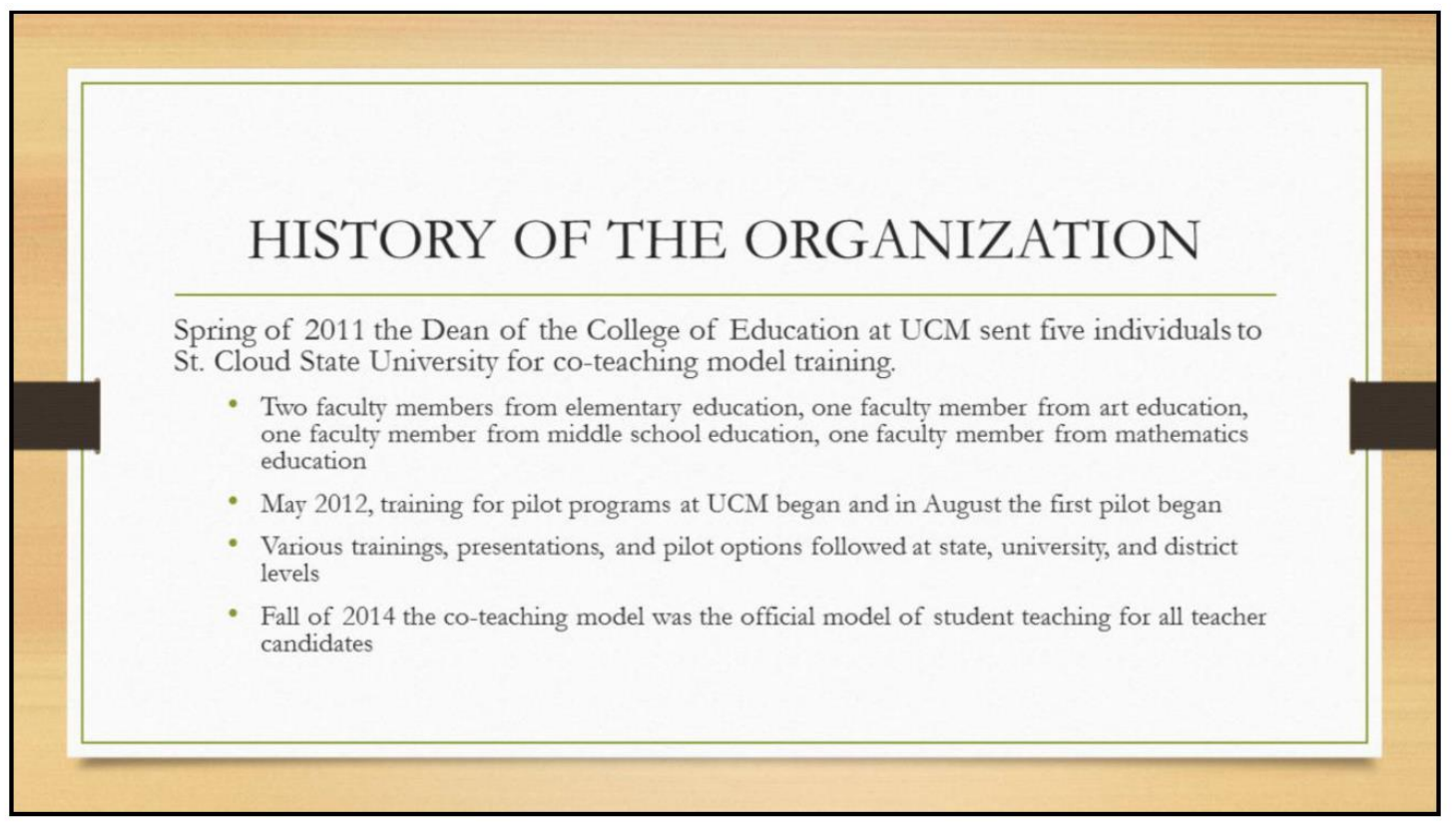

Talking Points

- Discuss strategy for faculty input and items on slide 


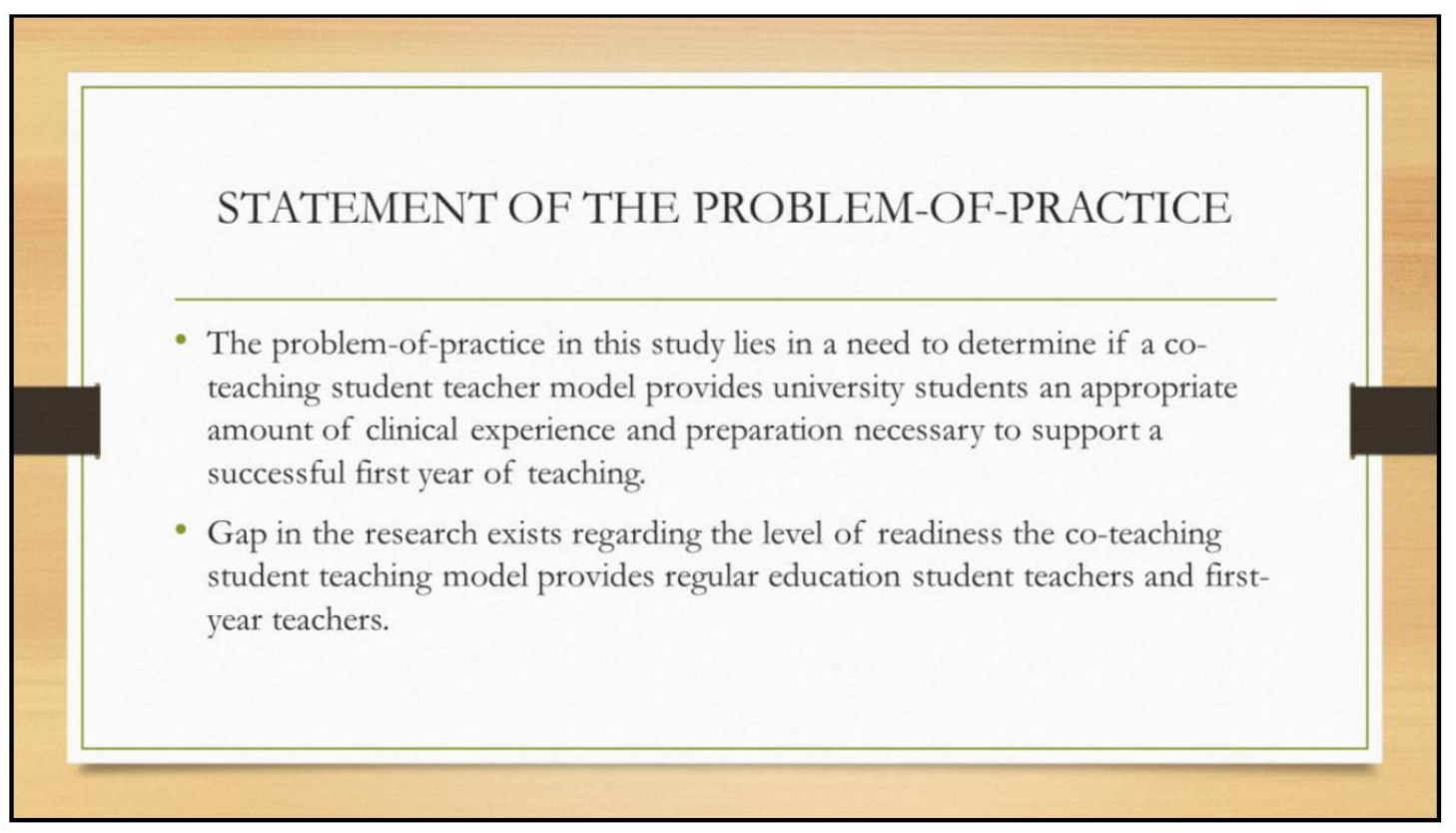

Above P-o-P 


\section{PURPOSE OF THE STUDY}

- To determine and synthesize the perceptions of current and former student teachers, cooperating teachers, and university supervisors on the co-teaching model of student teaching and its ability to prepare student teachers for their first year of teaching.

- The Missouri Teacher Standards (Missouri Department of Elementary and Secondary Education, 2013) guides the criteria for this study when determining levels of readiness for teaching by both student teachers and second year teachers.

Talking Points

- Why I chose Teacher Standards to guide quantitative research

- Makes quality teachers

- State approved 


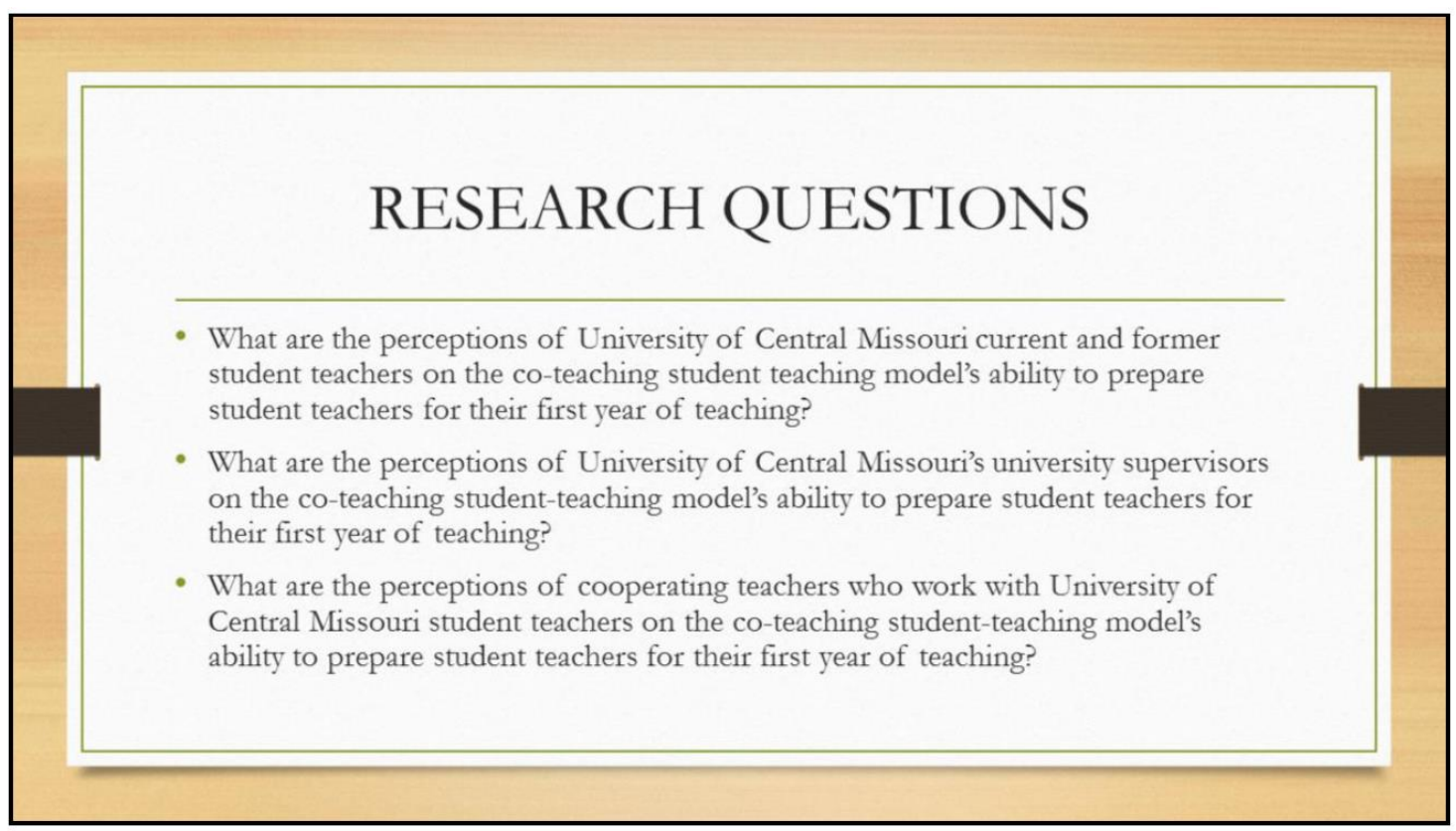

\section{Talking Points}

\section{- Same question but three populations}




\section{THEORETICAL FRAMEWORKS}

- The theoretical framework guiding this study is the Gradual Release of Responsibility (GRR) first coined by Pearson and Gallagher (1983) and based on the work of Vygotsky (1978)

- The four phases of GRR (Fisher and Frey, 2008) will frame the co-teaching model of student teaching when using various co-teaching models (Friend and Cook, 2003)

- "I do..."

- "We do..."

- "You do it together"

- "Independent Phase"

Talking Points

- How I felt GRR guided student teaching as a whole

- GRR is a highly researched and grounded social learning theory

- Based on Vygotsky's idea of Social Learning, Zone of Proximity, and More Knowledgeable Other 


\section{DESIGN OF THE STUDY}

- Context- University of Central Missouri (UCM), districts that placed UCM student teachers, districts that hired UCM teachers

- Participants - 42 total - 1 for not providing demographics - 41 total used

- Current and former UCM student teachers (22 quantitative survey; Nine follow-up qualitative interviews)

- Cooperating teachers who have UCM co-teaching student teachers and have also had traditional model student teachers (14 quantitative survey; Six follow up qualitative interviews)

- UCM university supervising teachers who have supervised both the traditional and coteaching models of student teaching (five quantitative survey; three follow-up qualitative interviews)

Talking Points

- Student teachers - 296 survey attempts sent out

- Cooperating teachers -128 survey attempts sent out

- University supervisors - 28 survey attempts sent out 


\section{DESIGN OF THE STUDY MIXED METHODS}

- Quantitative Survey using a Likert-type (Fink, 2013) one-to-nine scaled survey formatted to resemble that developed by Tschannen-Moran and Woolfolk Hoy (2001). Items formatted as belief statements mirroning Missouri Teacher Standards (TEST-RETEST)

- Qualitative Data (Merriam, 2009)-Reviewed for clarity

- Qualitative interviews - Open-ended questions in a semi-structured interview; preset list of questions but include a mix of less structured questions (current and former student teachers, cooperating teachers, and university supervisors)

- Quantitative descriptive statistics of mean, mode, and median from survey data, One-Way ANOVA, $t$-Tests, Repeated Measures One-IVay ANOVA, Single Sample $t$-Test (Field, 2013)

- Qualitative Approach to Research Analysis - Transcribed interviews coded for generalizations, categories, and findings within and across belief systems (perceptions, thoughts, and feelings) of participants

- Consulted with Dr. Kreiner

- Dr. Kreiner suggested free calculators

- One-way ANOVA used to compare three respondent groups for significant difference

- T-Tests used to compare two groups to each other

- Repeated Measures One-Way ANOVA used to compare the educational concept item groupings

- Single Sample t-test used to find perception of "effectiveness 


\section{SURVEY SAMPLE}

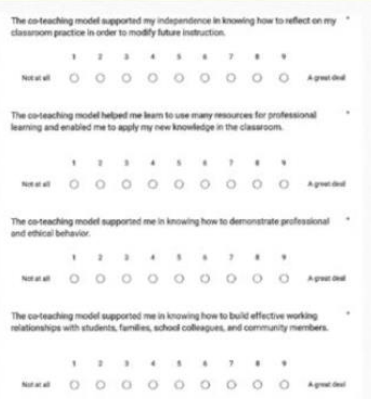

Talking Points

- (5-some) - (9-quite a bit) to be the range of "effective" in preparing students

- Survey was tested and retested by sample population (student teacher/cooperating teacher) for reliability with items scoring too far apart revised or deleted.

- Items were shared with Dr. of literacy for clarity.

- 552 consent forms and participation requests were sent - Response rates were ST (296) - 8\%, CT (128)- 11\%, US (28) 18\% 


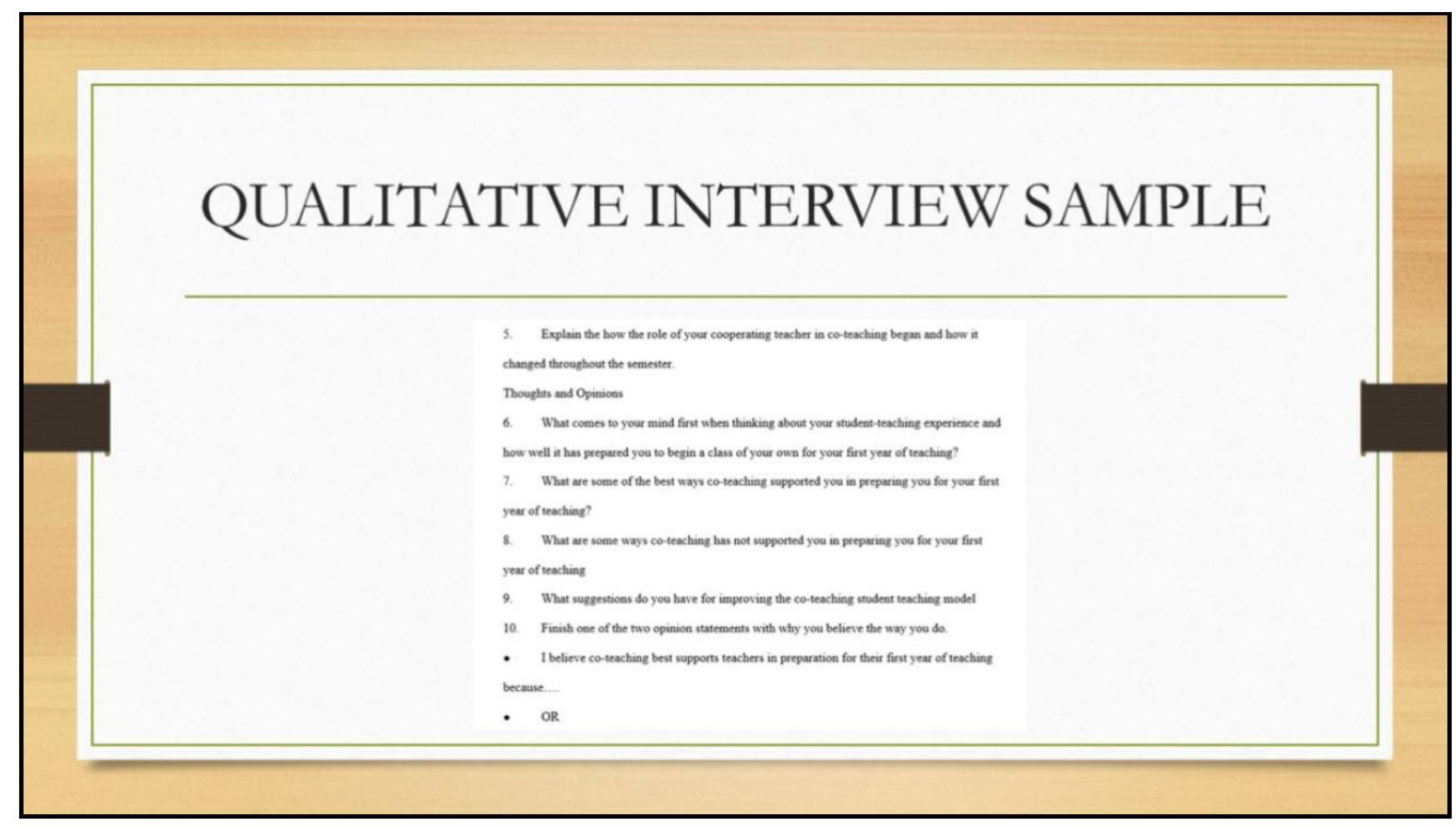

Talking Points

- Items shared with various sample populations for clarity

- Review types of items 


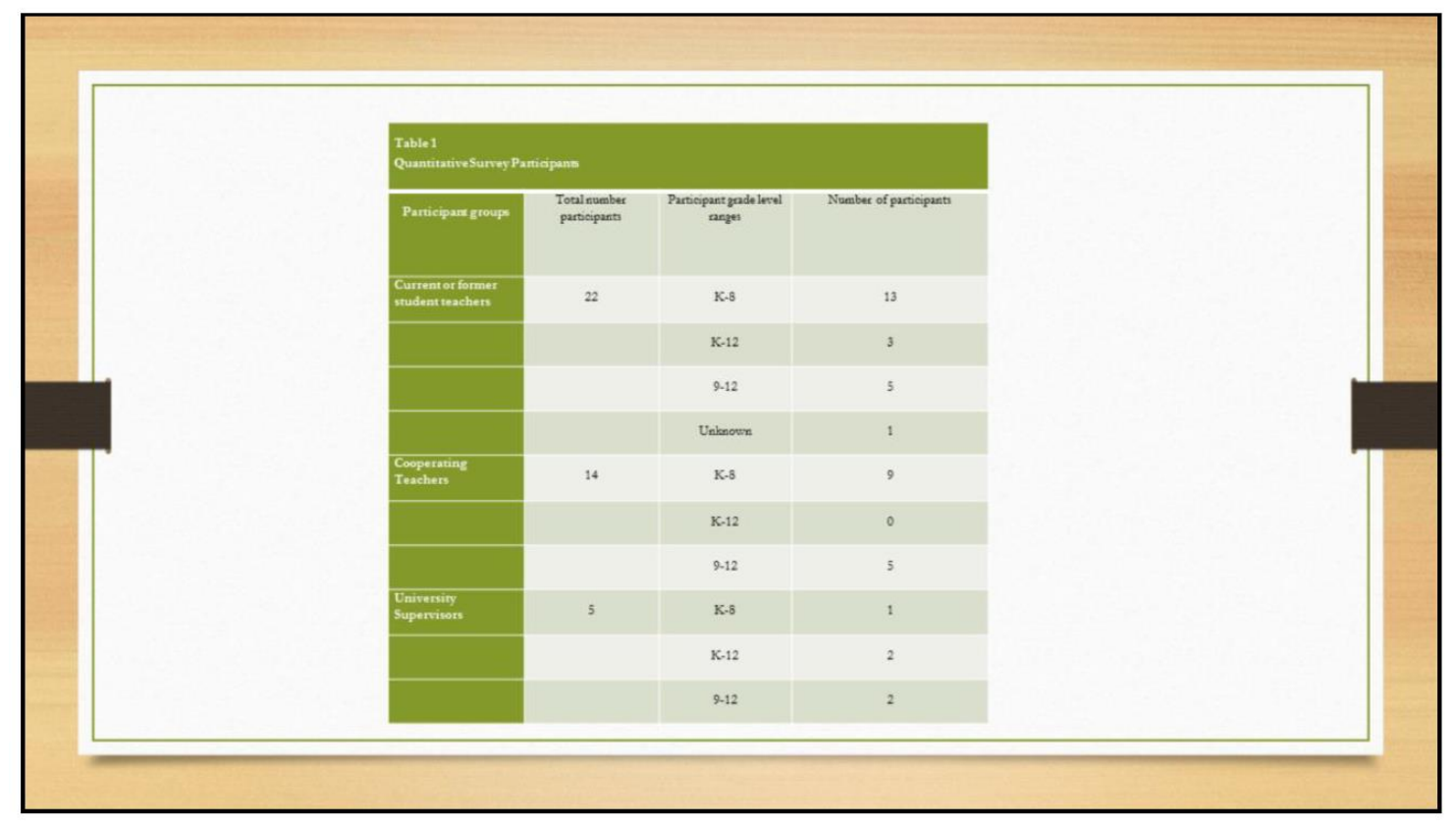

Talking Points

- Quantitative Survey- 22, 14, 5

- Note the heavy K-8 in Elementary

- Note the 9-12 and K-12 in university supervisors 


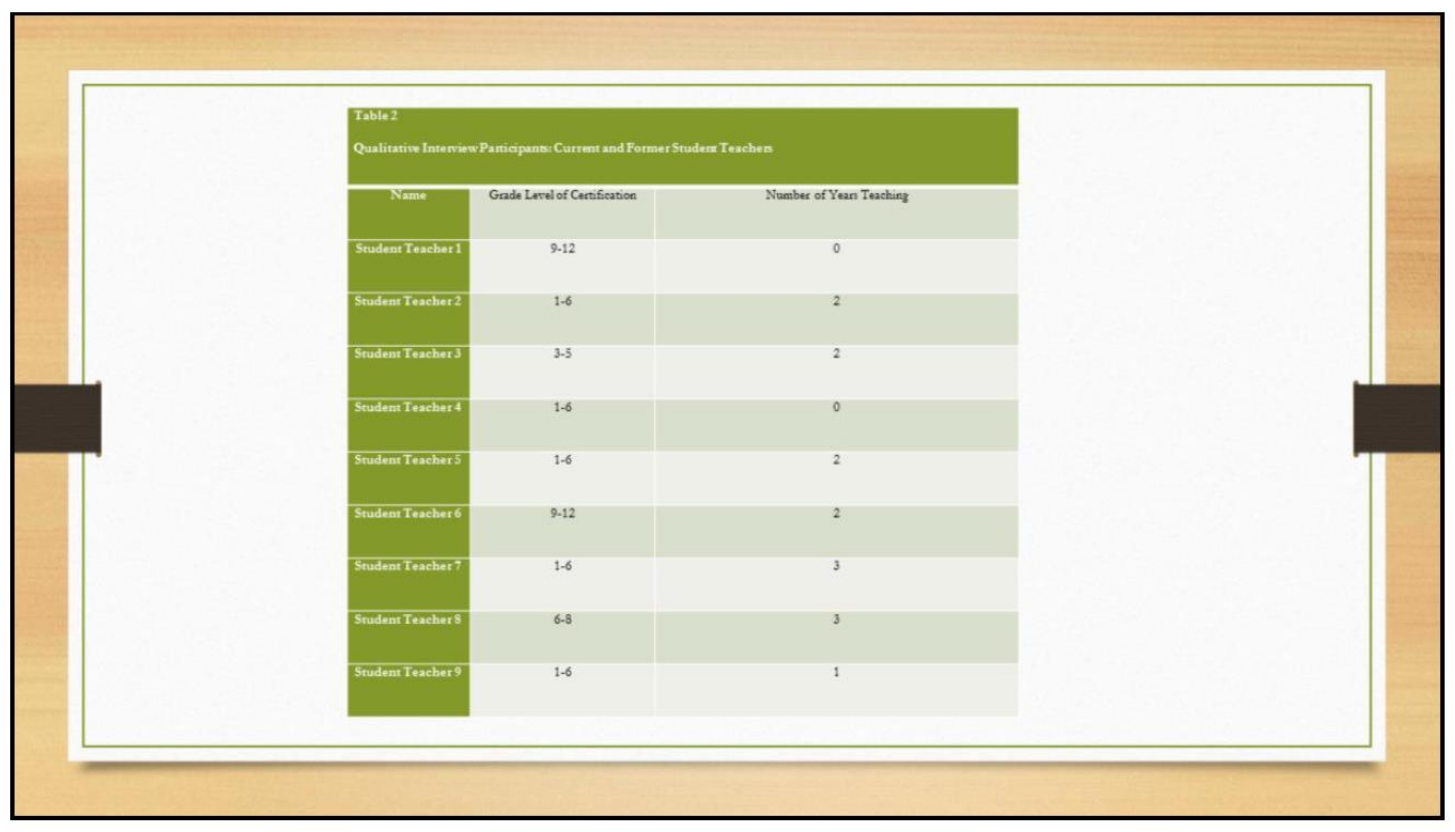

Talking Points

- Qualitative Survey - ST - 9 out of 22 quant

- Of the 9 , only 2 had not yet taught 


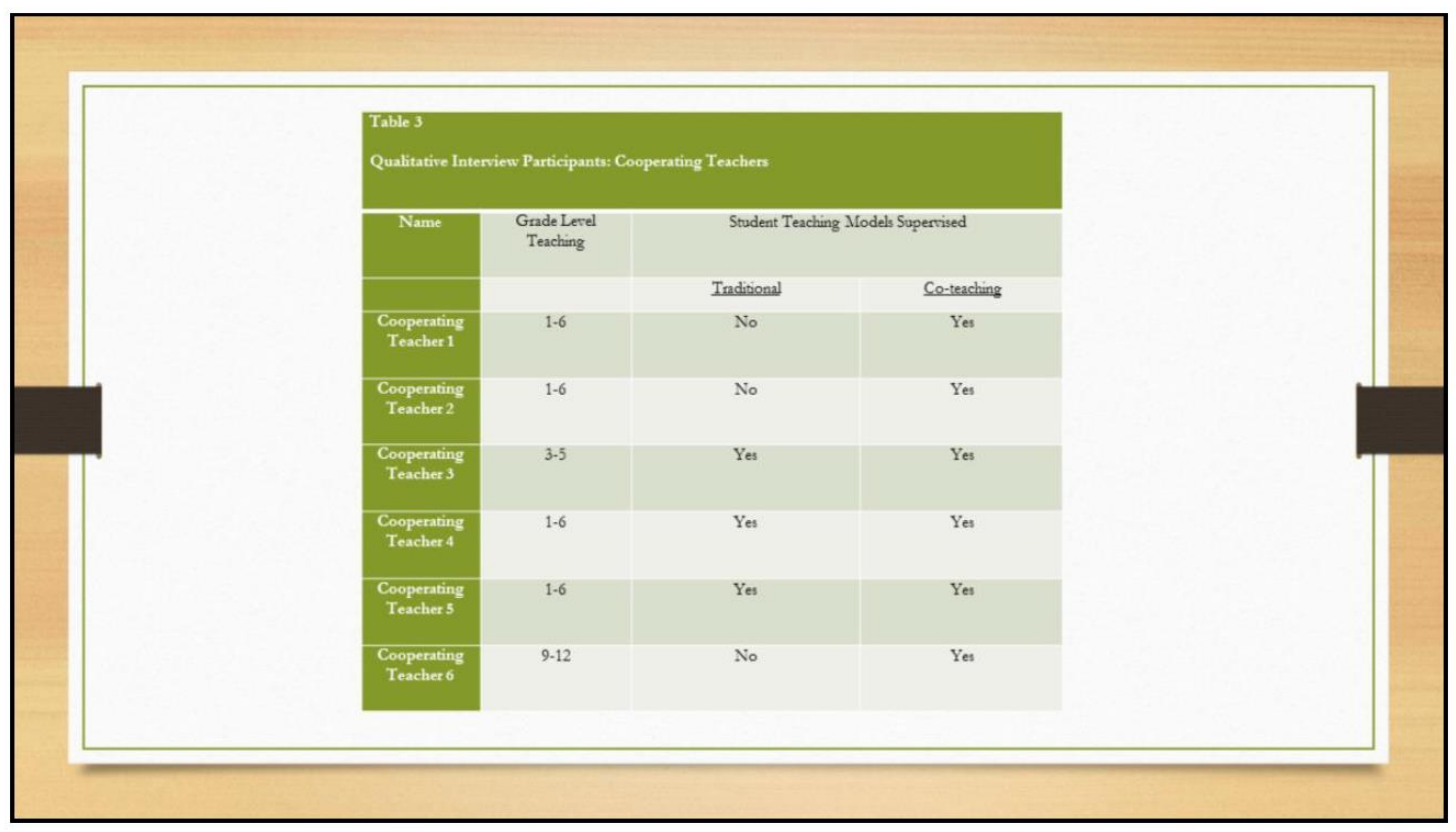

Talking Points

- Qualitative Survey 6 out of the 14 CT from quant

- Half had experienced both traditional and co-teaching models 


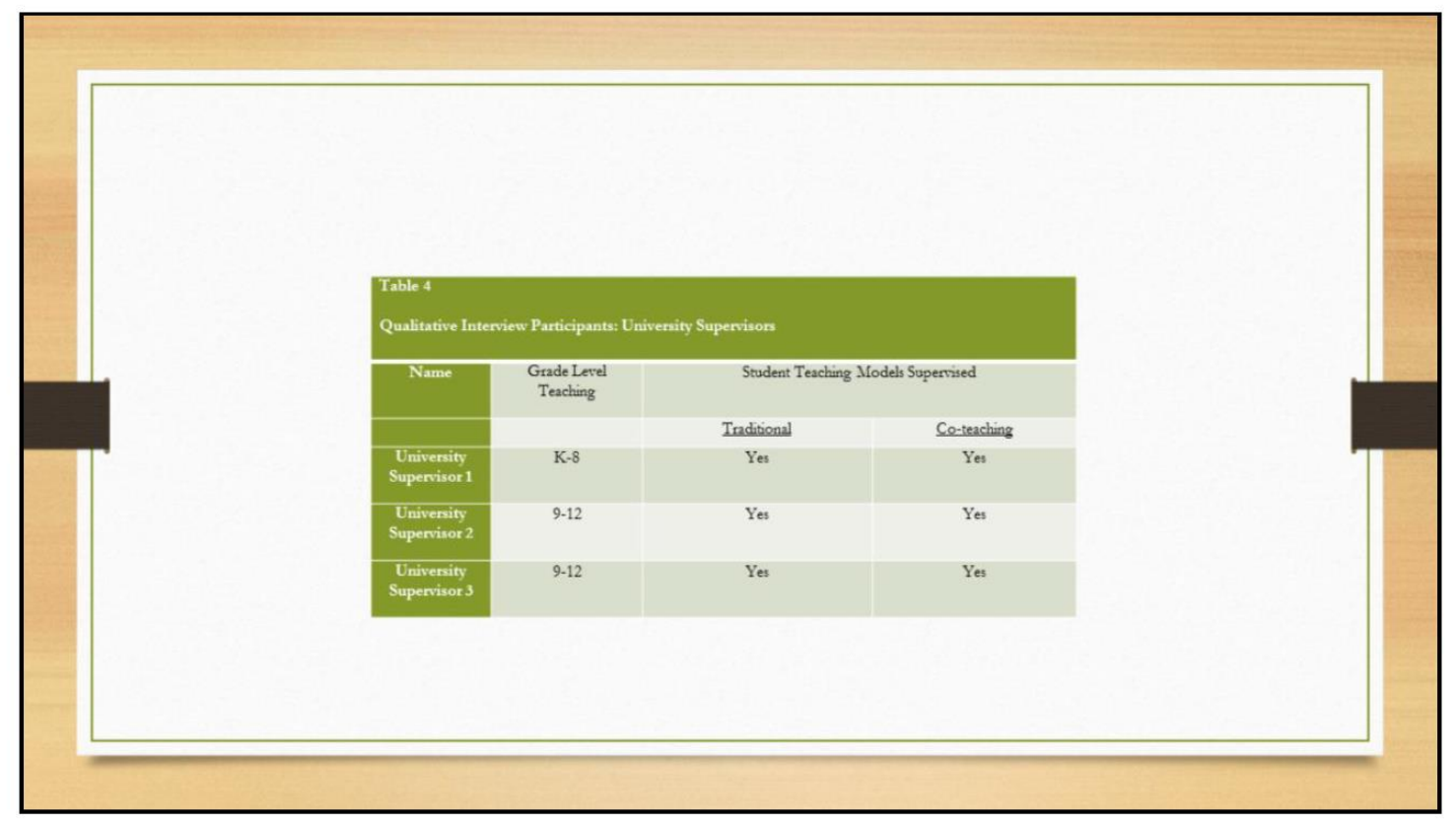

Talking Points

- Qualitative Survey - Of the 5 quant, there were three

- All three had supervised both traditional and co-teaching models 


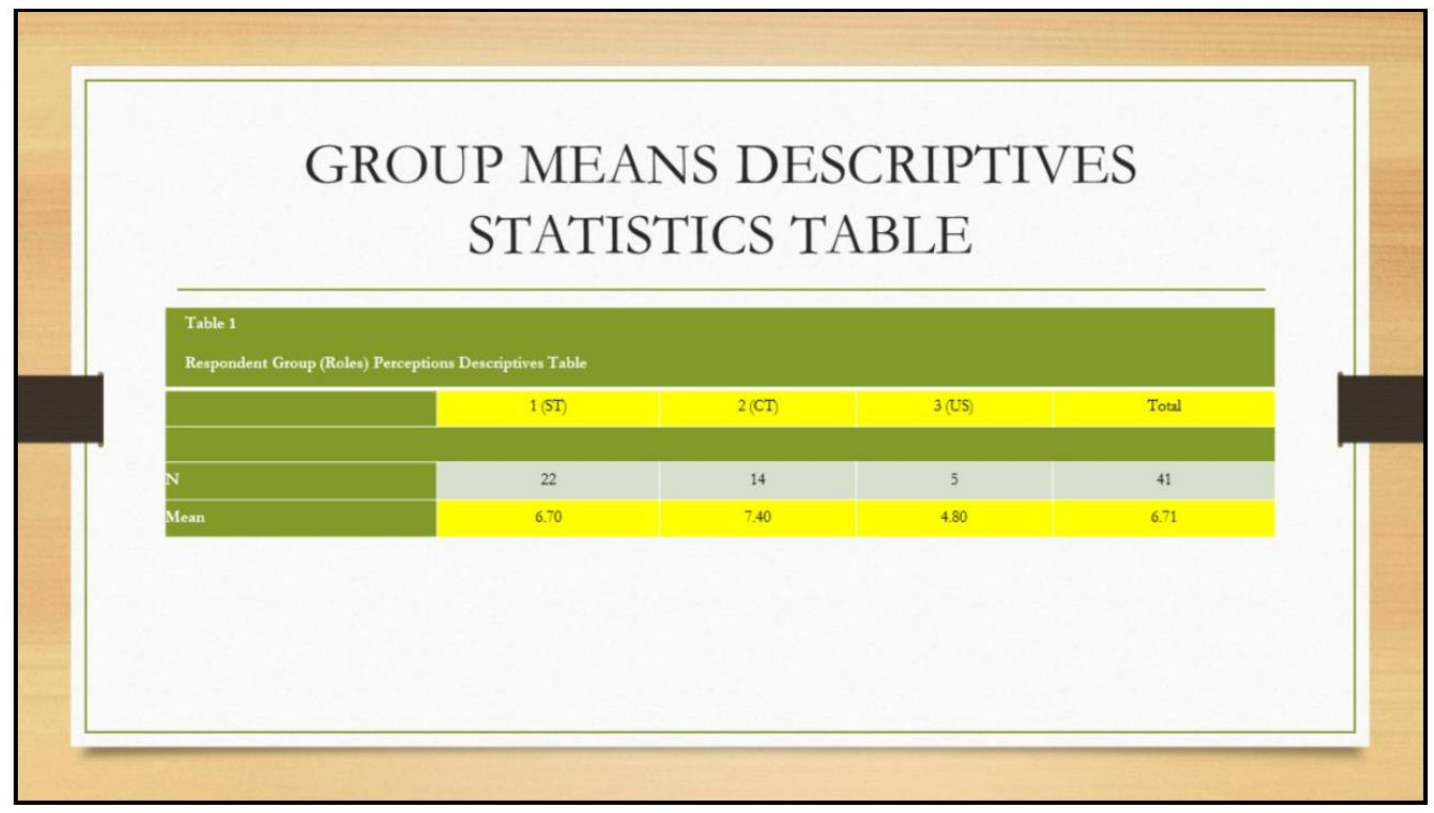

Talking Points

- Point out average means of each population and number in group 


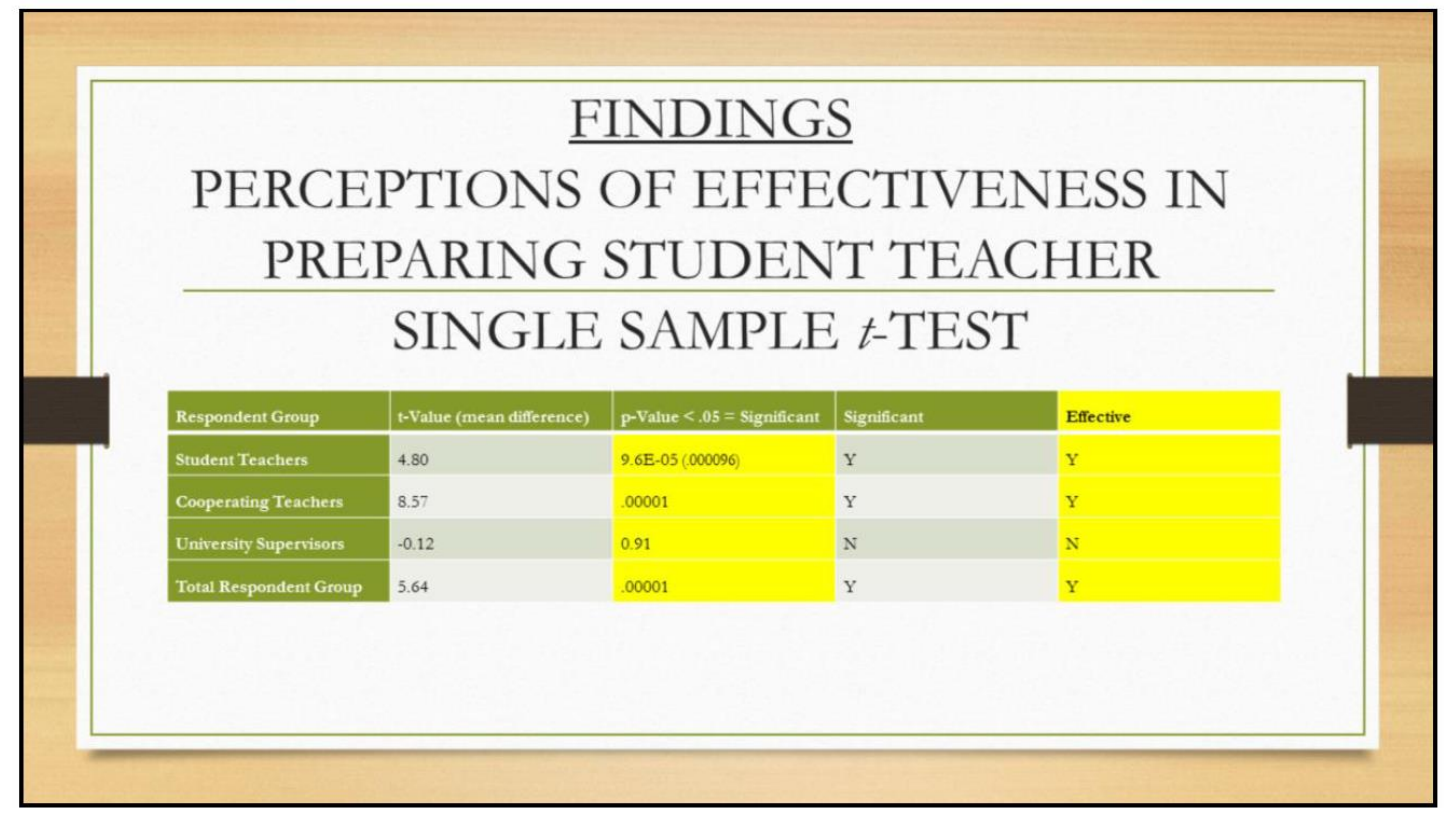

Talking Points

- Single sample t-Test - (5) or higher determined to be the criterion for "effective."

- Single sample t-Test compared the (5) mean to all of the means of a population and determined if there was a significant difference, then that group's perceptions were high enough to be considered "effective"

- Review each group and total group 


\section{QUALITATIVE DATA SIX STEP CODING}

(Creswell, 2014,pp. 197-201)

1. Organized and prepared the notes.

2. Looked for data consistency within and across the groups.

3. Grouped common observations into generalization categories triangulating qualitative data with quantitative data

4. Generated descriptive findings based on generalizations.

5. Created a narrative passage to describe the themes represented in the data.

6. Interpreted the qualitative data couched in personal understandings and comparisons to literature and known theories.

\section{Talking Points}

- Transcribed and printed scripts. Created a coding sheet to identify participant ie. CT1 is "name" in grade/s "number"

- Read and underlined points and wrote out to the side a generalization of that comment. Did this through all scripts.

- Took each script and wrote CT1, US3, etc. next to each comment underlined and generalized. Then cut each underlined comment into strips. This way I knew which participant had made each comment.

- Then I sorted the comment slips into common groups, placed them in an envelope, and labeled the envelope with the commonality or generalization.

- Then based on my personal understandings or known theories, I combined similar or related groups/envelopes into overarching findings. I rubber banded these envelopes together and labeled the finding with a sticky note. 


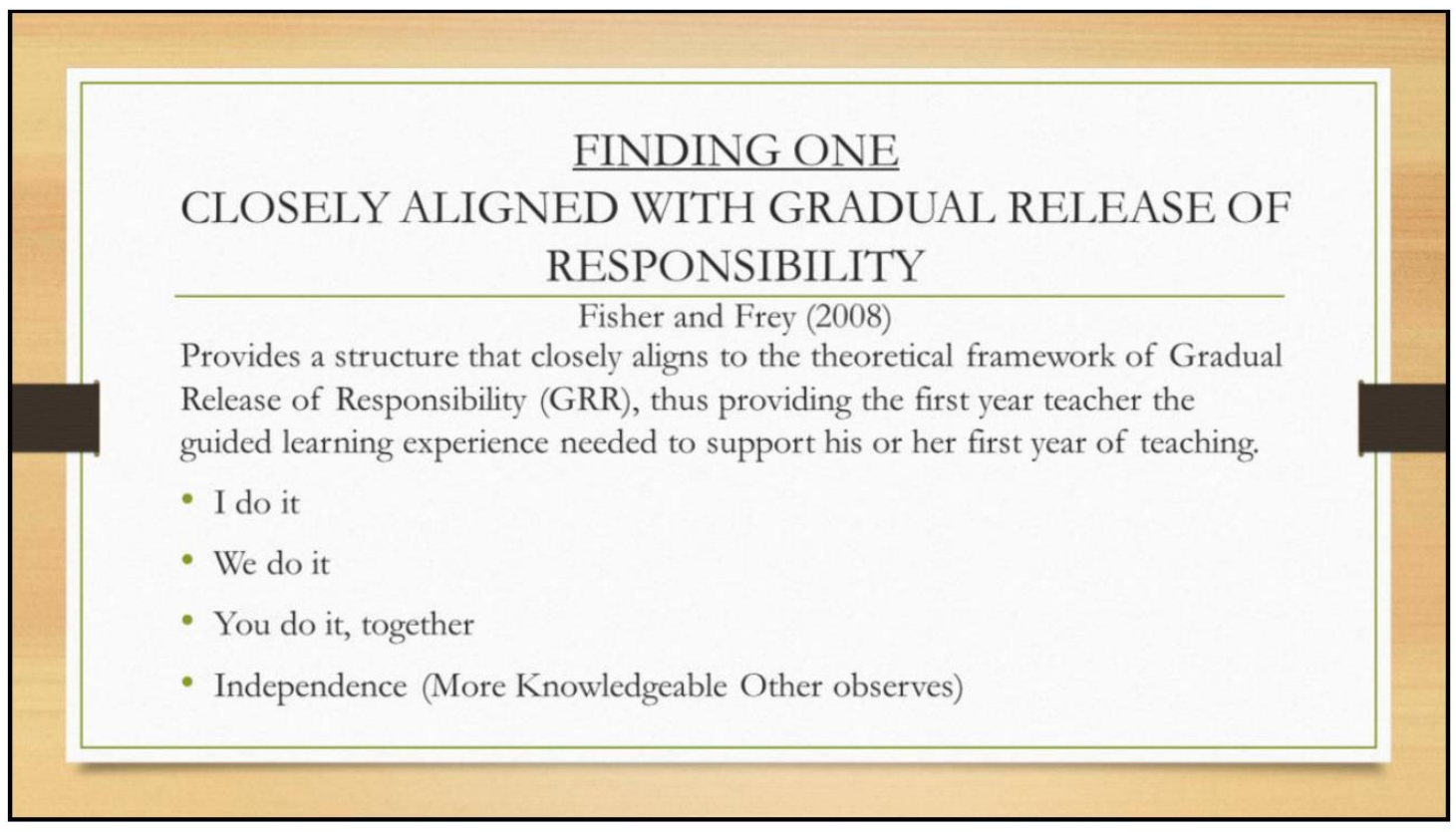

Talking Points

- As I looked at the generalizations, I realized that they closely aligned to GRR 


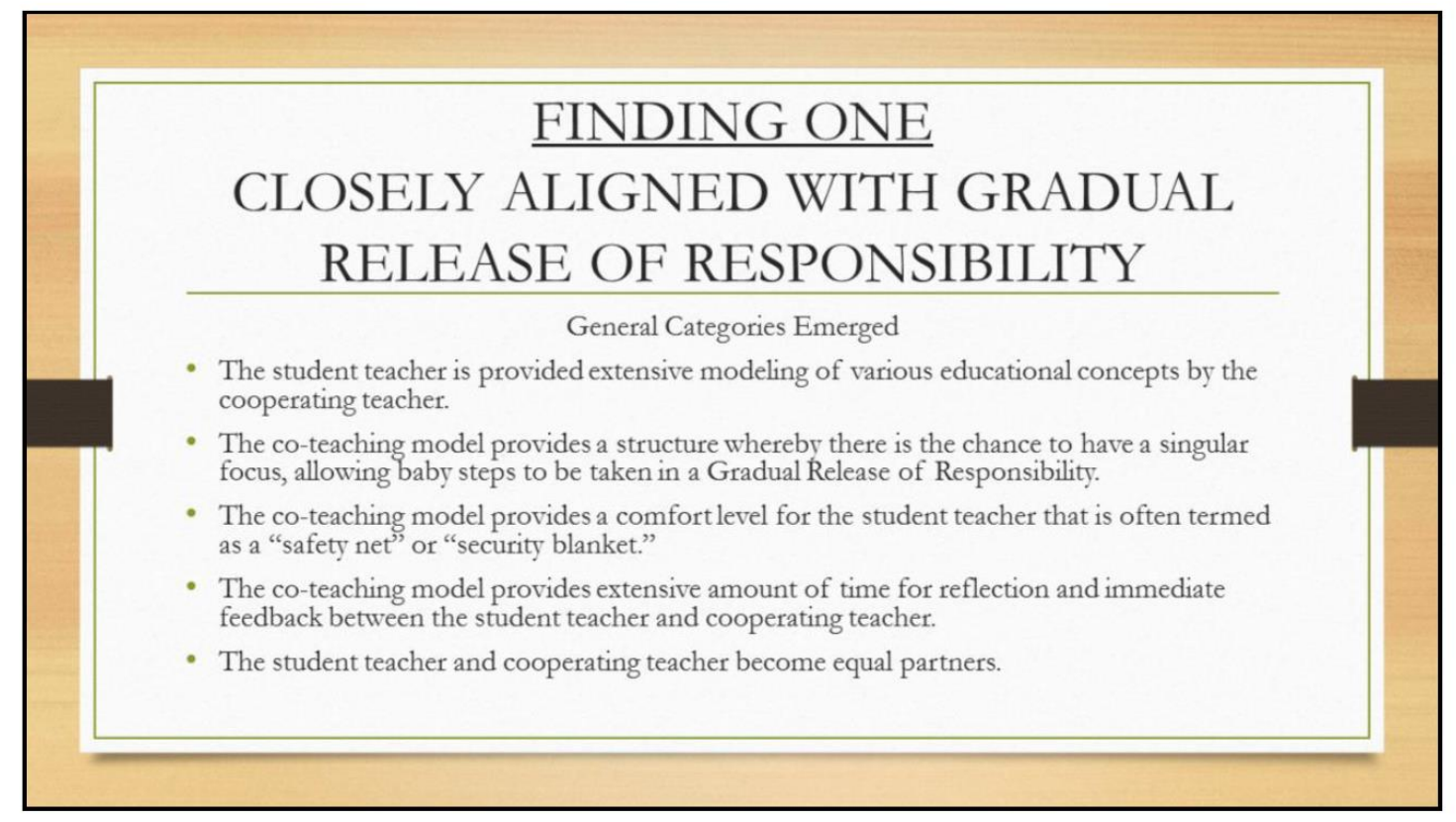

Talking Points

- These categories/envelopes were grouped/banded together 


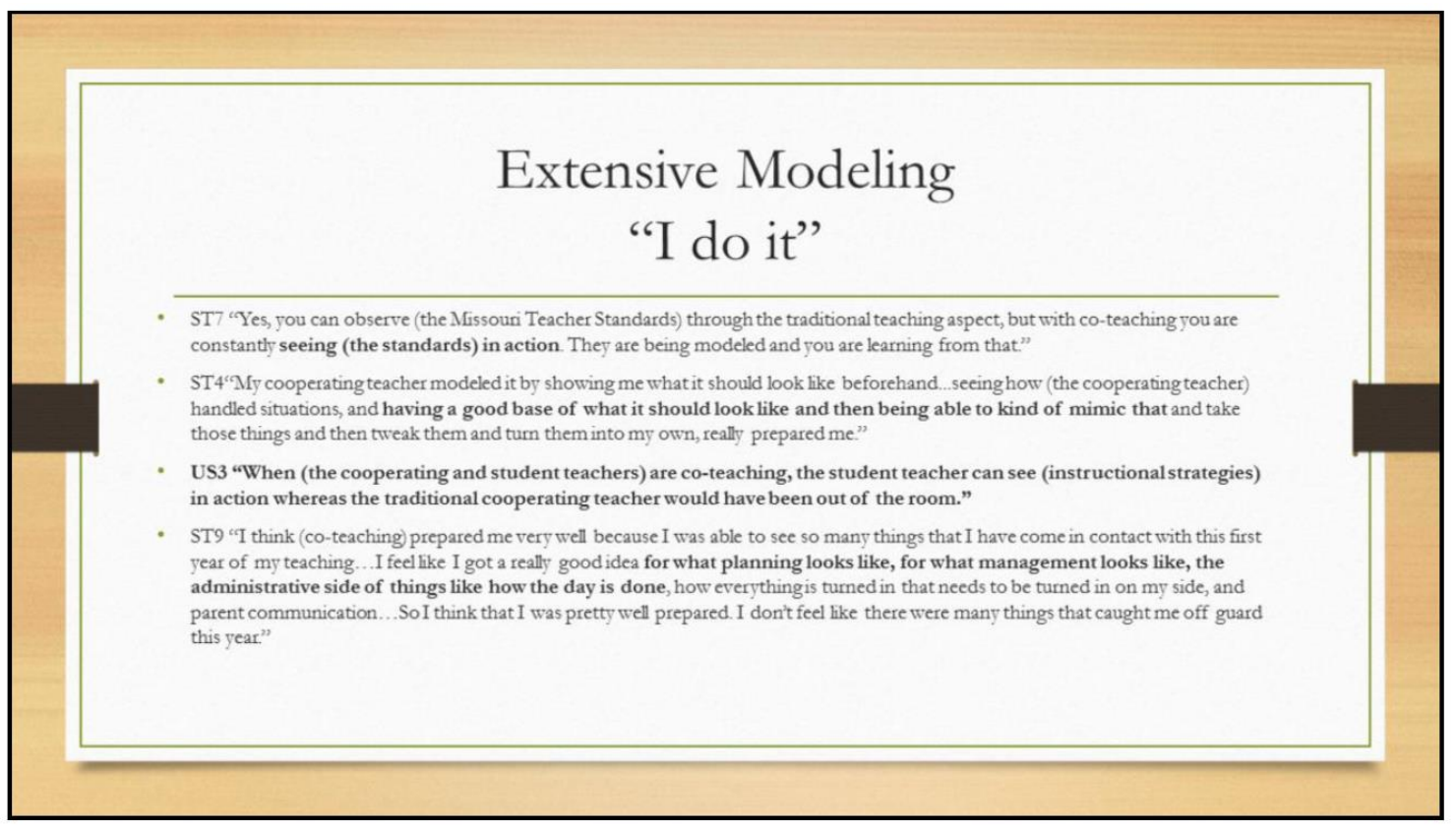

Talking Points

- I encourage you to read them in Appendix $\mathrm{G}$ of the dissertation. They are quite powerful

- Point out the US comparison to traditional student teaching 


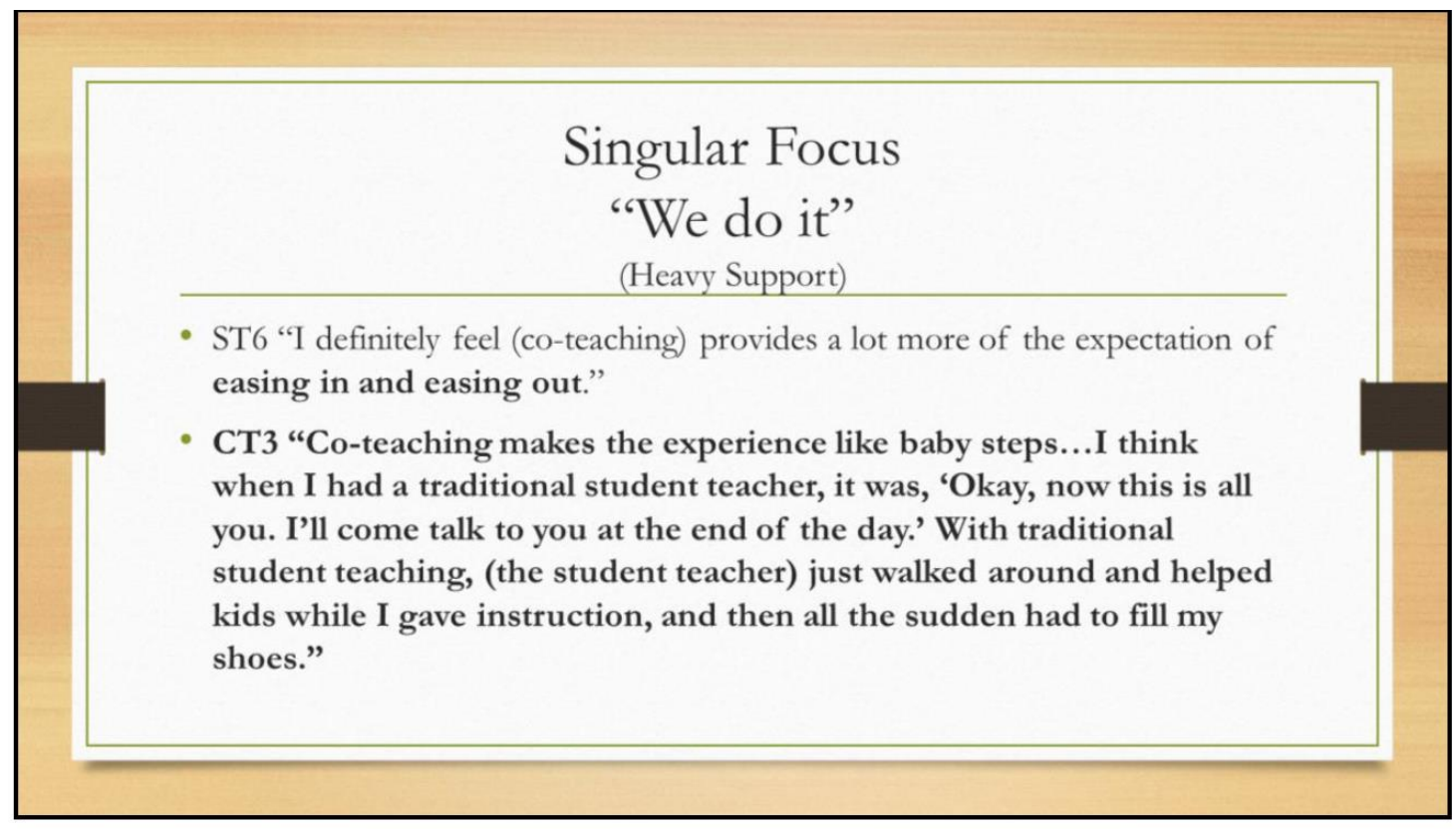

Talking Points

- Interesting comparison by the CT to traditional student teaching experience 


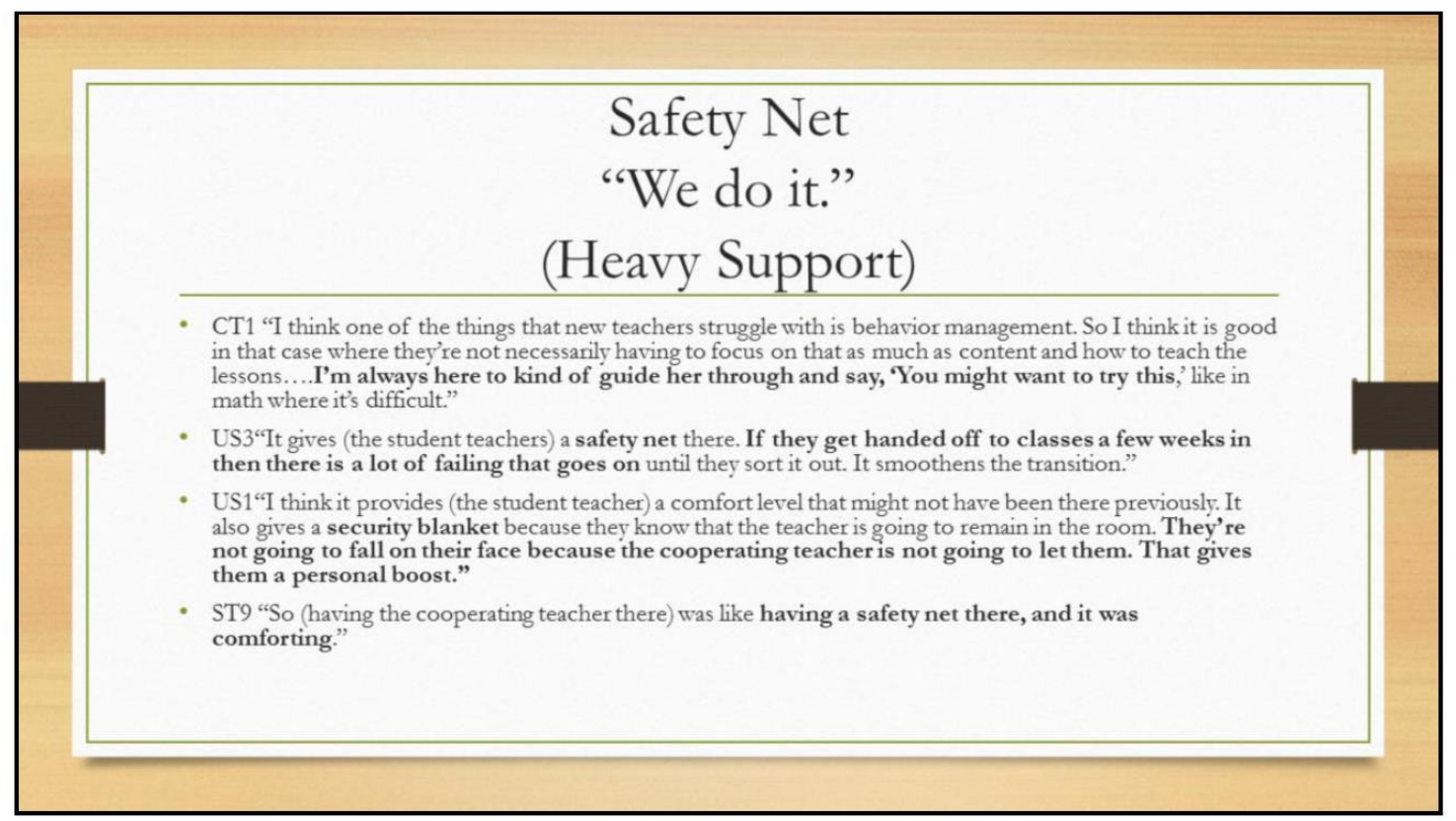

Talking Points

- This was seen a strong positive at the beginning and middle of the semester 


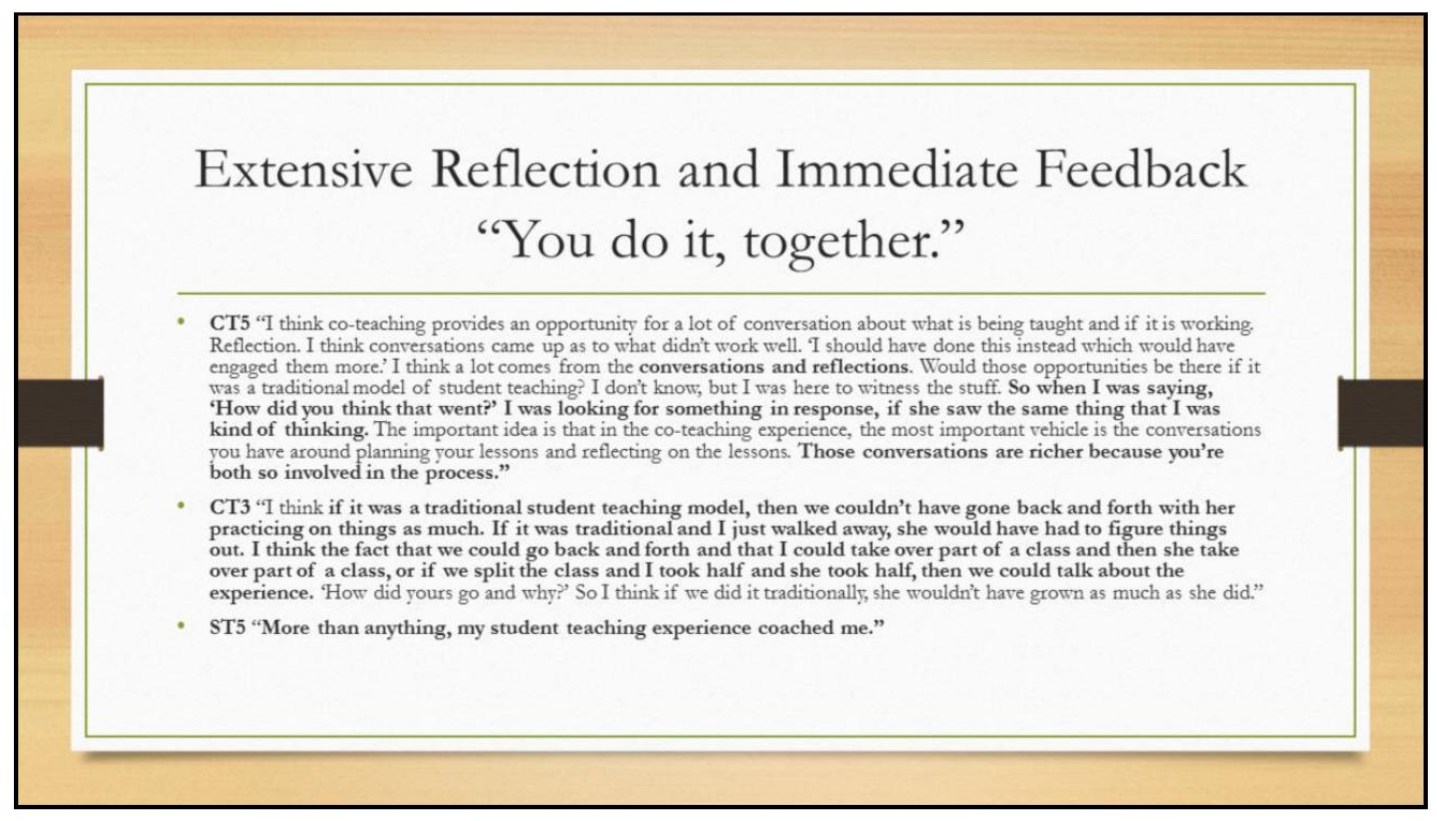

Talking Points

- Probably one of the strongest points. The collaboration and reflection and feedback

- The CT saw things and knew how to lead a reflection

- So when I was saying, 'How did you think that went?' I was looking for something in response, if she saw the same thing that I was kind of thinking.

- Those conversations are richer because you're both so involved in the process."

- If it was traditional and I just walked away, she would have had to figure things out. I think the fact that we could go back and forth and that I could take over part of a class and then she take over part of a class, or if we split the class and I took half and she took half, then we could talk about the experience.

- This is powerful stuff. This is what I began to see as the meat and bones of the coteaching model 


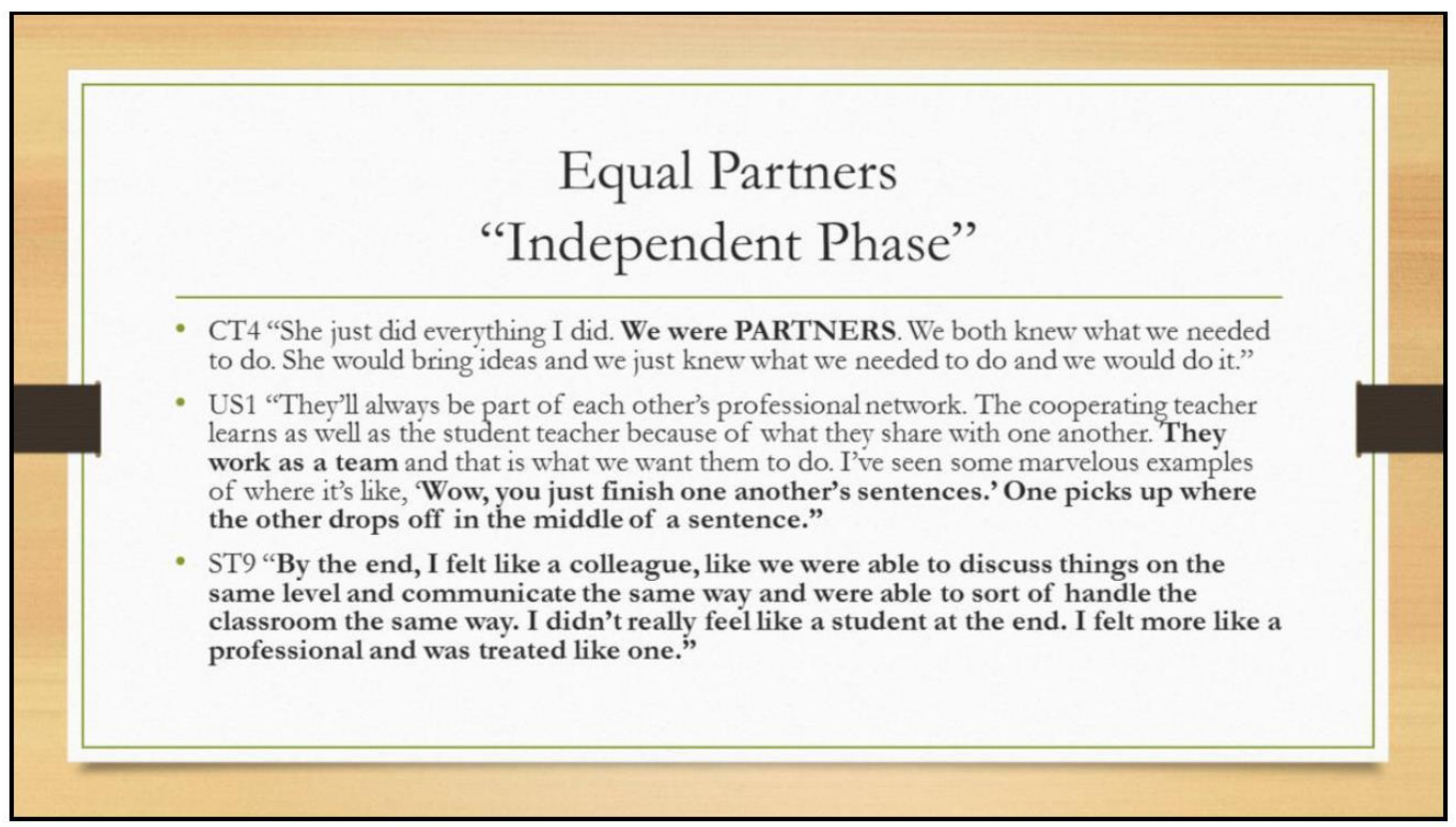

Talking Points

- ST9 was very emphatic about this. She often emphasized the collaboration and partnership that developed 


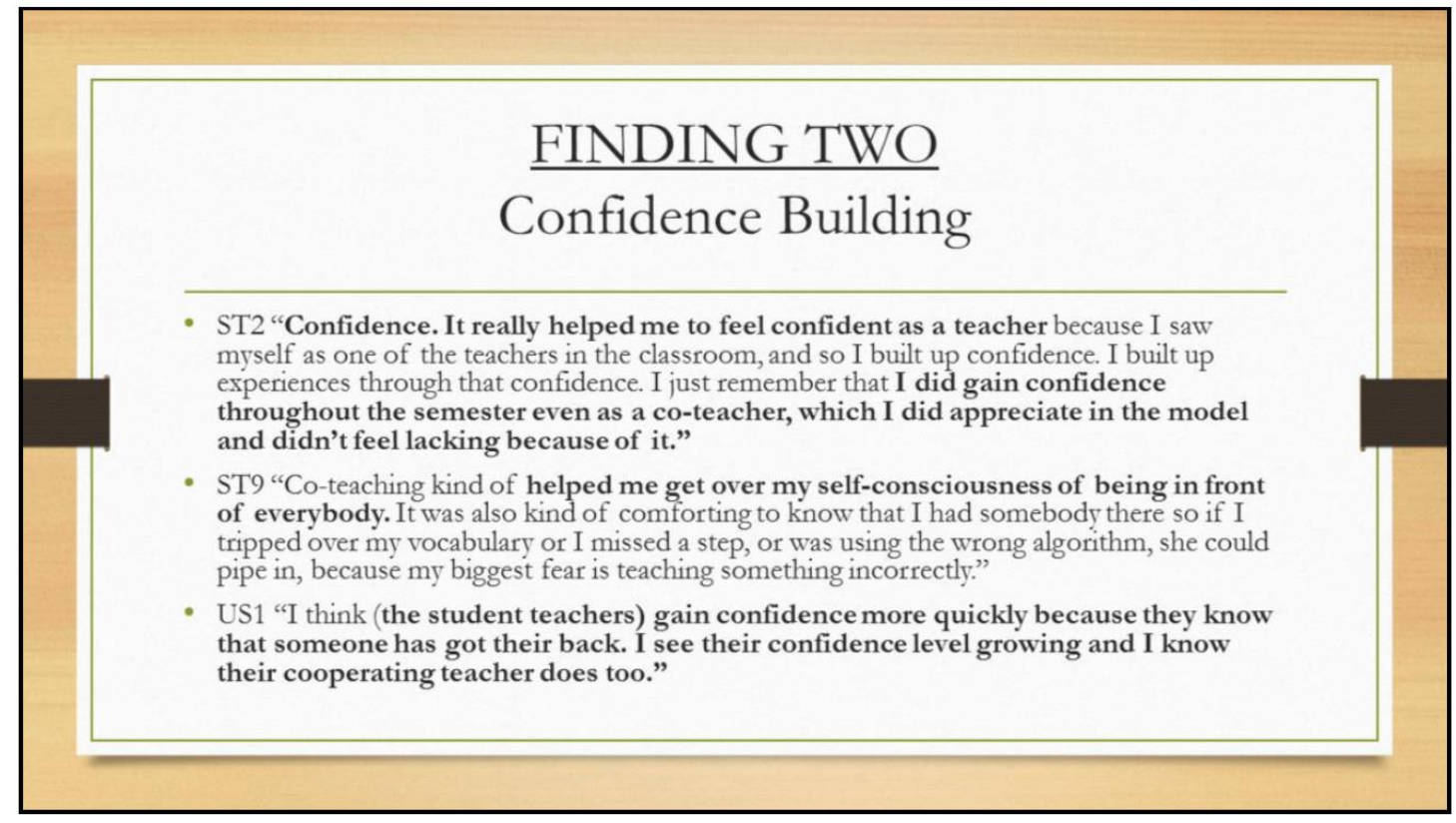

Talking Points

- With this modeling, feedback, reflection, singular foci came confidence 


\section{FINDING THREE}

By not completely and independently taking over the classroom, the student teacher does not get a fully realistic experience of teaching.

- ST3 "It would have been HELPFUL to have had the opportunity to plan EVERYTHING rather than being a co-planner, because then I would have had an idea of what it was like before I became a teacher. Co-teaching does not give student teachers the opportunity to be in charge of an entire class for all subjects, ever."

- ST5 "The only thing that I didn't like was that I always had somebody else in there with me. So then my first year of teaching I never had anybody in there with me, so I didn't have someone to lean on. I would have liked to have had two or three weeks of just me, solely me, making the decisions, making the plans, making the decisions about management. Those kinds of things. I would have liked to have had a couple of weeks of being solely responsible. I feel like I didn't get that from the co-teaching experience."

- ST9 "I do kind of wish I had that other time on my own, because I think it really impaired my classroom management experience, because (classroom management) was sink or swim this whole (first) year. It's the end of the year, and I feel JUST me, let them test my limits, and then have that experience with correcting and redirecting. If I were to go back and do it again, I would ask to just let me take them for a day or two,"

- US2 "It gives (the student teachers) a false sense of what teaching really is. It gives them a false sense of, Tm going to have someone catch me when I fall, and I'm going to have someone to take over that has more knowledge than me, and when I mess up,
someone is going to fix it?

\section{Talking Point}

- One of the questions in the interview was to provide one way the co-teaching model did not prepare first year teachers. This finding was repeated over and over by every participant interviewed

- So whereby they LIKED that safety net towards the front end of the semester, they voiced that they kind of wished it was pulled at the end.

- ST9 was with a well managed classroom with her CT. She never really had to deal with hard issues, because the kids were already in so much control and routine. 


\section{PARTICIPANT RECOMMENDATIONS}

\section{"Recommend Some Extended Alone Time"}

- ST2 "I definitely like the idea of the co-teaching model, but I still think it is important that the student teacher has an opportunity, even if it is just one week, to be the sole planner of the lessons. And to be the sole person in charge of the lessons for the entire week so they have an idea of what it's really like when they become a teacher."

- CT1 "I think they need to have a time where it's just them. I mean, what if they hate being the only one in the classroom? I think they need some of that. Maybe it's just half day, maybe it's full days, maybe it's a week, maybe it's two, but I think that would give them more of an immersion in teaching, maybe.

- US3 "I think there is no beating the wisdom of an experienced teacher as a guiding hand...When I get a very experienced cooperating teacher, I don't question what they do. They may fudge the rules of coteaching because they believe that will help prepare this student teacher for his or her own classroom. So I trust the wisdom that comes with years of teaching...Use an experienced teacher's wisdom as one of the guides to help structure co-teaching."

\section{Talking Points}

- So with the idea that this was a barrier to first teacher preparation, came the following suggestion. The ST be allotted an somewhat extended period of time alone

- US3 believes the amount of time should not necessarily be specified, but should be guided by the wisdom of the CT. 


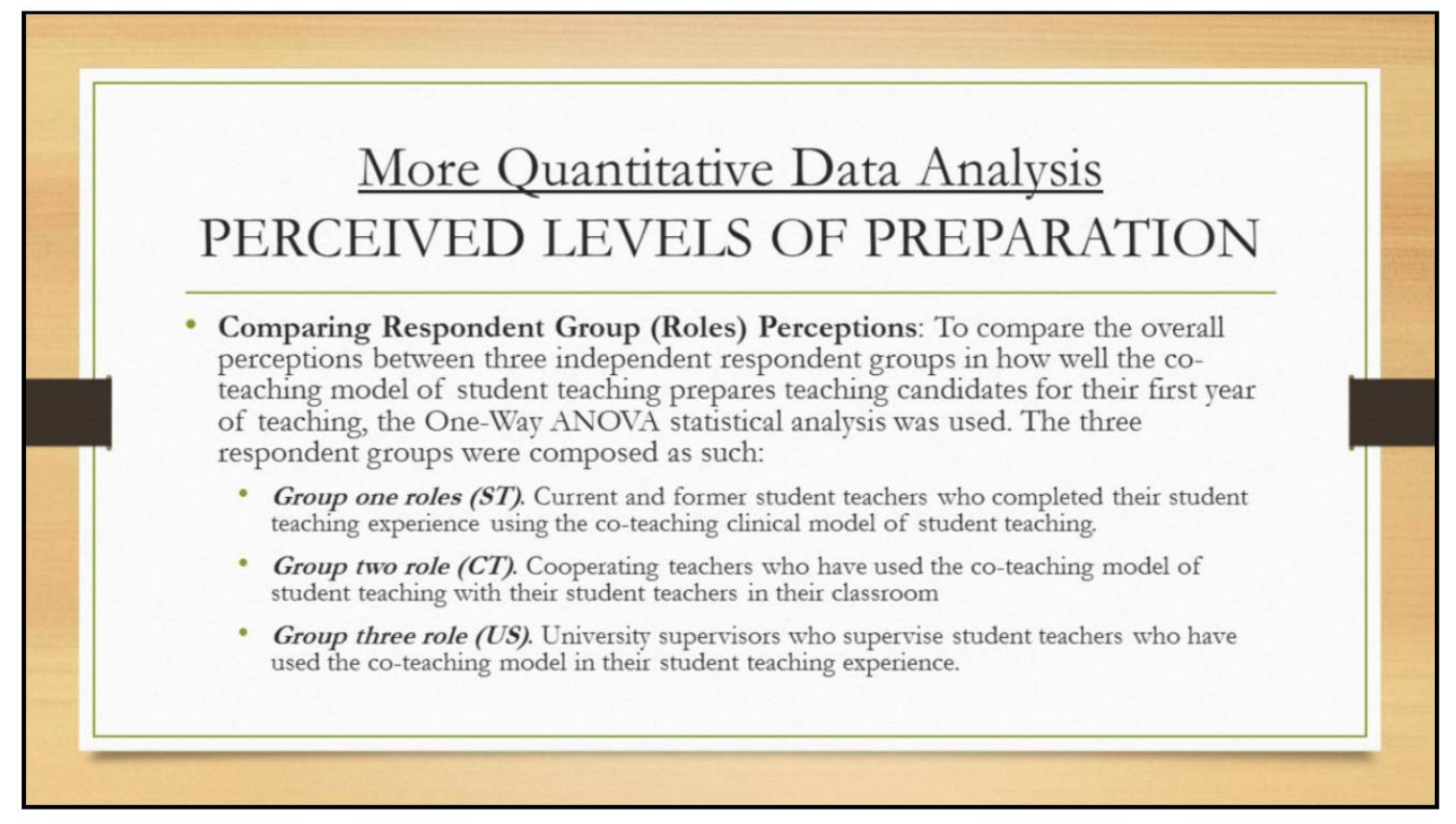

- Dr. Kreiner's help

Talking Points

- One-Way ANOVA 


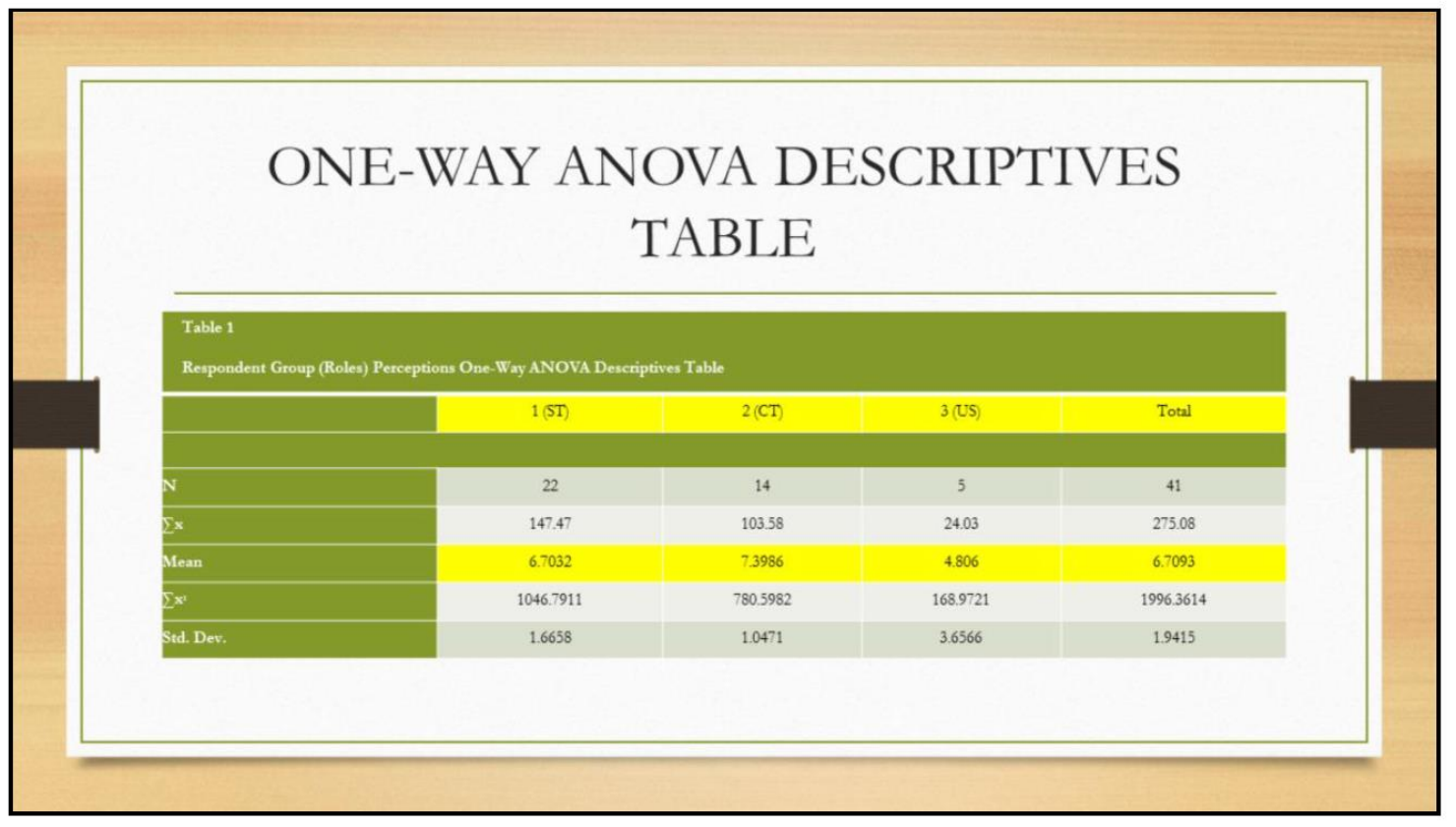

Talking Points

- Point out average means of each population and number in group 


\section{SIGNIFICANT DIFFERENCE BETWEEN GROUP RESPONDENTS}

ANOVA Test results showed an $f$-value of 3.73 and a significance value $(p$-value $<.05)$ of .03 indicating a significant difference across the three groups of respondents in perceptions of how well the co-teaching model of student teaching prepares teaching candidates for their first year of teaching.

\section{Talking Points}

- F-value is simplistically the variance between means. The $\mathrm{F}$ value is the ratio of two mean square values. No significance you would expect about a 1.0. A large $F$ value means that the variation among group means is more than you'd expect to see by chance.

- P-value determines if the variance between means is statistically significant. Yes if

$<.05 \mathrm{P}$-value $<.05$ there is a significant difference.

- This f-value was 3.73 and p-value was less than .05 at .03 


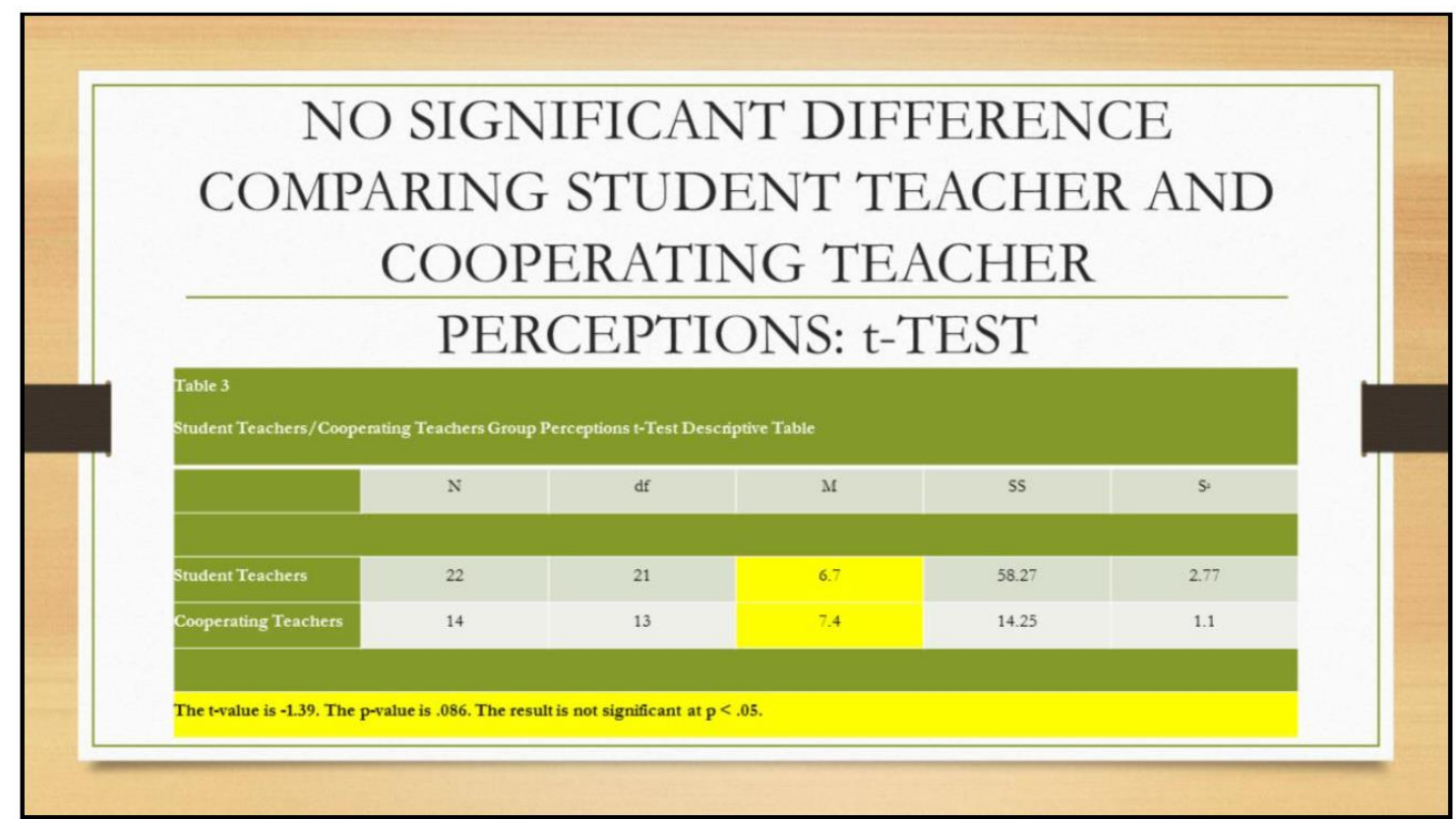

Talking Points

- T- test compares two groups means to determine if there is a significant difference in means

- T-value measures those differences

- Point out average mean of population and number in group 


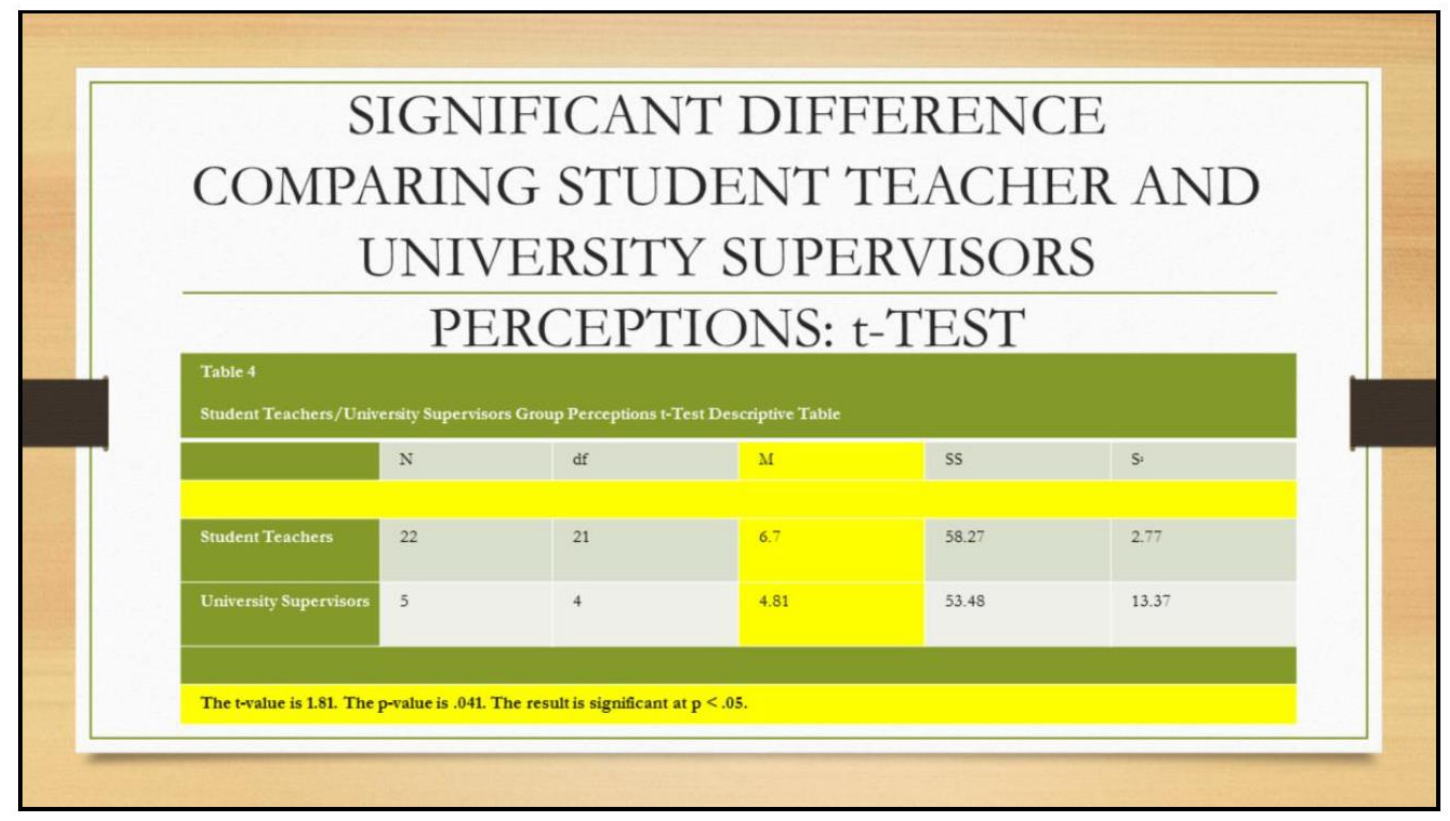

Talking Points

- Point out number in each group and average mean

- T-value is 1.81 and p-value is , .05 at .041 


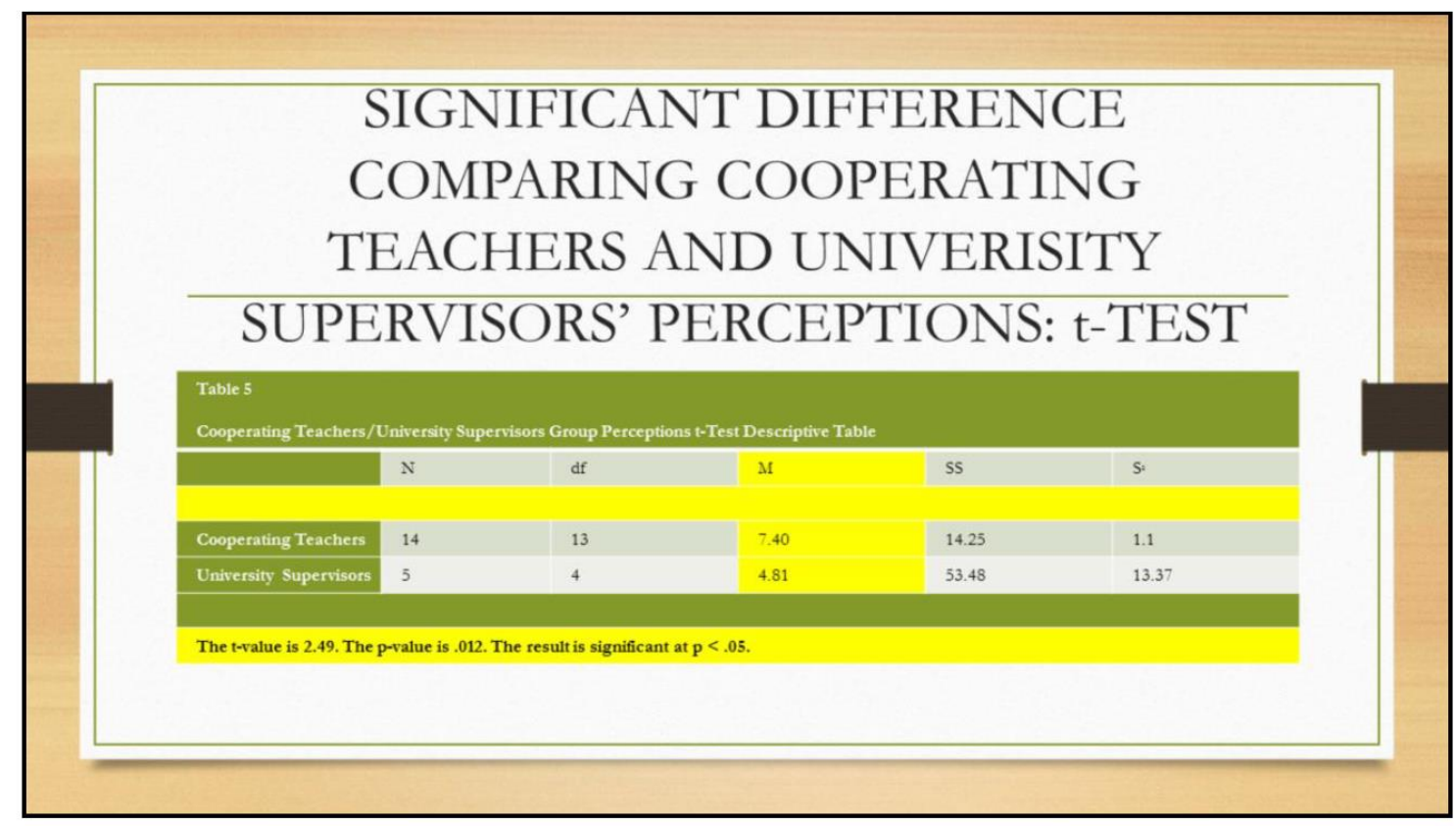

Talking Points

- Point out number and mean of each group

- Largest t-value at 2.49 and smallest p-value at .012 indicating largest significant difference in perceptions between two groups 


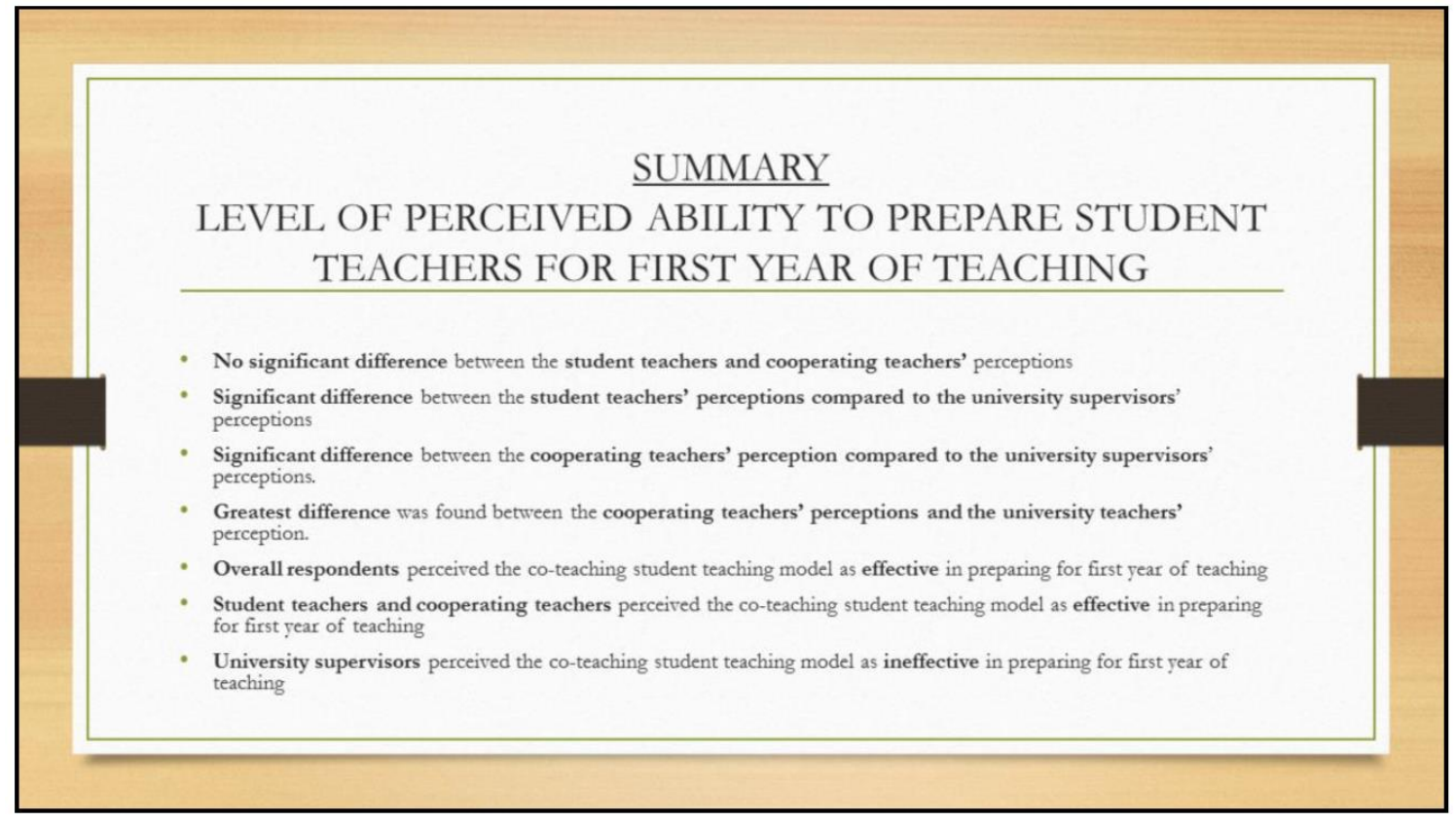

\section{Talking Points}

- Review results

- Must always remember that when referring to "significant difference" we relate that to what we are measuring 


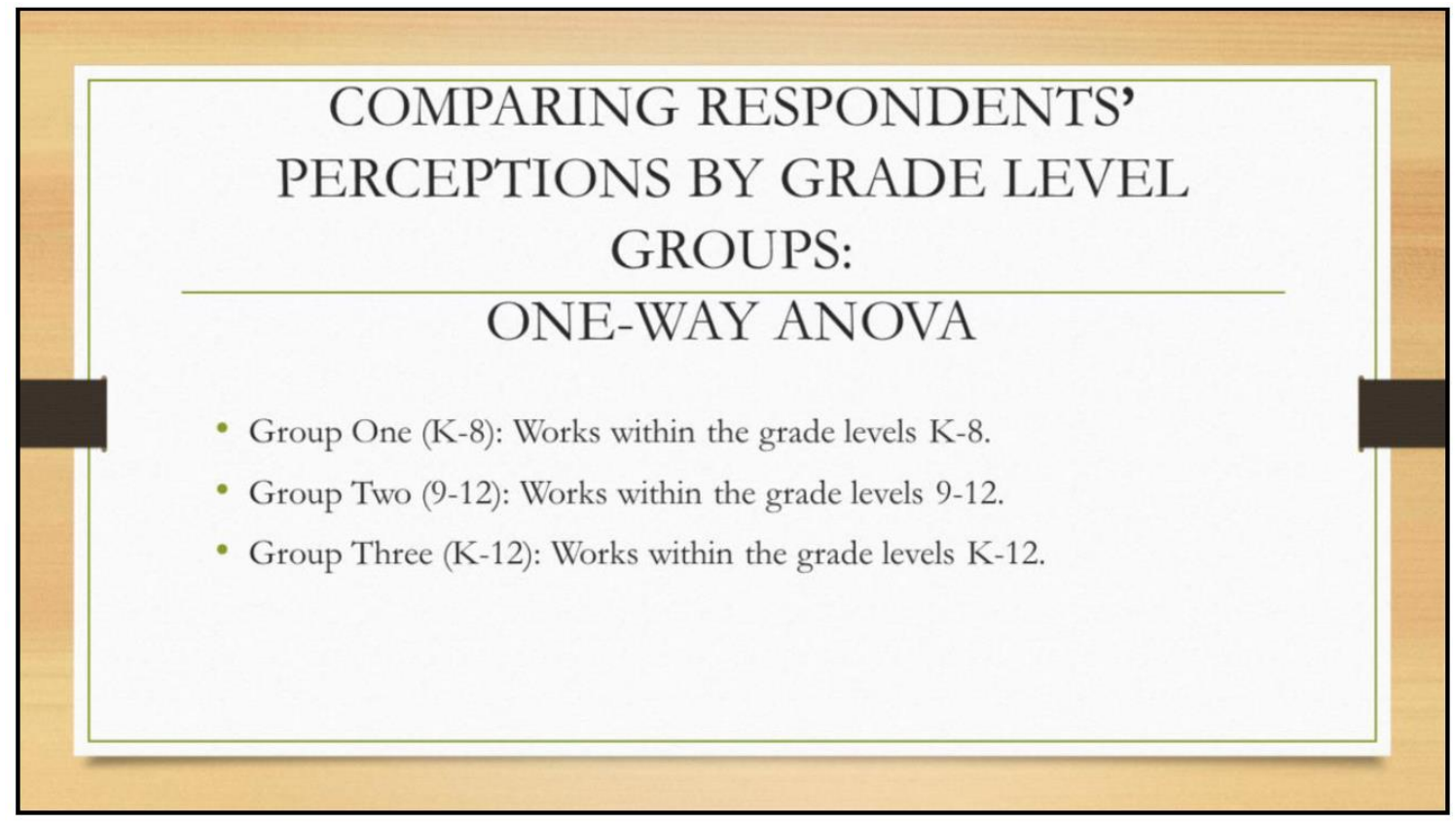

Talking Points

- I became curious based on quantitative and qualitative data if there was a significant difference in perceptions between grade levels. 


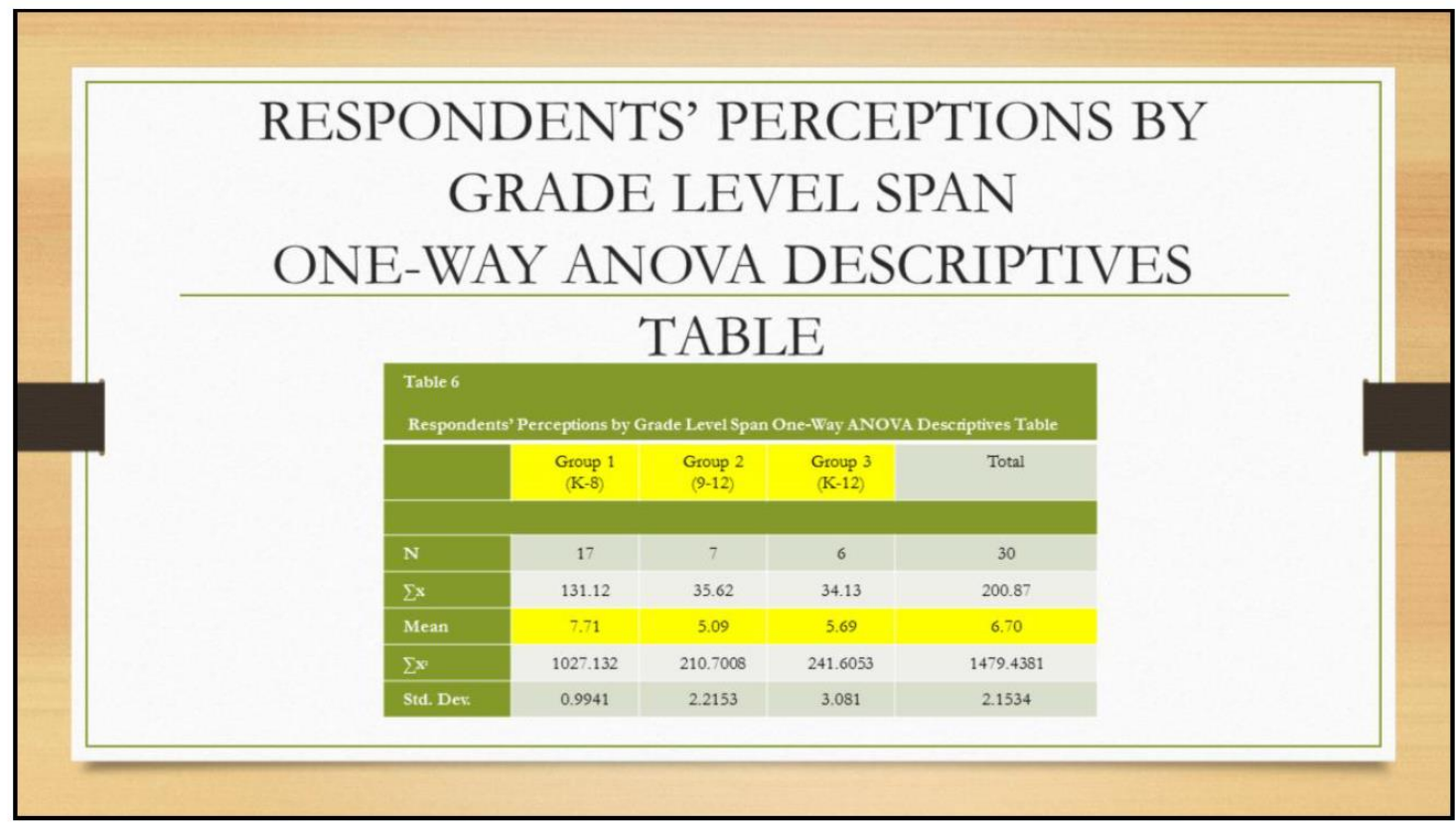

Talking Points

- Now we've mixed our population groups. Numbers not divided out by roles

- Now by grade span

- Review means and numbers of groups 


\section{SIGNIFICANT DIFFERENCE BETWEEN RESPONDENTS’ PERCEPTIONS BY GRADE LEVEL}

- ANOVA Test results showed an $f$-value of 6.08 and a significance value $(p$-value $<.05)$ of .01 indicating a significant difference across the three groups of grade level respondents in perceptions of how well the coteaching model of student teaching prepares teaching candidates for their first year of teaching.

Talking Points

- F-value of 6.08 (large) and p-value of .01 (small) = significant difference

- Lead to t-tests to compare group' perceptions 


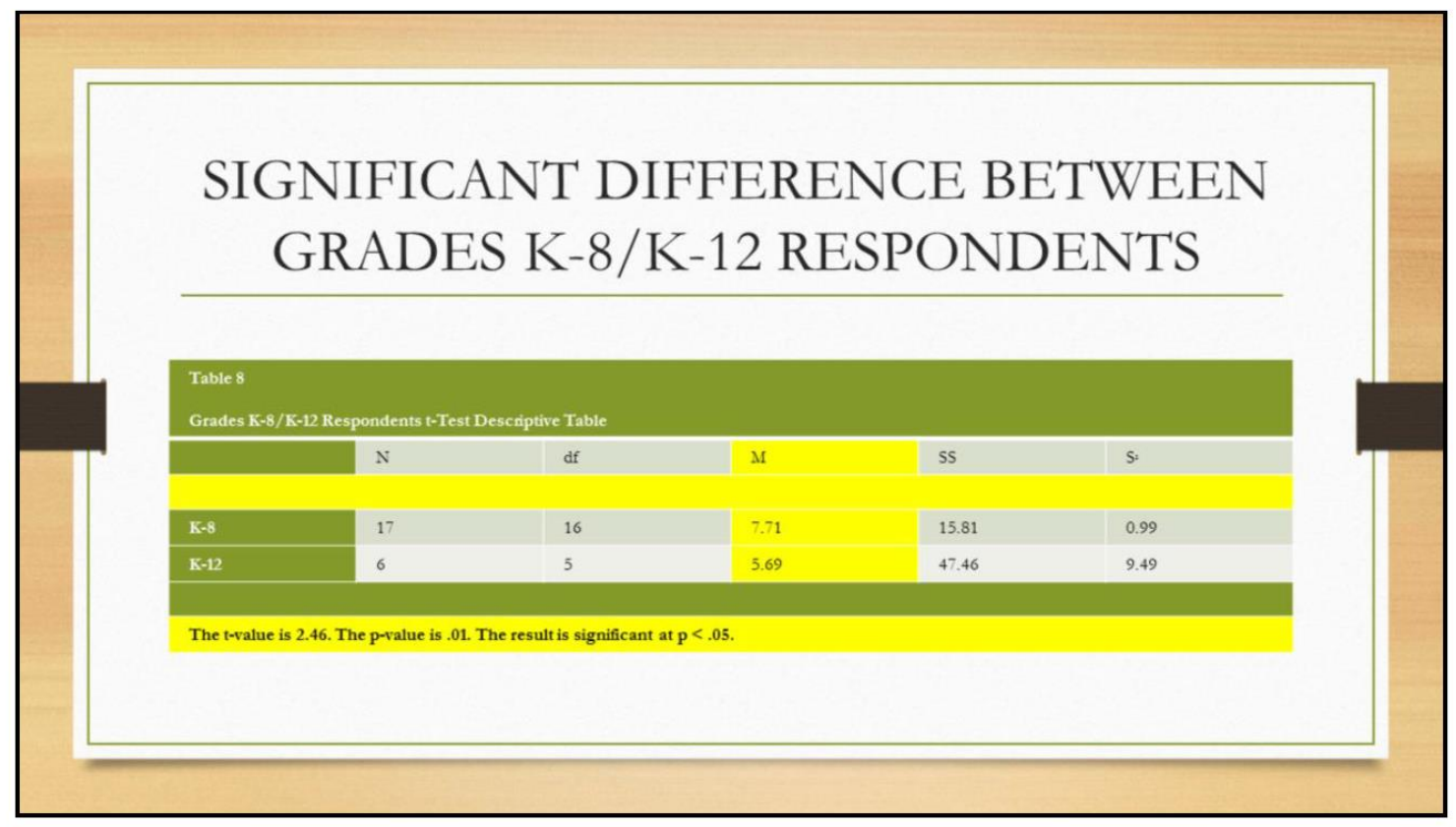

Talking Points

- Review means

- T-value of 2.46 (large) and p-value of .01 (small) = significant difference 


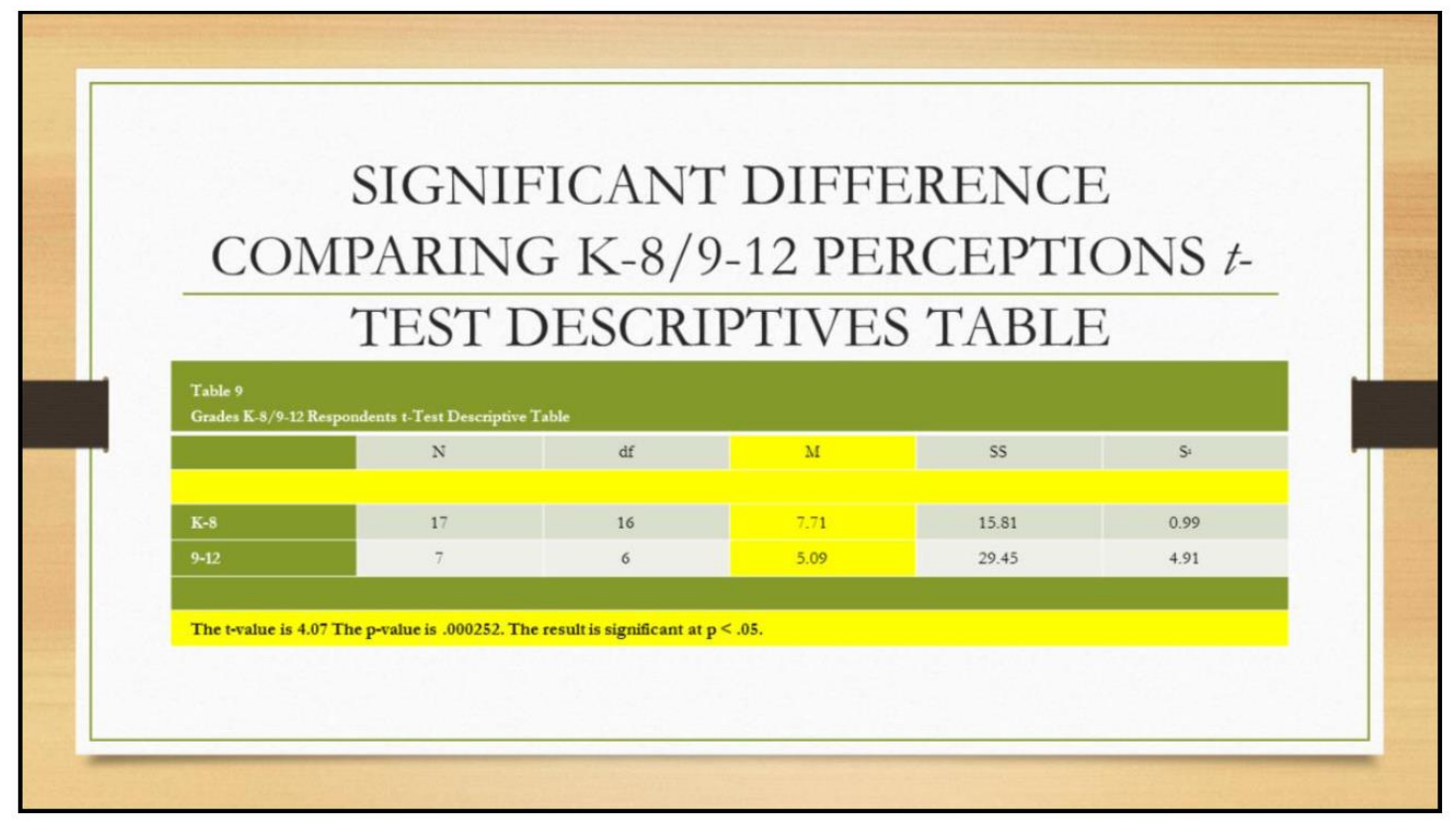

Talking Points

- Review means

- T-value of 4.07 (very large) p-value of .000252 (very small)

- P-value was VERY small indicating a large discrepancy 


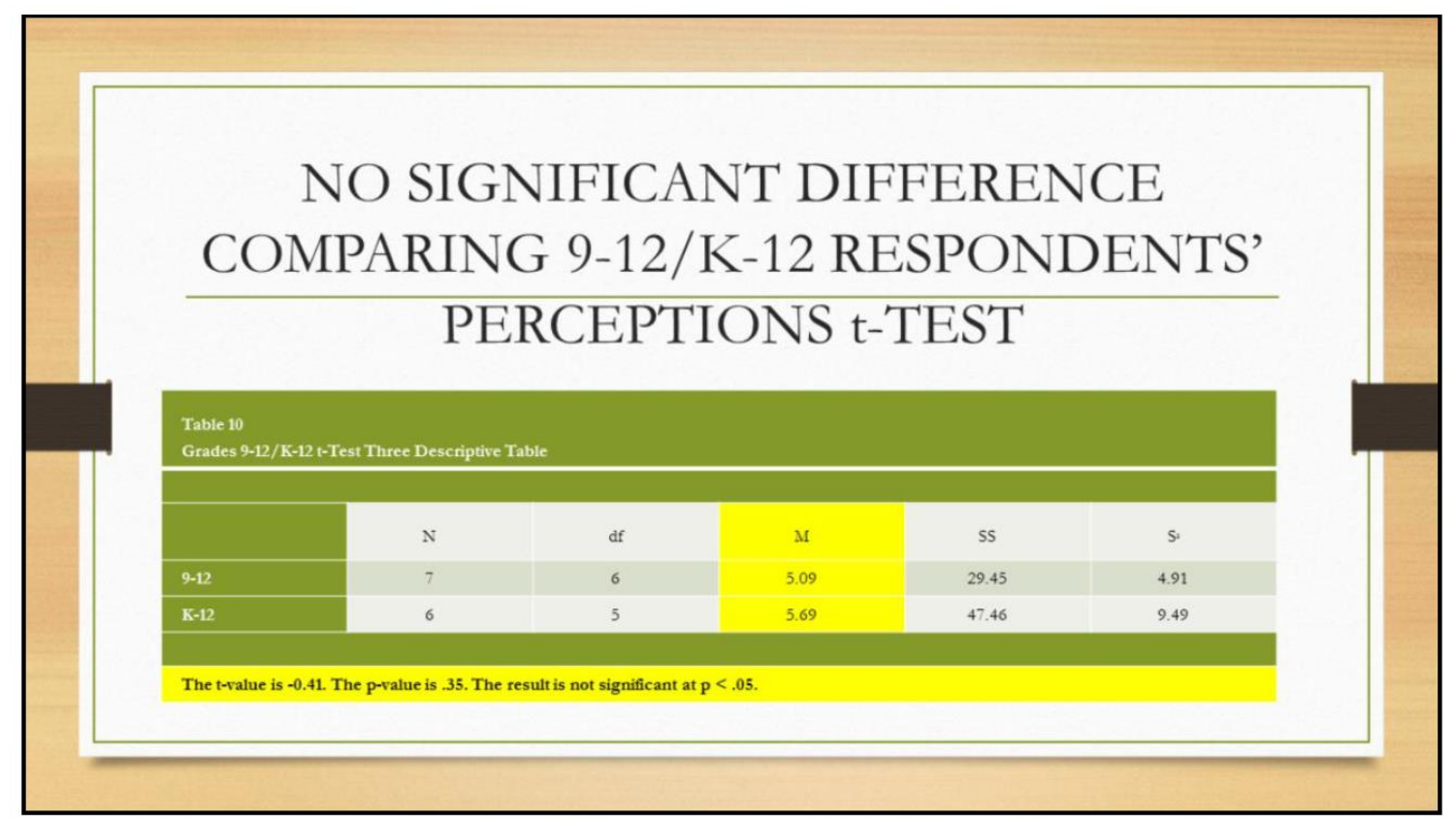

\section{Talking Points}

- Review means

- T-value of -.41 (very small) and p-value of .35 (very large) = no significant difference 


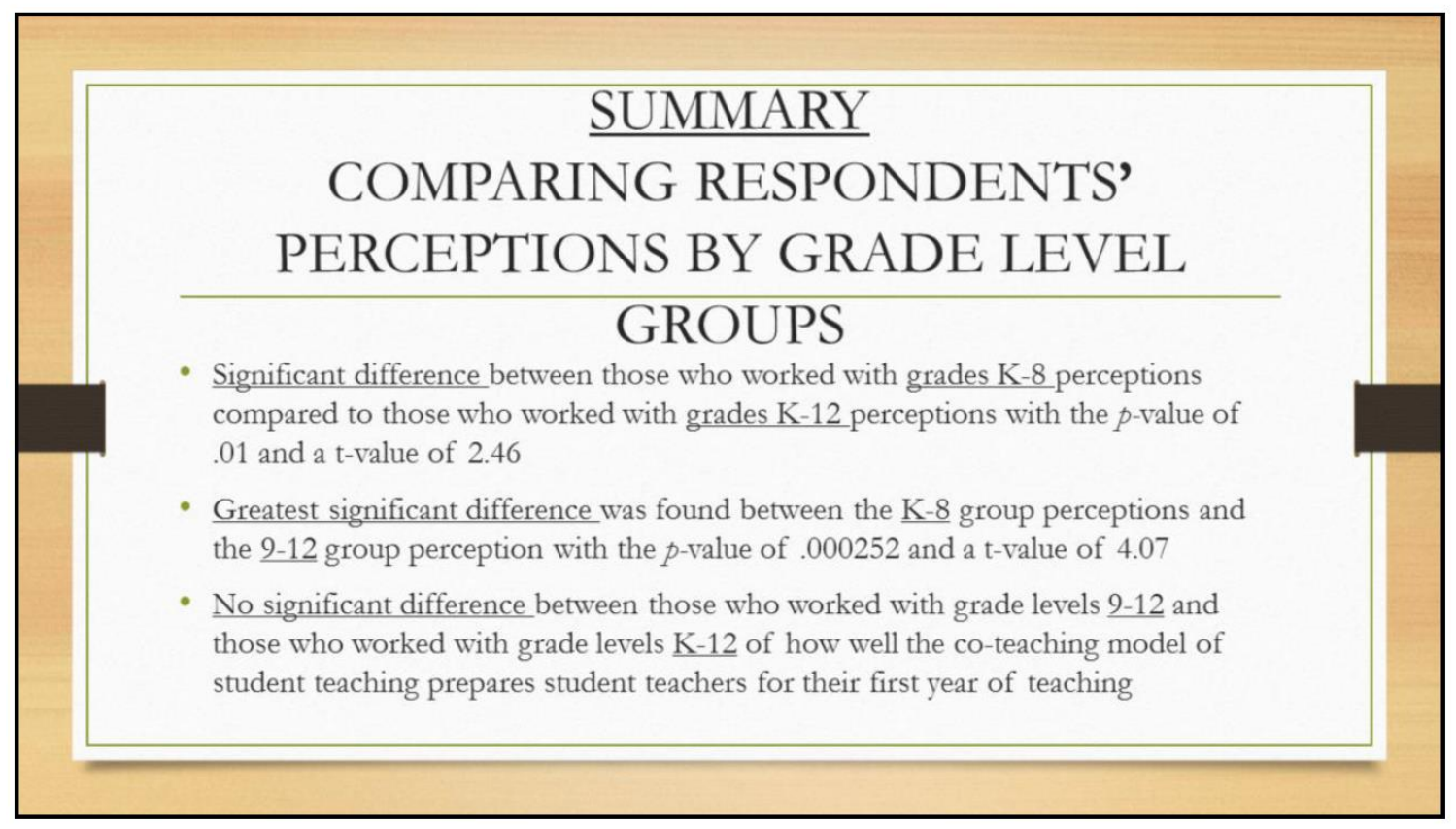

\section{Talking Points}

- In reflection, I found that the $40 \%$ of US were $9-12$ and $40 \%$ were $\mathrm{K}-12$ totaling $80 \%$ of those respondents. Only $20 \%$ of the US were K- 8

- Perhaps grade level influenced university supervisor responses as much as or possibly more than the role they play in teacher preparation. This could be explored in further research 


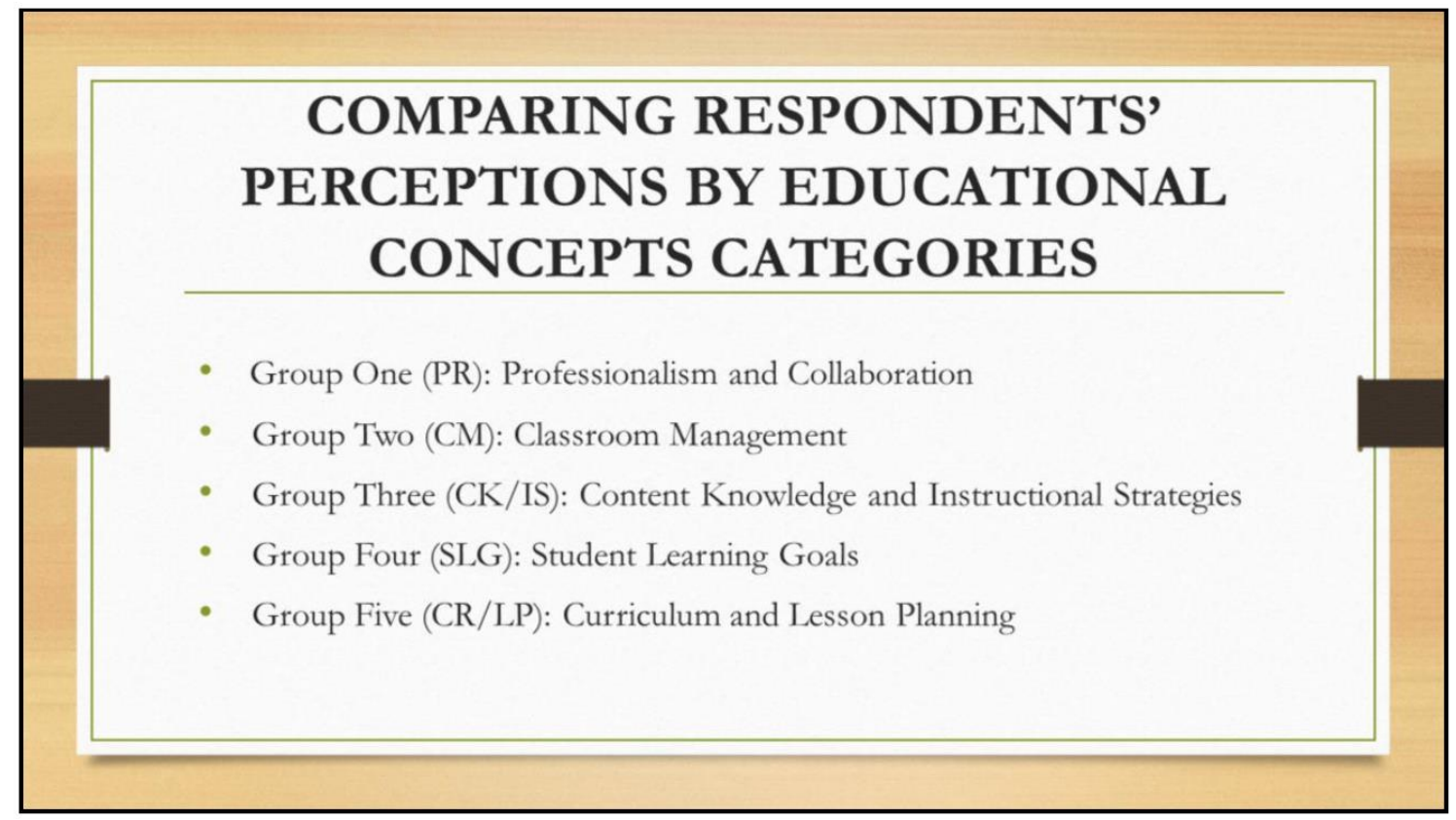

Talking Points

- Curious as to the types of items ranked. Was there a sign diff there?

- Missouri Teacher Standards are grouped in then these educational concept categories 


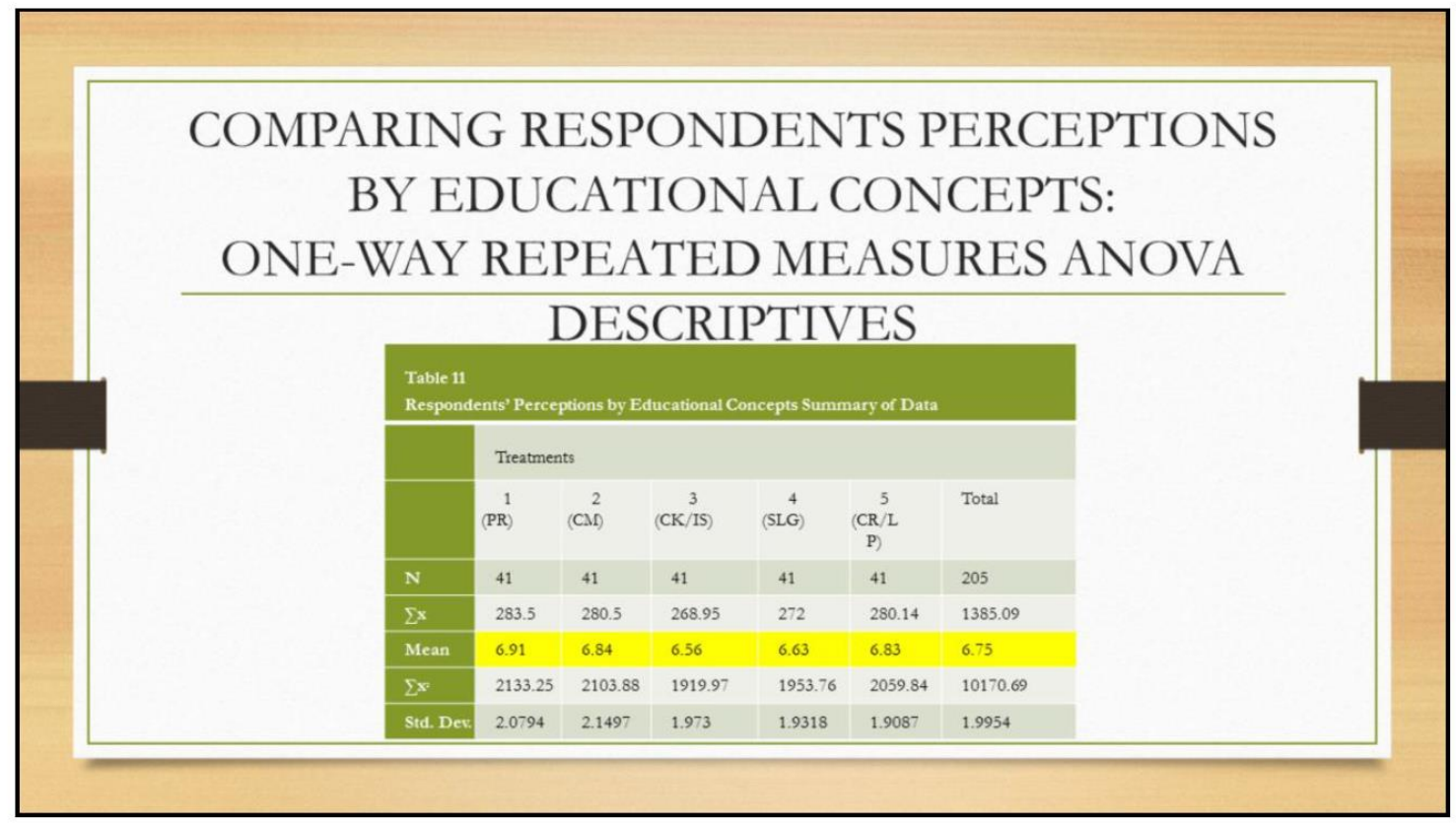

Talking Points

- All groups means were found and entered into the above five categories

- Notice the means between concepts and how close they are 


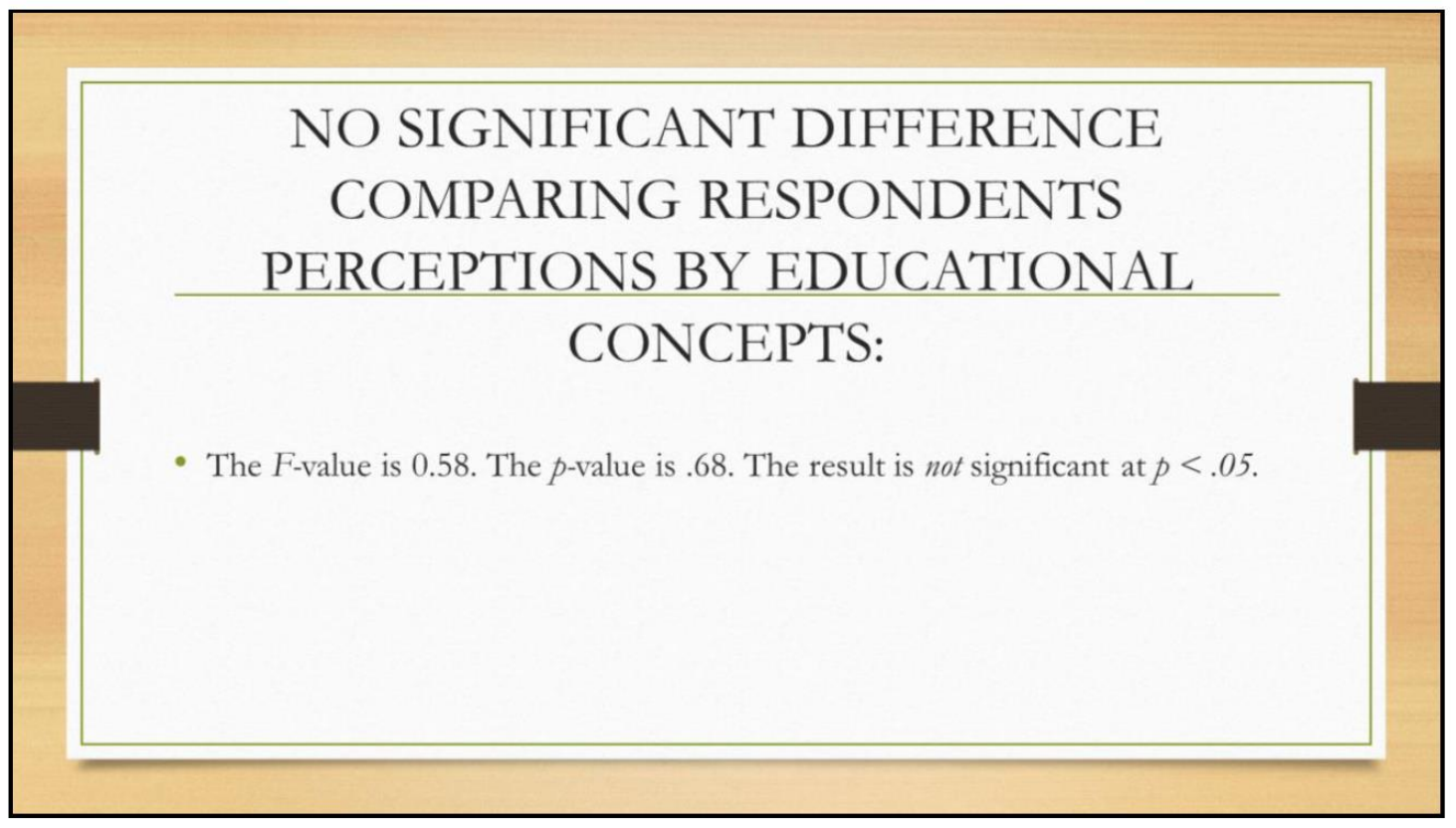

Talking Points

- F-value is .58 (low) and p-value is .68 (very high) No sign diff

- I reviewed and if someone scored low, they generally scored everything low. If someone scored high, they generally scored everything high, and if someone scored middle, they generally scored everything middle. Not always, but enough to make it not significant difference

- This was slightly disappointing after having analyzed the qualitative data, because the qualitative data revealed areas that were perceived as being stronger or weaker with the co-teaching model. 


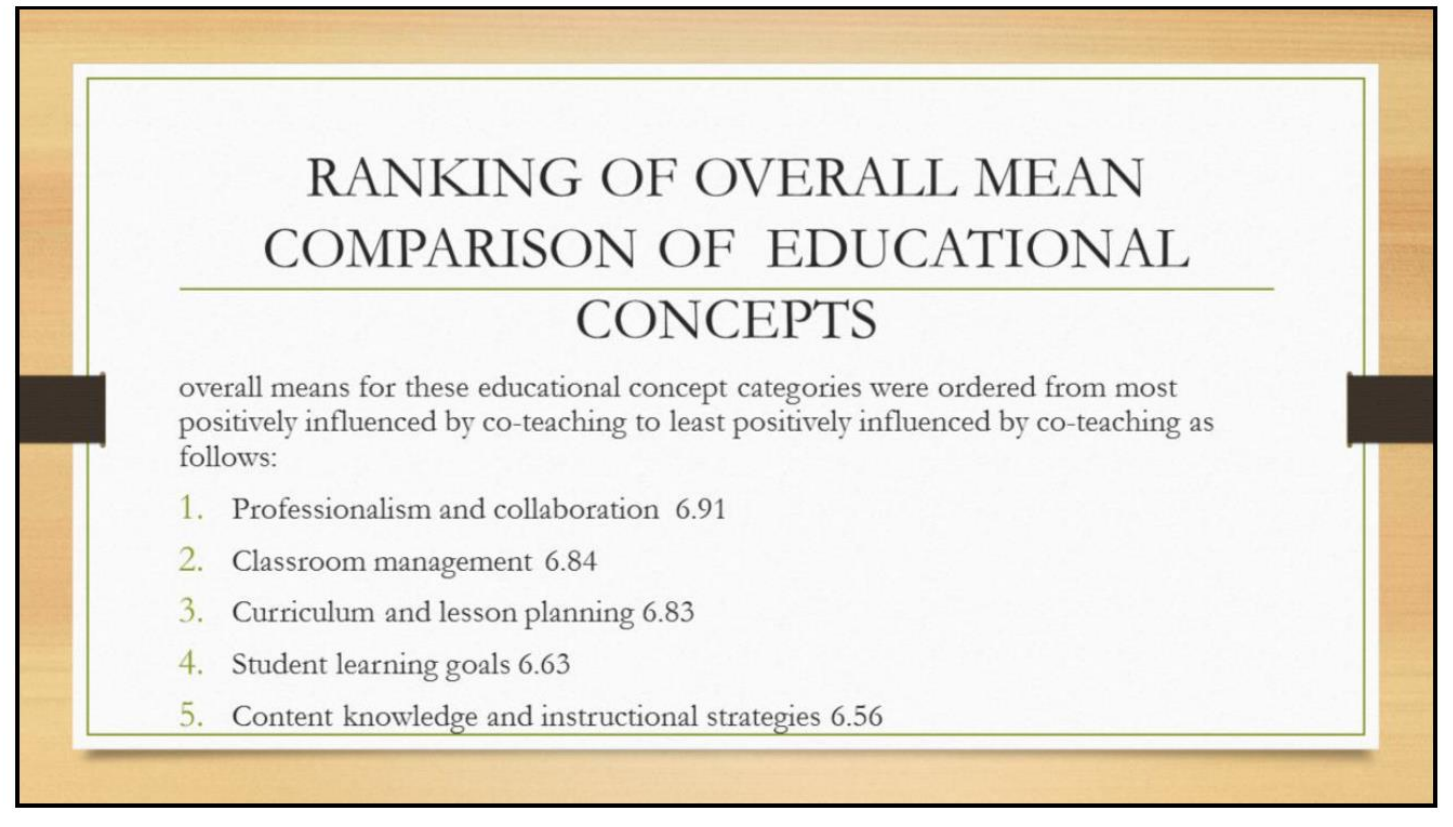

Talking Points

- So I sequenced the means and it more closely reflected to the qualitative responses 


\section{LIMITATIONS, ASSUMPTONS, AND DESIGN CONTROLS}

- Transferability of findings across other institutions are limited

- Present research proceeds under the assumption that each pre-service student teacher is at a somewhat equal level of preparedness as other student teachers before the co-teaching clinical experience begins.

- Small sampling (41 participants)

\section{Talking Points}

- I didn't want to use various university populations because of the varying background knowledge that would bring.

- I had to run on the assumption STs were equal coming into the ST experience and the closest way to do that for me was to use one university with one group of required courses and field experiences. 


\section{SIGNIFICANCE OF THE STUDY}

Using this research at the university level, universities can determine whether the co-teaching model is a viable model for clinical experience OR analyze areas of strengths and areas in need of improvement in preparing students for their first year of teaching

- Seven distinct groups of stakeholders within the practitioner's setting affected by the level of preparation the co-teaching model provides first year teachers:

- University teacher education faculty and staff

- Student teachers

- Cooperating teachers and districts

- Students of student teachers

First-year teachers

- Districts of first-year teachers

Students of first-rear teachers

Talking Points

- University teacher education faculty and staff - Preservice model affected

- Student teachers - Support during the ST experience affected

- Cooperating teachers and districts - Time for CT to develop highly support ST and not relinquish classes for long periods of time

- Students of student teachers - They receive new teacher experience and veteran experience simultaneously. Two teachers in class for support

- First-year teachers- Level of preparation affected. Modeling and feedback/reflection key

- Districts of first-year teachers - Stronger first year teachers

- Students of first-year teachers - More highly prepared teachers may equal higher achievement in academics and/or behaviors 


\section{IMPLICATIONS, USES OF STUDY, AND FUTURE RESEARCH}

- Implication - Use of the co-teaching model is highly effective in preparing teachers for their first year of teaching

- Implication - Co-teaching model should be modified to allow for two to three weeks of alone time in the classroom by the student teacher as long as it does not disrupt the extensive modeling, reflection, feedback, and collaboration for the majority of the semester.

- Uses - Universities design of teacher preparation programs

- Uses - Other states use of UCM data from study to further research

- Uses - Locally, UCM may use results to determine if the co-teaching clinical model is perceived to prepare students for their first year of teaching

- Uses - Results can highlight co-teaching areas of strengths and areas in need of improvement in preparing students for teaching

- Future Research - Similar studies can be conducted on other clinical teacher preparation models for comparison

\section{Talking Points}

- Recommendations based on both the quantitative numbers and the qualitative data

- How long this solo time should be is not in the scope of this study. The only boundary would be that it be short enough no to intrude on the modeling, reflection, feedback, can collaboration portion of the semester. 


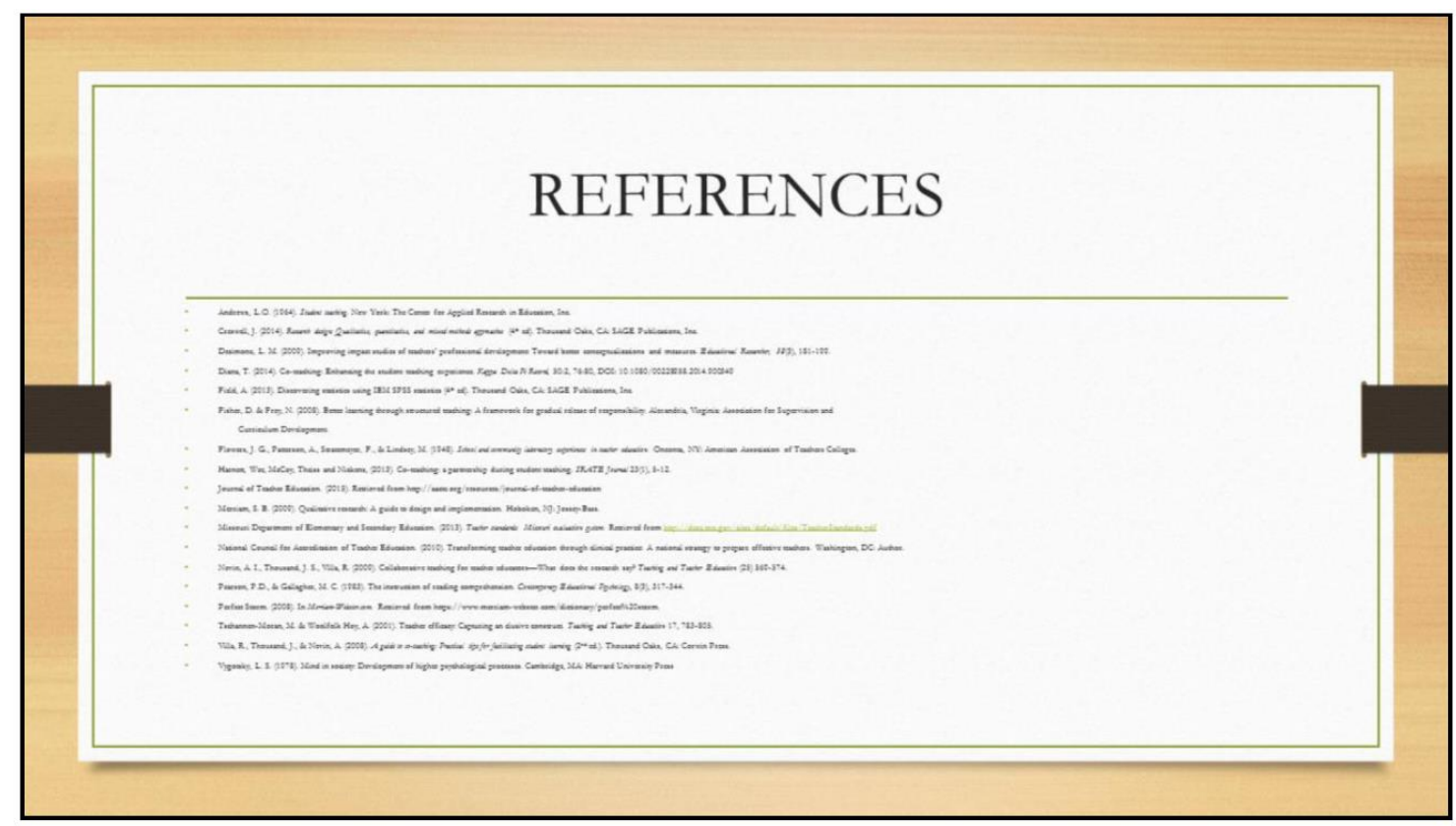

- Review slide

Talking Points 
SECTION FIVE

CONTRIBUTION TO SCHOLARSHIP 


\title{
Target Journal
}

Journal of Teacher Education (JTE) - Official journal of American Association of Colleges for Teacher Education (AACTE)

\section{Rationale for this Target}

The focus of my study (co-teaching as a clinical model) aligns with the focus of content for JTE: policy, practice, and research that contribute to teacher preparation (Journal of Teacher Education, 2015). The JTE is one of the most widely read peer reviewed journals for teacher educators I the nation. It has been in publication for 60 years and publishes five thematic volumes per year. Student teaching is among the common themes. The editorial board is overseen by the AACTE Committee on Research an Dissemination and includes 60 members and hundreds of ad hoc peer reviewers who "enable the journal to publish dozens of top-quality manuscripts each year" (Journal of Teacher Education, 2015). I believe the finds of my study will be of interest and professional importance to the readers of JTE.

\section{Plan for Submission}

I will submit my manuscript following approval of my dissertation defense in April, 2018. I will create an account in ScholarOne Manuscripts for access to electronic submission.

\section{Journal Submission}

Journal of Teacher Education (JTE) - Official journal of American Association of Colleges for Teacher Education (AACTE)

\begin{abstract}
The purpose of this mixed methods study is to determine and analyze the perceptions of student teachers, cooperating teachers, and university supervisors on the co-teaching pre-service model's ability to prepare student teachers for first year teaching. Forty-two respondents affiliated with the University of Central Missouri participated.
\end{abstract}


Data were collected by a valid and reliable survey and neo-positive interview. Collected data sets were analyzed with SPSS-16 and triangulated with coded qualitative data. Results indicate student teachers, cooperating teachers, and overall respondents perceive the pre-service model as effective in preparing student teachers for first-year teaching, while university supervisors do not. Findings suggest the co-teaching pre-service model is an effective pre-service model closely aligned to the Gradual Release of Responsibility learning theory, however, the student teacher should also assume full, solitary classroom responsibilities for an allotted period of time.

\section{Introduction}

The University of Central Missouri's (UCM) teacher preparation program was struggling to find enough school districts to participate in the student teaching program. Upon informal investigation, the university's College of Education found local public school teachers and their administrators were reluctant to hand over classrooms of students to novice teachers for nearly full semesters. With high stakes accountability for test scores, teachers voiced their need to be present in the classroom, particularly during spring semester statewide testing (Diana, 2014). Within this same time of struggling to find cooperating teachers, the Blue Ribbon Panel of the National Council for Accreditation of Teacher Education (NCATE, 2010) published a national report calling for PK-12 teachers and teacher preparation programs to see teacher preparation as a shared responsibility. The NCATE report called for clinical experiences of student teachers that would increase the learning and achievement of students and empower "teachers to meet the urgent needs of schools and the challenges of the 21 st Century Classroom," (2010). Additionally, the Missouri Department of Elementary and 
Secondary Education was asking universities to clearly articulate the clinical practices of their institution. A metaphorical "perfect storm" was created in which a critical situation developed from a powerful concurrence of various factors. A co-teaching clinical model from St. Cloud State University in Minnesota was closely researched by UCM staff (Hartnett et al., 2013) as a possibility of meeting the local, state, and national needs for pre-service programs.

Co-teaching, also called team-teaching or collaborative teaching, became a viable method of inclusive instruction in the special education discipline to access the regular classroom setting and curriculum. Co-teaching, as defined by Villa, Thousand, and Nevin (2008), is an instructional model whereby two or more people of equal status share the responsibility of planning for, instructing, and assessing some or all of the students in a classroom. Higher education teacher preparation programs followed suit by implementing the co-teaching model in teacher preparation programs to prepare their student teachers to meet the needs of diverse student populations by modeling the coteaching partnership (Nevin, 2009). Finally, in a lesser-researched application, the coteaching model was implemented into clinical practices of regular education teacher preparation programs whereby regular education student teachers team-taught with their mentor teachers throughout their student teaching experience.

Having the mentor teacher and student teacher team-teach seemed a positive solution for UCM's partnering school districts, the call of the National Council of Accreditation of Teacher Education (NCATE), and the Missouri Department of Elementary and Secondary Education's request for articulation of clinical practices. The co-teaching clinical model from St. Cloud State University in Minnesota was closely 
researched by UCM staff (Hartnett et al., 2013). UCM developed a strategic action plan to educate UCM stakeholders and facilitate the piloting and implementation of a coteaching model in partnering districts

\section{Statement of the Problem}

The problem-of-practice in this study lies in a need to determine if a co-teaching student teacher model provides university students an appropriate amount of clinical experience and preparation necessary to support a successful first year of teaching. Public school teachers are held accountable for the success of their students. Student teaching is generally the last opportunity universities have to help prepare students for teaching. Does the use of a co-teaching clinical model support both parties' needs?

A gap in the research literature exists regarding the level of readiness the coteaching student teaching model provides regular education student teachers and firstyear classroom teachers. The research available on co-teaching as a model of student teaching generally focuses on the co-teaching process, professional development of coteachers, and the benefits of co-teaching partnerships to stakeholders.

\section{Purpose of the Study}

The purpose of this study was to determine the perceptions of current and former student teachers, cooperating teachers, and university supervisors on the co-teaching model of student teaching and its ability to prepare student teachers for their first year of teaching. Analyzing the perceptions of current and former student teachers, cooperating teachers who have experienced the co-teaching model, and university supervisors who have overseen the co-teaching clinical experience determined this level of readiness.

The state of Missouri provides Missouri Teacher Standards outlining the qualities 
of best practices in the field of teaching (Missouri Department of Elementary and Secondary Education, 2013). The Missouri Teacher Standards guide the quantitative criteria for this study when determining levels of readiness for teaching by both current and former student teachers. The Missouri Teacher Standard categories are as follows: content knowledge aligned with appropriate instruction; student learning growth and development; curriculum implementation; critical thinking; positive classroom environment; effective communication; student assessment and data analysis; professionalism; and professional collaboration. Quantitative and qualitative data were collected from both current and former student teachers who have experienced the coteaching student teaching model, as well.

\section{Research Questions}

The research questions guiding this study are as follows:

1. What are the perceptions of University of Central Missouri current and former student teachers on the co-teaching student-teaching model's ability to prepare student teachers for their first year of teaching?

2. What are the perceptions of University of Central Missouri university supervisors on the co-teaching student-teaching model's ability to prepare student teachers for their first year of teaching?

3. What are the perceptions of cooperating teachers who work with University of Central Missouri student teachers on the co-teaching student-teaching model's ability to prepare student teachers for their first year of teaching?

\section{Conceptual/Theoretical Frameworks}

The theoretical framework guiding this study is the Gradual Release of 
Responsibility (GRR), first coined by Pearson and Gallagher (1983) and based upon the work of Vygotsky (1978). The GRR model of instruction theorizes that the more skilled peer, or as Vygotsky termed, More Knowledgeable Other (MKO), leads the learner through explicit instruction and guidance. The MKO gradually releases the responsibility of the determined skill or strategy until the learner is capable of independently applying the skill to new situations. Fisher and Frey (2008) define four phases of the GRR model based upon Vygotsky's theory. The first phase provides the learner with explicit instruction from the MKO. Fisher and Frey (2008) refer to this stage as a Focused Lesson or the "I do it" portion of instruction in which "I" refers to the MKO. The next stage of GRR is Guided Instruction or the "We do" phase of learning. This stage is based heavily on Vygotsky's idea of instructional scaffolding in which the lesson provides adult and peer support for performing the skill or strategy. During instructional scaffolding, the MKO works with the learner/s in a place of learning where the novice must rely on support from the MKO or collaboration with peers to perform the targeted skill. Vygotsky refers to this place of learning as the Zone of Proximal Development (ZPD). The next phase of the GRR model is the collaborative phase or "You do it together" phase. This stage is the beginning of the transfer of learning in which the MKO pulls away from a central role and becomes an observer of the learning. The learner must independently apply the skill or strategy while still engaged with peers. The last phase of the GRR model is the independent phase in which the learner applies his or her new learning to a new situation. The role of the MKO is to observe the independent work of the learner.

The researcher wondered if the GRR model is applicable to the co-teaching model 
of student teaching if applied appropriately for independence. In the co-teaching model of student teaching, the senior teacher does not leave the room. Rather, the goal of the coteaching student teacher model is to reach the GRR Independent Phase in a Teaming or Collaborative Model. The teaming or collaborative model as defined by Easterby-Smith and Olve (1984) and Pugach and Blanton (2009) promote sharing the sharing of the responsibility of teaching equitably in lesson planning, instruction, and assessment. The Teaming or Collaborative Model assumes the independent application of needed skills and strategies by junior teachers within a teaming setting and the novice teacher is an equal partner with the expert teacher. So, would the co-teaching pre-service model provide enough of gradual release of responsibility or would pieces be missing?

\section{Design of the Study}

\section{Method}

The purpose of this study was to derive an understanding of the perceptions of current and former student teachers, university supervisors, and cooperating teachers on the co-teaching model of student teaching and its ability to prepare student teachers for their first year of teaching. The researcher used a mixed method approach to research. By combining descriptive statistics, an analysis of variance on SPSS using ANOVA and $t$ Test data from survey responses, and open-ended participant responses from open-ended interview questions, the research results reflect the perceptions and belief systems of the participants. Each survey item and interview question or prompt was used to answer particular research questions.

\section{Setting/Context}

The College of Education at the University of Central Missouri produces 
approximately 250 Bachelor of Science in Education degrees per year in various educational disciplines (University of Central Missouri Fact Book, 2014). The University of Central Missouri as a whole has an enrollment of approximately 12,500 students with $54 \%$ female and $66 \%$ white non-Hispanic students. The average age of the UCM undergraduate is 22.9 and the student/faculty ratio is $16: 8$.

The University of Central Missouri's (UCM) College of Education fully implements the co-teaching model of student teaching. By enlisting participants involved in this one university, the researcher was able to identify the perceptions of the level of teaching readiness based more distinctly upon the student teaching experience rather than on background knowledge from previous university work varying universities might have provided. Ultimately, being able to use one university helped to eliminate other background experiences students from varying universities might have received from varying course work. Because of this unique ability to more closely cue into the influence of the student teaching experience, the researcher solicited student teaching participants solely from the University of Central Missouri.

The current and former student teacher participants experienced the co-teaching model of clinical practice while a student at the University of Central Missouri. The current student teacher participants completed a full semester of student teaching but had not yet experienced a first year of teaching. The former student teacher participants are all currently employed in a school district and have experienced at least one full year of teaching. The size and demographics of the employing school districts are randomly based upon the employment of the UCM students. The University supervisors are employed by UCM, but the district cooperating teachers come from various Central and 
Western Missouri school districts where student teachers have been assigned to complete their student teaching.

\section{Participants}

Study participants totaled 41 in number. The current and former student teacher participants enlisted for this study are K-12 UCM regular education classroom current or former student teachers. The researcher received names and emails of student teachers from the UCM College of Education and independently contacted the students via email, requesting permission for the study by way of an electronic consent form. Twenty-five current or former student teachers consented participation via an electronic consent form sent by the researcher.

The university supervisors were employed by UCM. They were contacted by the researcher via email. Five University of Central Missouri (UCM) student teaching supervisors participated in the study.

The cooperating teachers came from various assigned school districts located in Central and Western Missouri. The researcher received names and emails from the UCM College of Education and independently contacted 128 cooperating teachers via email requesting permission for the study by way of an electronic consent form. Fourteen cooperating teachers participated in the study. 


\begin{tabular}{|l|c|c|c|}
\hline \multicolumn{3}{|l|}{ Table 1. Quantitative Survey Participants } \\
\hline Participant groups & $\begin{array}{c}\text { Total number } \\
\text { participants }\end{array}$ & $\begin{array}{c}\text { Participant grade } \\
\text { level ranges }\end{array}$ & $\begin{array}{c}\text { Number of } \\
\text { Participants }\end{array}$ \\
\hline $\begin{array}{l}\text { Current or Former } \\
\text { Student Tea } \\
\text { Teachers }\end{array}$ & 22 & K-8 & 13 \\
& & K-12 & 3 \\
Cooperating & 14 & Unknown & 5 \\
Teachers & & K-8 & 1 \\
& & K-12 & 9 \\
University & $5-12$ & 0 \\
Supervisors & 5 & K-8 & 5 \\
& & K-12 & 1 \\
& & $9-12$ & 2 \\
\hline
\end{tabular}

\section{Quantitative Data Source}

All research participants completed a quantitative survey consisting of 25 belief statements regarding the perceived level of readiness the co-teaching experience provided or provides new teachers. Each survey was specific to the participant group (current or former student teachers, cooperating teachers, and university supervisors). Categorical rating scales (Fink, 2013) included identifying the role of the participant and the level at which he/she works; however, names and locations were excluded to ensure confidentiality of participants.

To define the concept of "level of readiness for first year of teaching," the survey belief statements were based on the Missouri Teacher Standards (DESE, 2013), the 
rationale being standards for teachers serve as benchmarks for teacher quality, thus are representative of a well-prepared teacher. To develop the survey, each standard was tied to a lead-in statement or item stem that asked the participant to note how well he or she perceives the co-teaching model prepares the first year teacher for his or her first year of teaching. For example, one Missouri Teacher Standard states the effective teacher will engage in reflective practice in order to modify future instruction (Department of Elementary and Secondary Education, 2013). For current and former student teachers, this standard was phrased in a belief statement to be scored on a Likert-type scale as follows. The co-teaching model positively prepared me for my first year of teaching in the following way: to engage in reflective practice in order to modify future instruction. The survey participant then marked his or her level of belief on a scale of 1 (Not at all) to 9 (A good deal). For supervising and cooperating teachers, the same standard was phrased as follows. The co-teaching model positively prepares student teachers for their first year of teaching in the following way: to engage in reflective practice in order to modify future instruction. The participant from this group then marked his or her level of belief on a scale of 1 (Not at all) to 9 (A good deal). The items were grouped in overarching educational concept groupings: professionalism and collaboration; classroom management; content knowledge and instructional strategies; student learning goals; curriculum and lesson planning; assessment and data.

Participants marked their perceived level of readiness for each standard on an ordinal, Likert-type (Fink, 2013) one-to-nine scaled survey formatted to resemble that of the Teachers' Sense of Efficacy Scale developed by Tschannen-Moran and Woolfolk Hoy (2001). A (1) represents the answer "Not At All," a (3) represents "Very Little," a 
(5)"Some," a (7) “Quite A Bit," and a (9) represents the answer "A Great Deal.”

\section{Qualitative Data Source}

Within two weeks following the quantitative survey, qualitative interviews (Merriam, 2009) were held with each participant to provide data on the perceived level of preparedness the co-teaching model provides first year teachers in relation to the Missouri Teacher Standards. Open-ended questions in a semi-structured interview structure (Merriam, 2009) allowed for participant personal insight and feedback. Questions focused on the student teaching process and experience and the co-teaching pre-service model's perceived impact on the student teacher's readiness for his or her first year of teaching.

\section{Limitations}

Transferability of findings across other institutions will be limited as this study specifically explores UCM's co-teaching clinical model and students who have attended UCM's pre-service courses. Additionally, the present research proceeds under the assumption that each pre-service student teacher is at a somewhat equal level of preparedness as other student teachers before the co-teaching clinical experience began. This assumption stems from the application of common coursework of all pre-service education students within the UCM College of Education. Finally, the small sample size particularly limits the generalizability of the quantitative data. However, findings were strengthened by triangulating data from the same participants using both quantitative and qualitative data. 


\section{Data Analysis}

\section{Quantitative Survey Data Analysis}

Descriptive statistics, One-Way ANOVA, One-Way Repeated Measures

ANOVA, and $t$-Tests were used to analyze the quantitative survey results. The Likerttype responses were treated as continuous (Fink, 2013) and each participant group's (current and former student teachers, cooperating teachers, university supervisors) set of data were entered into a spreadsheet determining the median, mode, and mean in the frequency distribution of the data (Field, 2013). A Single Sample $t$-test was then run to determine if respondent groups and the overall group perceived the co-teaching preservice model to be effective. The survey items labeled the ranking of (5) as "somewhat" preparing the first year teacher, so a ranking of (5) and above was considered the range for perceiving the co-teaching model as effective.

A One-Way ANOVA compared the three participant groups' overall means. A significant difference was found between the participant groups as to what level of preparedness each perceived the co-teaching model provided the first year teacher. The researcher then performed three $t$-tests to compare the participant groups two at a time.

An additional One-Way ANOVA was performed comparing the overall means of the grade-level participants to determine if there was a significant difference in gradelevel groups' perceptions of how well the co-teaching pre-service model prepared the first year teacher. A significant difference was found between groups so three $t$-tests were run to compare the means of the groups two at a time. Finally, a One-Way Repeated Measures ANOVA was run to determine if there was a significant difference between survey stem items grouped by educational concepts. 


\section{Qualitative Interview Data Analysis}

The qualitative data were coded for patterns, generalizations, and themes (Creswell, 2014). Upon analysis, the researcher followed the six step coding process for qualitative data (Creswell, 2014, pp. 197-201) to review data. Step 1: The researcher organized and prepared the noted. Step 2: The researcher looked for data consistency within and across the groups. Step 3: The researcher began to group common observations into generalization categories. Step 4: The researcher generated a descriptive theme or themes based on generalizations. Step 5: The researcher created a narrative passage to describe the themes represented in the data. Step 6: The researcher interpreted the qualitative data couched in personal understandings and comparisons to literature and known theories.

\section{Bringing the Data Together}

To determine if the respondent groups of student teachers, cooperating teachers, university teachers, and the total response group perceived the co-teaching model as effective in preparing the student teacher for first year teaching, the researcher ran a Single Sample $t$-Test. The labeling of the Likert-style scale named a (5) as "somewhat effective." A (5) and above was considered the range for perceiving the co-teaching model as effective. The (5) mean was then compared to each group member's means. If the test found the results Significant, the group results were determined to be high enough to perceive the co-teaching model of student teaching as effective in preparing student teachers for first year teaching. The results were as follows: 


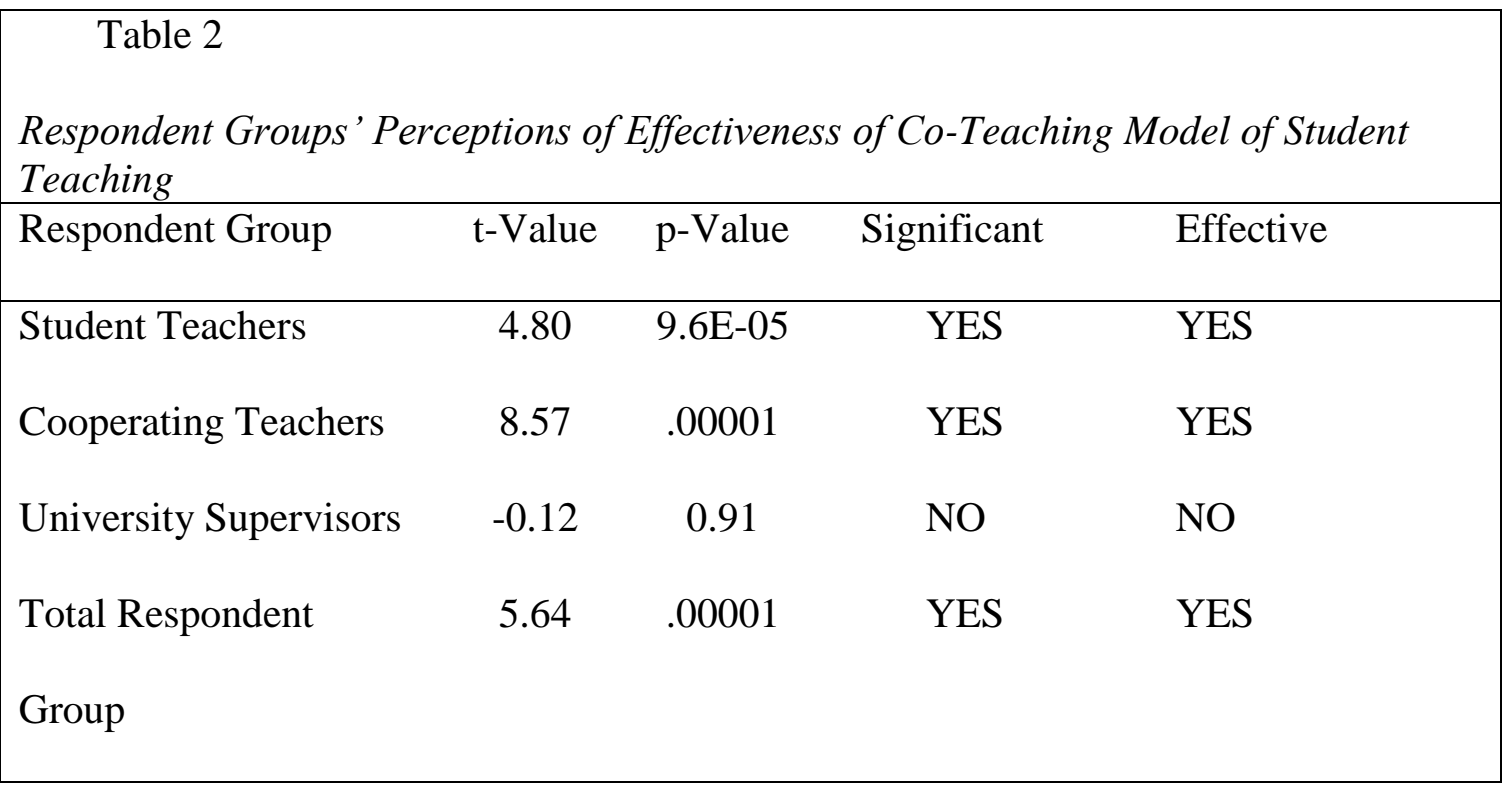

While analyzing the qualitative data, questions arose that brought the researcher back to the quantitative data to run various tests. For instance, through qualitative data analysis, a pattern appeared to emerge in regard to the qualitative responses and the grade level in which the participant worked. The researcher then returned to the quantitative data and ran a One-Way ANOVA to see if there were a significant difference between the responses of the three grade levels. Qualitative and quantitative data were triangulated to identify overarching themes. The researcher interpreted the overall data within the context of personal understandings and comparisons to literature and known theories

\section{Findings}

\section{Summary of Quantitative Data}

The quantitative data revealed that current and former student teachers and cooperating teachers significantly scored co-teaching higher than did university supervisors in the co-teaching model's ability to support first year teachers. There was no significant difference between the student teachers' and the cooperating teachers' 
perceptions of how well the co-teaching pre-service model prepared students for first year with a p-value of .086 (Table 2). However, there was a significant difference between student teacher perceptions compared to university supervisors' with a p-value of .041 (Table 3) with the greatest disparity of means between cooperating teachers' perceptions and university supervisors' perceptions with a p-value of .012 (Table 4).

Table 3

Student Teachers/Cooperating Teachers Group Perceptions t-Test Descriptive Table

\begin{tabular}{|lccccc|}
\hline & $N$ & $d f$ & $M$ & $S S$ & $S^{2}$ \\
\hline Student Teachers & 22 & 21 & 6.7 & 58.27 & 2.77 \\
Cooperating Teachers & 14 & 13 & 7.4 & 14.25 & 1.1 \\
\hline
\end{tabular}

The $t$-value is -1.39 . The $p$-value is .086 . The result is not significant at $p<.05$.

Table 4

Student Teachers/University Supervisors Group Perceptions t-Test Descriptive Table

\begin{tabular}{|lllccc|}
\hline & $N$ & $d f$ & $M$ & $S S$ & $S^{2}$ \\
\hline Student Teachers/1s-3 & 22 & 21 & 6.7 & 58.27 & 2.77 \\
University Supervisors & 5 & 4 & 4.81 & 53.48 & 13.37
\end{tabular}

The $t$-value is 1.81 . The $p$-value is .041 . The result is significant at $p<.05$. 
Table 5

Cooperating Teachers/University Supervisors Group Perceptions t-Test Descriptive Table

\begin{tabular}{|lccccc|}
\hline & $N$ & $d f$ & $M$ & $S S$ & $S^{2}$ \\
\hline Cooperating Teachers & 14 & 13 & 7.4 & 14.25 & 1.1 \\
University Supervisors & 5 & 4 & 4.81 & 53.48 & 13.37 \\
\hline
\end{tabular}

The $t$-value is 2.49 . The $p$-value is .012. The result is significant at $p<.05$.

Additionally, K-8 respondents significantly scored co-teaching higher in its ability to support first year teachers than did K-12 with a p-value of .001. There was also a significant difference between K-8 respondents' perceptions and 9-12 respondents' perceptions with a p-value of .0002 . There was no significant difference between $\mathrm{K}-12$ perceptions and 9-12 perceptions with a p-value of .035 .

In relation to the Missouri Learning Standards educational concepts categories of professionalism and collaboration, classroom management, content knowledge and instructional strategies, student learning goals, and curriculum and lesson planning, there was no significant difference in how these item categories were scored by any respondent group. However, the overall means for these educational concept categories were ordered from most positively influenced by co-teaching to least positively influenced by coteaching as follows: professionalism and collaboration; classroom management; curriculum and lesson planning; student learning goals; content knowledge and instructional strategies; and assessment/data. 


\section{Summary of Qualitative Data and Findings}

Through both the qualitative data analysis process and quantitative data analysis, four findings emerged: 1. Co-teaching student teaching model provides a structure that closely aligns to the theoretical framework of Gradual Release of Responsibility (GRR), thus providing the first year teacher the guided learning experience needed to support his or her first year of teaching. 2. Co-teaching as a student teaching model provides the student teacher with confidence in his or her teaching early in the process. 3. By not completely and independently taking over the classroom, the student teacher does not get a fully realistic experience of teaching. 4. Participants suggest that student teachers would benefit from a structured time for the student teacher to totally take over the classroom based upon the professional decision of the cooperating teacher.

\section{Finding One}

The co-teaching student teaching model provides a structure that closely aligns to the theoretical framework of Gradual Release of Responsibility (GRR), thus providing the first year teacher the guided learning experience needed to support his or her first year of teaching.

- $\quad$ As the qualitative data were analyzed, some general categories emerged.

- $\quad$ The student teacher is provided extensive modeling of various educational concepts by the cooperating teacher.

- $\quad$ The co-teaching model provides a structure whereby there is the chance to have a singular focus, allowing baby steps to be taken in a Gradual Release of Responsibility.

- $\quad$ The co-teaching model provides a comfort level for the student teacher 
that is often termed as a "safety net" or "security blanket."

- $\quad$ The co-teaching model provides extensive amount of time for reflection and immediate feedback between the student teacher and cooperating teacher.

- $\quad$ The student teacher and cooperating teacher become equal partners.

In the co-teaching model of student teaching, the cooperating teacher is always in the room providing extensive modeling. This structure aligns to the first stage of the Gradual Release of Responsibility called the "I do it" stage. The student teacher is able to observe the cooperating teacher in all daily student, parent, and teacher interactions, transitions, and instructional methods. Student teacher participants frequently mentioned how helpful it was to have an extended period of time to observe the cooperating teacher particularly when handling behavioral issues, classroom management procedures, and curricular misconceptions. Extensive modeling was one of the most frequently referenced positives of co-teaching supporting first year teachers. As Student Teacher Seven noted in reflection of the modeling of the Missouri Teaching Standards, "Yes, you can observe (the Missouri Teacher Standards) through the traditional teaching aspect, but with coteaching you are constantly seeing (the standards) in action. They are being modeled and you are learning from that." Student Teacher Seven also said, "My cooperating teacher modeled it by showing me what it should look like beforehand ... seeing how (the cooperating teacher) handled situations, and having a good base of what it should look like and then being able to kind of mimic that and take those things and then tweak them and turn them into my own, really prepared me." Student Teacher Four noted, "I was one-on-one working with someone, getting her stuff, and seeing the observation of it all. I think I worked better working with someone like that. I am a hands-on, visual person, 
so seeing it done and doing it with her is more memorable to me probably for me to be able to use in my classroom next time. But also it was nice to observe someone to see how they handled a situation differently than I probably would have and it gave me a better viewpoint on the situation." Student Teacher Nine also said about her cooperating teacher, "She was a good role model as a teacher but also as a professional to show, like, this is how you behave in an educational environment."

The second phase of GRR, described as the Guided Instruction or "We do" stage, is also closely aligned to the benefits of the co-teaching student teaching model. Data support the philosophy that in the co-teaching pre-service model the learner is eased into teaching with heavy support by the MKO. Cooperating Teacher Two noted, "(Coteaching) helps on being able to focus on one thing as you're learning instead of everything at the same time. I think that it probably helped with narrowing your focus instead of being so overwhelmed. Co-teaching allows the student teacher to focus on more specific things they are trying to improve on or learn about instead of the whole thing at once." Cooperating Teacher Three said, "Co-teaching makes the experience like baby steps...I think when I had a traditional student teacher, it was, 'Okay, now this is all you. I'll come talk to you at the end of the day."' The co-teaching model of student teaching provides a structure for guided instruction.

The co-teaching model continued to scaffold the student teacher learning in the "We do" phase of the GRR model of instruction by allowing the MKO to provide a comfort level of support for the student teacher often termed a safety net or security blanket. This is a part of the "We do" phase whereby the student teacher receives needed support from the MKO. University Supervisor Three said, "It gives (the student teachers) 
a safety net there. If they get handed off to classes a few weeks in then there is a lot of failing that goes on until they sort it out. Co-teaching smoothens the transition." Student Teacher Nine said, "So (having the cooperating teacher there) was like having a safety net there, and it was comforting."

The "You do, together" phase of the GRR model is heavily supported by the coteaching model of student teaching due to the amount of immediate feedback and collaborative reflection the cooperating teacher can provide the student teacher. In the "You do, together" phase of GRR, the learner is responsible for the learning, but the MKO is closely watching and monitoring to provide feedback and reflection. The interview participants frequently mentioned immediate feedback and collaborative reflection as strong benefits of the co-teaching model. Collaborative Teacher Three said, "If it was a traditional student teaching model, then we couldn't have gone back and forth with her practicing on things as much. If it was traditional and I just walked away, she would have had to figure things out. I think the fact that we could go back and forth and that I could take over part of a class and then she take over part of a class, or if we split the class and I took half and she took half, then we could talk about the experience. 'How did yours go and why?' So I think if we did it traditionally, she wouldn't have grown as much as she did." Student Teacher Five said, "You have someone there that you can lean on to guide you, because it is a learning experience. You're still learning and (coteaching) provides several, actually not even several, TONS of coachable moments." Cooperating Teacher Five noted that because she was there in the room, she could hear the co-teacher giving lessons even when she was with another group. It gave the cooperating teacher the opportunity to guide the reflection, asking questions that she felt 
would pull out things she had seen or heard when they were reflecting on how the lesson went, how they would change it, and what they would do differently. Cooperating Teacher Five shared the same sentiment. "I think co-teaching provides an opportunity for a lot of conversation about what is being taught and if it is working. Reflection. I think conversations came up as to what didn't work well. 'I should have done this instead which would have engaged them more.' I think a lot comes from the conversations and reflections. Would those opportunities be there if it was a traditional model of student teaching? I don't know, but I was here to witness the stuff. So when I was saying, 'How did you think that went?' I was looking for something in response, whether she saw the same thing that I was kind of thinking. The important idea is that in the co-teaching experience, the most important vehicle is the conversations you have around planning your lessons and reflecting on the lessons. Those conversations are richer because you're both so involved in the process." Student Teacher Five summed up the reflection and feedback element of co-teaching and GRR with the following. "More than anything, my student teaching experience coached me.”

The last phase of the GRR model is the independent phase in which the learner applies his or her new learning to a new situation. The role of the MKO is to observe the independent work of the learner. Where the traditional and co-teaching student teaching models differ is that in the traditional model, the MKO is gone and in the co-teaching model, the MKO remains as a collaborative partner. Respondents frequently mentioned the benefits of this final phase of GRR when the co-teachers are seen more as equal partners collaborating. Cooperating Teacher Four said of her student teacher, "She just did everything I did. We were PARTNERS. We both knew what we needed to do. She 
would bring ideas and we just knew what we needed to do and we would do it." Cooperating Teacher Three supported that idea. "When we planned it was like, 'Here's what we need to do,' and then we'd come back and say what each thought the best way to do this was. If her ideas was awesome, we'd go with that. I mean it was just nice. The planning and the team work would be the best part of co-teaching." University Supervisor One said of the equal partner relationship that builds, "The cooperating teacher learns as well as the student teacher because of what they share with one another. They work as a team and that is what we want them to do. I've seen some marvelous examples of where one picks up where the other drops off in the middle of a sentence." Student Teacher Nine said, "By the end, I felt like a colleague, like we were able to discuss things on the same level and communicate the same way, and were able to sort of handle the classroom the same way.

The first finding that emerged from the qualitative data analysis was the coteaching student teaching model provides a structure that closely aligns the theoretical framework of Gradual Release of Responsibility (GRR). Participant responses supported this theme with statements that aligned to the phases of GRR. The quantitative descriptive data which reflects the overall mean ordering of the educational concepts categories supports the qualitative data. Professionalism and Collaboration was the highest scoring category in how well the co-teaching model supports professionalism and collaboration for first year teachers.

\section{Finding Two}

Another positive supporting the first year teacher that emerged from the qualitative data was co-teaching as a student teaching model provided the student 
teacher with confidence in his or her teaching early in the process. Cooperating teachers and university supervisors frequently mentioned the evolution of the student-teacher in the area of confidence. Student teachers also noted how the co-teaching model prepared them for teaching by providing an opportunity to grow in confidence. When asked how the co-teaching model best supported her first year of teaching, Student Teacher Two said, "Confidence. It really helped me to feel confident as a teacher because I saw myself as one of the teachers in the classroom, and so I built up confidence. I built up experiences through that confidence." Student Teacher Nine mentioned, "Co-teaching kind of helped me get over my self-consciousness of being in front of everybody. It was also kind of comforting to know that I had somebody there so if I tripped over my vocabulary or I missed a step, or was using the wrong algorithm, she could pipe in, because my biggest fear is teaching something incorrectly." University Supervisor One supported the idea of confidence building by the co-teaching model. "I think (the student teachers) gain confidence more quickly because they know that someone has got their back. I see their confidence level growing, and I know their cooperating teacher does too."

\section{Finding Three}

By not completely and independently taking over the classroom, the student teacher does not get a fully realistic experience of teaching. While the participants report the co-teaching student-teaching experience as building a strong base of knowledge and confidence, many reflect on the need to completely take over the planning, curriculum, delivery, and management of the classroom for a period of time to prepare the student teacher for time alone his or her first year of teaching. As Student Teacher Five said, "It 
would have been HELPFUL to have had the opportunity to plan EVERYTHING rather than being a co-planner, because then I would have had an idea of what it was like before I became a teacher. Co-teaching does not give student teachers the opportunity to be in charge of an entire class for all subjects, ever.” Student Teacher Four said, "The only thing that I didn't like was that I always had somebody else in there with me. I would have liked to have had two or three weeks of just me, solely me, making the decisions, making the plans, making the decisions about management. Those kinds of things. I would have liked to have had a couple of weeks of being solely responsible. I feel like I didn't get that from the co-teaching experience."

In addition to the planning and delivery, not having the opportunity to completely manage behaviors alone is seen as a barrier to preparing the student teacher for his or her first year of teaching. As Student Teacher Two reported, "I do wish I would have had some opportunity to be the sole teacher in the classroom, because then it would have helped me to have that classroom management over the whole group without the other teacher there." Cooperating Teacher One said, "Because, with two people in here, that certainly made sure there wasn't a lot of behavior issues. I think that since (behavior management) is probably something that you have to navigate on your own and figure out how to do, she probably didn't have as much of a chance to try her own thing and see what worked and kind of fall and have to figure it out on her own." Student Teacher Nine noted, "I do kind of wish I had that other time on my own, because I think it really impaired my classroom management experience. I wish I had had more time with them, let them get more comfortable with JUST me, let them test my limits, and then have that experience with correcting and redirecting. If I were to go back and do it again, I would 
ask to just let me take them for a day or two. Because of this lack of an extended period of solo teaching, it was noted that the co-teaching model may not completely prepare teachers for their first year of teaching because it does not give a fully realistic teaching experience.

Finally, not having the opportunity to completely take over the class may develop a dependency of the student teacher on the cooperating teacher. Student Teacher Five said, “There are times now where I'm like, 'Oh, I really wish I had someone to lean on right now. Someone who could kind of coach me through this, right now in this moment. I know that I can always go to other teachers across the hall or to other teachers in the building, but it might not be right at that moment that I need them in my classroom. So that is the only reason why I feel co-teaching might not have supported my first year of teaching." Student Teacher Seven noted, "In the real setting, I mean I have grade level partners, but I don't really have anyone else's opinion...I don't have anyone to run things by, so I'm kind of on my own. As long as I cover the standards, it's up to me how I want to teach it. In co-teaching, I always had support. I always had someone to bounce ideas off of. So that is one way I feel like I was kind of babied with co-teaching." So a barrier to the co-teaching student teaching model in preparing the first year teacher for his or her first year of teaching is that, by not completely and independently taking over, the student teacher does not get a fully realistic experience of teaching.

Participants suggest that student teachers would benefit from a structured time for the student teacher to totally take over the classroom. When ask what suggestions they might have to improve the co-teaching student teaching model, almost every participant mentioned having an extended, allotted amount of time where the student teacher was 
solely responsible for the classroom and the cooperating teacher was out of the room. Suggestions deferred from the traditional model of student teaching in that the recommended amount of time ranged from one-three weeks. It was also noted that during that time, the cooperating teacher should always have daily reflections at the end of the day. Student Teacher Five said, "I think that there should be a couple of weeks where the student teacher is having to make all the decisions. The co-teaching experience helped me more than it did not help me, but I do think that there should be a couple of weeks where the mentor teacher should kind of be phased out completely and the student teacher becomes $100 \%$ the teacher, BECAUSE in our district where I am, the majority of teachers are on their own for the day. I think that would have better prepared me by having just a few weeks of just me.” Student Teacher Two said, "I definitely like the idea of the co-teaching model, but I still think it is important that the student teacher has an opportunity, even if it is just one week, to be the sole planner of the lessons. And to be the sole person in charge of the lessons for the entire week so they have an idea of what it's really like when they become a teacher." Cooperating Teacher One noted, "I think they need to have a time where it's just them. I mean, what if they hate being the only one in the classroom? I think they need some of that. Maybe it's just half day, maybe it is full days, maybe it's a week, maybe it's two, but I think that would give them more of an immersion in teaching. The fourth finding that unfolded was the recommendation that student teachers would benefit from a structured time for the student teacher to totally take over the classroom based upon the professional decision of the cooperating teacher.

\section{Discussion}

A qualitative investigation of the perceptions of current and former student 
teachers, cooperating teachers, and university supervisors on the co-teaching model of student teaching and its ability to prepare student teachers for their first year of teaching revealed that the co-teaching model of student teaching is perceived as an effective preservice model. It was determined that the model closely aligns to the Gradual Release of Responsibility learning theory. The positives that support this alignment include extensive modeling, immediate feedback and professional reflection, a structure whereby there is the chance to have a singular focus, allowing baby steps to be taken in a Gradual Release of Responsibility, a comfort level provided through a "safety net," and the evolution of student teacher and cooperating teachers becoming equal partners. The model also allows the student teacher time to gain confidence.

Alternately, the findings reveal that each participant group believes that the model does not provide a fully realistic teaching experience by not allowing for time where the student teacher is solely responsible for the classroom. This theme emerged from all participants. Participants noted the co-teaching model has more benefits than not and should be used as a pre-service model; however, suggestions included incorporating some extended period time where the student teacher is alone. Participants recommended one to three weeks.

The quantitative data revealed that the co-teaching model is perceived by overall tot participants, student teachers, and cooperating teachers as an effective model of student teaching in preparing pre-service teachers for their first year of teaching. University supervisors scored the co-teaching pre-service model significantly lower than did student teachers and cooperating teachers. Data also revealed that participants working in grades 9-12 and K-12 scored the co-teaching model significantly lower than 
participants working in grades K-8. Upon a closer review, however, the researcher noted the sampling of university supervisors included $40 \% \mathrm{~K}-12,40 \% 9-12$, and $20 \% \mathrm{~K}-8$. A larger sampling crossing grade levels would need to be used to accurately determine if those lower perception results are based on the university supervisor roles or on the grade levels in which they work. More research could also focus on the discrepancies between perceptions between grade levels using co-teaching. For instance, what elements of the co-teaching model affect 9-12 participant perceptions as lower than K-8?

Another interesting finding that emerged but which was not fully developed was that the participants did not often mention the models of co-teaching (i.e. One Teach-One Assist, Parallel Teaching, Station Teaching, Team Teaching) when discussing the effectiveness of the pre-service model of student teaching. The discussion most generally focused on the interactions between the cooperating teacher and the student teacher. Questions arise as to how the co-teaching instructional models affect that interaction between the cooperating teacher and the student teacher. Further research could examine the influence the co-teaching instructional models have on the co-teaching pre-service model.

\section{Implications and Conclusion}

These findings leave teacher education programs with evidence that the coteaching model of student teaching is perceived as a strong pre-service model for preparing student teachers for their first year of teaching. Many positives of the coteaching pre-service model emerge from the findings. Universities, however, might consider adding an extended period of time towards the final third or fourth of the semester whereby student teachers are given sole responsibility for the classroom. The 
cooperating teacher should be available at the end of the day for reflection, however, the planning and all other responsibilities should be absorbed by the student teacher during this period. This differs from the traditional student teaching model in that this time period transitions in slowly and is not as lengthy as a traditional model of student teaching.

\section{Summary}

The purpose of this study was to determine and analyze the perceptions of current and former student teachers, cooperating teachers, and university supervisors on the coteaching model of student teaching and its ability to prepare student teachers for their first year of teaching. This study used a mixed-methods research approach. Participants included current and former student teachers, cooperating teachers, and university supervisors from the University of Central Missouri. Quantitative data from surveys administered to student teachers, cooperating teachers, and university supervisors who experienced the co-teaching model eliciting perceptions of the level of preparedness the co-teaching model provides student teachers for their first year of teaching. The quantitative surveys provided data on each participant group's perception of the benefits and/or weaknesses of the co-teaching models of student teaching. Qualitative data from one-on-one interviews were collected from each participant group. Participant data were analyzed to determine the overall perceived impact of the co-teaching model of student teaching on the level of preparedness for the first year teacher. Participant group data were cross-analyzed to determine any similarities or disparities in perceptions between participant groups.

Quantitative data revealed that student teachers and cooperating teachers 
perceived the co-teaching model as supporting first year teachers significantly more than did university teachers. The quantitative data also showed a significant difference in K-8 perceptions of the co-teaching model's ability to more positively supporting first year teachers than did the K-12 or 9-12 respondents.

Research data unfolded four findings. First, the co-teaching model of student teaching highly supports the growth of student teachers in preparation for their first year of teaching by tightly aligning to the Gradual Release of Responsibility social learning theory. General categories that supported this finding were that the co-teaching model provided the following components of GGR for the student teacher: extensive modeling, immediate feedback and professional reflection, the ability to have singular foci, collaboration. Another finding emerged reflecting the strength of the co-teaching student teaching model's ability to build the student teacher's self-confidence. A third finding was the common perception that the co-teaching model does not provide the student teacher with a realistic teaching experience in a classroom that does not employ another co-teacher. And the final finding was the recommendation that the co-teaching model be implemented by universities due to the strength in its learning structure, but the student teacher be allowed two-three weeks of sole classroom responsibility without the cooperating teacher in the classroom. 


\section{References}

Creswell, J. (2014). Research design: Qualitative, quantitative, and mixed methods approaches ( $4^{\text {th }}$ ed). Thousand Oaks, CA: SAGE Publications, Inc.

Diana, T. (2014). Co-teaching: Enhancing the student teaching experience. Kappa Delta Pi Record, 50(2), 76-80, DOI: 10.1080/00228958.2014.900849

Easterby-Smith, M., \& Olve, N. (1984). Team teaching: Making management education more student-centred? Management Learning, 15(3), 221-236.

Field, A. (2013). Discovering statistics using IBM SPSS statistics ( $^{\text {th }}$ ed).Thousand Oaks, CA: SAGE Publications, Inc.

Fisher, D., \& Frey, N. (2008). Better learning through structured teaching: A framework for gradual release of responsibility. Alexandria, Virginia: Association for Supervision and Curriculum Development.

Hartnett, J., Weed, R., McCoy, A., Theiss, D., \& Nickens, N. (2013). Coteaching: A new partnership during student teaching. SRATE Journal, 23(1), 5-12.

Merriam, S. B. (2009). Qualitative research: A guide to design and implementation. Hoboken, NJ: Jossey-Bass.

Missouri Department of Elementary and Secondary Education. (2013). Teacher standards: Missouri evaluation system. Retrieved from http://dese.mo.gov/sites/default/files/TeacherStandards.pdf

National Council for Accreditation of Teacher Education. (2010). Transforming teacher education through clinical practice: A national strategy to prepare effective teachers. Washington, DC: Author.

Nevin, A. I., Thousand, J. S., Villa, R. (2009). Collaborative teaching for teacher 
educators-What does the research say? Teaching and Teacher Education (25) 569-574.

Pearson, P. D., \& Gallagher, M. C. (1983). The instruction of reading comprehension. Contemporary Educational Psychology, 8(3), 317-344.

Pugach, M., and Blanton, L. (2009). A framework for conducting research on collaborative teacher education. Teaching and Teacher Education (25). 575-582.

Tschannen-Moran, M., \& Woolfok Hoy, A. (2001). Teacher efficacy: Capturing an elusive construct. Teaching and Teacher Education 17, 783-805.

University of Central Missouri College of Education. Fast facts. Retrieved from https://www.ucmo.edu/ir/documents/factbook.pdf

Villa, R., Thousand, J., \& Nevin, A. (2008). A guide to co-teaching: Practical tips for facilitating student learning ( ${ }^{\text {nd }}$ ed.). Thousand Oaks, CA: Corwin Press.

Vygotsky, L. S. (1978). Mind in society: Development of higher psychological processes. Cambridge, MA: Harvard University Press 


\section{SECTION SIX}

SCHOLARLY PRACTITIONER REFLECTION 


\section{How This Dissertation Influenced My Practice as an Educational Leader}

Just as I arrived on my topic of "co-teaching as a clinical model of student teaching," there was a shift occurring in my current school district leadership. The Assistant Superintendent, who was the student teacher point of contact between universities and the school district, announced his retirement. I went to his office and asked if he thought I might take over as the point of contact for university per-service programs. Both he and my superintendent agreed and he provided me the opportunity to take over as district point-of-contact second semester so that he could be available for questions. He told me that it was a difficult job and wanted to be there as support. I was excited with the new duty and believed this opportunity would provide me insight into the student teaching experience. This insight, however, came in surprising ways both positively and negatively.

During my Assistant Superintendent's time in Central Office, Odessa schools had been partners with the University of Central Missouri as Professional Development School (PDS). We had serviced multiple PDS students who worked a semester with teachers, followed by a semester of student teaching. It was a great experience; however, right at the time of my takeover of duty, the building administrators came to the Administrator Meeting with the concern that their teachers were getting burned out on hosting pre-service teachers. Their teachers enjoyed the pre-service students, but had been full with pre-service teachers for the past three years and wanted a break. Sadly, it then became my duty to contact the University of Central Missouri's College of Education and request such a break. The university was very understanding and accommodating. When students requested our district, they were always quick to ask if that would be okay or if they should ask the district of second choice. I began to see the struggles the university pre-service programs came across on a first-hand basis. 
I began to also experience the struggles at the district level. I found that when I sent out student-teacher and observation student assignment requests to principals, the principals were very slow in responding. I had to follow-up several times to get responses for assignments. I saw that this was not only a district problem, but lead to a problem for the university seeking those assignments as well. I found that if I sent out the assignment requests to the school staff AND the principal, I would get several positive responses from several teachers. I was then able to approach the principal with those options and he or she would then select the partner. This expedited process and seem to meet the needs of the busy administrators, myself, and the university college of education.

Struggles my first year as the pre-service point of contact allowed me to see the struggles universities, districts, and teachers experience within the pre-service program. It might not be perfect, but it was perfectly real. And the struggles were not over yet.

A later problem occurred with a high school teacher and the quality of the experience the district teacher was providing the student teacher. A K-12 major was splitting her student teaching experience between this district teacher and one of our elementary teachers. The elementary teacher called me and told me that her student teacher said that during her high school assignment, she was rarely provided the opportunity to work with the students. I went over to the high school and spoke with the administrators. It was determined that the student teachers was indeed not getting an adequate amount of teaching time in the high school setting. This high school teacher was not a bad teacher. In fact, quite the opposite. The district teacher had just never had a student teacher and had not gone through any type of training as a cooperative teacher.

I then had another request from a different university K-12 education major to student 
teach at the secondary level. I took this opportunity as a coachable moment. I asked the university if we could split the quarters between the high school and the middle school teachers and they enthusiastically agreed. Here is where my personal research came into practice.

Using what I learned from my Dissertation-in-Practice, I designed a calendar and schedule which reflected a co-teaching pre-service model with a gradual release of responsibility. The intent was for the cooperating teacher to provide this schedule to the student teacher; however, it was also provide the cooperating teacher a guide as well. I included the recommendations of my research participants, since this university did not require a co-teaching model, and I added a specified amount of time for the student teacher to co-teach as well as take full responsibility for the class. This calendar and schedule was detailed. I believed this cooperating teacher needed a great deal of scaffolding. Although this was a detailed plan, flexibility was of course allowed. The detail was provided as support for the cooperating teacher to understand the flow of the gradual release of responsibility. I met frequently with the two cooperating teachers to clarify and support them in working with the student teacher. The high school teacher expressed concerns that this was the competition season, so we were able to design a class schedule to accommodate the students' needs along with the student teacher needs. In the end, both the high school and middle school cooperating teachers provided an excellent clinical experience for the student teacher and provided positive feedback on their own experiences as well.

Since the student teacher was to split the semester with another building, the schedule had to stay inside an eight week calendar. To align closely to the Gradual Release of Responsibility (Pearson \& Gallagher), the first week was the "I Do" phase where the cooperating teacher modeled as the student teacher observed, learned routines, learned student names, and 
assisted with procedures such as attendance, correcting papers, and developing and obtaining materials.

The second week began the "We do" phase of the Gradual Release of Responsibiltiy. The student teacher began planning with the cooperating teacher, working with small groups and individuals with observance and guidance from the cooperating teacher, prepared and taught at least one class period with the cooperating teacher, and assisted in non-teaching duties. The cooperating teacher still assumed the role of the lead teacher.

The third week was still in the "We Do" phase but with more opportunities. The student teacher began to study all the curriculum and create lesson plans for small groups or single classes. The student teacher then submitted and checked them with the cooperating teacher. One or two additional subjects or portions of classes were added to the teaching load with the cooperating teacher giving lots of feedback.

Week four was the "You Do" phase of the Gradual Release of Responsibility. Here the student teacher created and submitted for review the whole week's lesson plans to be taught by the student teacher with cooperating teacher as observer and note taker.

Weeks five the student teacher taught with the cooperating teacher coming in and out of particular classes. Week six and seven the student teacher took sole responsibility of planning and teaching. Each of these weeks the cooperating teacher provided time to reflect with the student teacher. Since it was competition season, the cooperating teacher would take over particular periods important to the teacher.

Although this calendar schedule moved more quickly through the stages of the Gradual Release of Responsibility than my research study suggested, the cooperating and student teacher both found the experience positive and effective. By the end of the co-teaching student-teaching 
experience, they each had wonderful things to say about the experience. I consider this my most successful application of my research into educational practice.

\section{How the Dissertation Process Has Influenced Me As a Scholar}

I self-published a book this past year in Kindle Direct Publishing. It was a self-help book. The process was exciting and the product success was fulfilling. I applied academic skills I had learned in through my dissertation process in research, writing, formatting, and referencing. I particularly focused on clarity of writing, removing of pronouns and simplifying thoughts. I have just begun receiving royalty deposits. I credit the dissertation writing process for the confidence to go forward with this personal endeavor.

The dissertation process has also provided me a lens through which I now view academic research. I cue in on the study methods, sample sizes, and limitations, as well as the findings. By doing so, I am able to have a clearer picture of how a study's findings might or might not be extrapolated.

Another scholarly influence my dissertation process has provided me centers on research methods, design, and data analysis. By applying a mixed methods approach to my dissertation study, I have a keener insight into the value of both quantitative and qualitative studies. I see the value when analyzing quantitative and qualitative data separately, and I see the value when triangulating the two types of data. I see how both data types might support, refute, or add clarity to a study. I understand how some studies might be best designed solely by a quantitative study and some might be best served by solely a qualitative approach. For me, I have no bias for one or the other. I find value in both.

My dissertation has sparked an excitement in me. I like research. I like developing questions, designing a study, collecting data, analyzing data, drawing conclusions, and discussing implications for further study. With answers to some questions brings more questions to answer. I hope that I will, in the future, be able to continue academic research in some way. 


\section{References}

Albrecht, N. M. R. (2003). University faculty collaboration and its impact on professional development. (Ed. D. dissertation, Kansas State University). Dissertation Abstracts International. A64/05, 1526.

Andrews, L.O. (1964). Student teaching. New York: The Center for Applied Research in Education, Inc.

Austin, V. (2001). Teachers' beliefs about co-teaching. Remedial and Special Education 22(4).

Bacharach, N., Heck, T., \& Dahlberg, K. (2008). Co-teaching in higher education. Journal of College Teaching \& Learning, 5(3), 9-16.

Bacharach, N., Heck, T., \& Dahlberg, K. (2008). What makes co-teaching work? Identifying the essential elements. College Teaching \& Methods Style Journal, 4(3), 43-48.

Bacharach, N., Heck, T., \& Dahlberg, K. (2010). Changing the face of student teaching through co-teaching. Action in Teacher Education, 32(1) 1-13.

Bass, B. M. (1985). Leadership and performance beyond expectations. New York: Free Press.

Bass, G. I. S. (2005, Feb.). The evolution of a collaborative teaching team in higher Education. (Ph.D. dissertation, The University of North Dakota). Dissertation Abstracts International, A 65/08, p. 2913.

Bessette, H. (2007). Using students' drawings to elicit general and special educators' perceptions of co-teaching. Teaching and Teacher Education (24) 1376-1396.

Bolman, L., and Deal, T. (2008). Reframing organizations: Artistry, choice, and 
leadership. San Fransisco, CA: Jossey-Bass.

Brinkman, J. \& Twiford, T. (2012). Voices from the field: Skill sets needed for effective collaboration and co-teaching. National Council of Professors and Educational Administrators Publications. Retrieved from http://enx.org/content/m44961/1.8/

Chanmugam, A., Gerlach, B.. (2103) A co-teaching model for developing future educators' teaching effectiveness. International Journal of Teaching and Learning in Higher Education, 25(1). 110-117.

Creswell, J. (2014). Research design: Qualitative, quantitative, and mixed methods approaches $\left(4^{\text {th }}\right.$ ed). Thousand Oaks, CA: SAGE Publications, Inc.

Darling-Hammond, L. (1996). What matters most: A competent teacher for every child. Phi Delta Kappan, 78(3), 19-22. Retrieved from http://www.pdkintl.org/kappan/k_v78/k9611dar.htm

Darling-Hammond, L. (2005). New standards and old inequalities. In King, J. (Ed.). Black education: A transformative research and action agenda for the new century (pp. 1997-224). Mahweh, NJ: Lawrence Erlbaum Associates.

DelColle, J., \& Keenan, C. (2015). Co-teaching partnerships for excellence in the age of accountability: A preliminary study of the effects of co-teaching in student teaching. Retrieved from http://digitalcommons.uconn.edu/nera_2014

Department of Elementary and Secondary Education. (2013) Teacher standards:

Missouri's educator evaluation system. Retrieved from http://dese.mo.gov/sites/default/files/pictures/TeacherStandards.pdf

Diana, T. (2014). Co-teaching: Enhancing the student teaching experience. Kappa Delta Pi Record, 50(2), 76-80, DOI: 10.1080/00228958.2014.900849 
Desimone, L. M. (2009). Improving impact studies of teachers' professional development: Toward better conceptualizations and measures. Educational Researcher, 38(3), 181-199.

Dugan, K.B., \& Letterman, M.R. (2004). Team teaching a cross-disciplinary honors course: Preparation and development. College Teaching, 8, 76.

Dugan, K.B., \& Letterman, M.R. (2008). Student appraisals of collaborative teaching. College Teaching, 56(1), 11-15.

Easterby-Smith, M., \& Olve, N. (1984). Team teaching: Making management education more student-centred? Management Learning, 15(3), 221-236.

Ellis, J. \& Bogle, D. (2008, November). Placement: An unforeseen casualty of No Child Left Behind. Paper presented at the annual meeting of the Southeastern Regional Association of Teacher Educators, Myrtle Beach, SC.

Field, A. (2013). Discovering statistics using IBM SPSS statistics ( $4^{\text {th }}$ ed).Thousand Oaks, CA: SAGE Publications, Inc.

Fishbaugh, M. S. E. (1997). Models of collaboration. Needham heights, MA: Allyn \& Bacon.

Fisher, D., \& Frey, N. (2008). Better learning through structured teaching: A framework for gradual release of responsibility. Alexandria, Virginia: Association for Supervision and Curriculum Development.

Flowers, J. G., Patterson, A., Stratemeyer, F., \& Lindsey, M. (1948). School and community laboratory experiences in teacher education. Oneonta, NY: American Association of Teachers Colleges.

Friend, M. \& Cook, L. (2003). Interactions: Collaboration skills for school professionals 
( $4^{\text {th }}$ ed.). Boston: Allyn \& Bacon.

Friend, M. \& Cook, L. (2010). Interactions: Collaboration skills for school professionals Upper Saddle River, N.J.: Pearson Education Inc.

Graziano, K. \& Navarrete, L. (2012). Co-teaching in a teacher education classroom: Collaboration, compromise, and creativity. Issues in Teacher Education, 21(1), 109-125.

Hartigan, B. (2014). Early childhood teacher preparation: Using the co-teaching model. Creative Education. Retrieved from http://dx.doi.org/10.4236/ce.2014.58076

Hartnett, J., McCoy, A. Weed, R., \& Nickens, N. (2014). A work in progress: Unraveling the lesson learned in a co-teaching pilot. The Renaissance Group, 3(1) 33-54.

Hartnett, J., Weed, R., McCoy, A., Theiss, D., \& Nickens, N. (2013). Co-teaching: A new partnership during student teaching. SRATE Journal, 23(1), 5-12.

Individuals with Disabilities Education Improvement Act (IDEIA) of 2004. Retrieved from: http://idea.ed.gov/explore/view/p/\%2Croot

Journal of Teacher Education. (2015) Retrieved from http://aacte.org/resources/journalof-teacher-education

Journal of Teacher Education. (2015). Retrieved from http://aacte.org/resources/journalof-teacher-education\#jte-editorial-board- advisers-and-reviewers

Krueger, R. A., \& Casey, M. A. (2009). Focus groups: A practical guide for applied research. Thousand Oaks, CA: Sage.

Merriam, S. B. (2009). Qualitative research: A guide to design and implementation. Hoboken, NJ: Jossey-Bass.

Missouri Department of Elementary and Secondary Education. (2013). Teacher 
standards: Missouri evaluation system. Retrieved from

http://dese.mo.gov/sites/default/files/TeacherStandards.pdf

Morton, B., Birky, G. (2015). Innovative school-university partnerships: Co- teaching in secondary settings. Retrieved from http://digitalcommons.georgefox.edu/soe_faculty

Murawski, W. (2010). Collaborative teaching in elementary schools: Making the coteaching marriage work! Thousand Oaks, CA: Corwin Press.

National Council for Accreditation of Teacher Education. (2010). Transforming teacher education through clinical practice: A national strategy to prepare effective teachers. Washington, DC: Author.

Nevin, A. I., Thousand, J. S., Villa, R. (2009). Collaborative teaching for teacher educators-What does the research say? Teaching and Teacher Education (25) $569-574$.

No Child Left Behind. (2002). Retrieved: http://www.2.3e.gov/nclb/choiece/index.html Northouse, P. (2013). Leadership: Theory and practice $\left(6^{\text {th }}\right.$ ed.). Thousand Oaks, CA: SAGE Publications, Inc.

Patton, M. Q. (2002). Qualitative Research \& Evaluation Methods. Thousand Oaks, CA: Sage Publications, Inc.

Pearson, P. D., \& Gallagher, M. C. (1983). The instruction of reading comprehension. Contemporary Educational Psychology, 8(3), 317-344.

Pugach, M., and Blanton, L. (2009). A framework for conducting research on collaborative teacher education. Teaching and Teacher Education (25). 575-582.

Office of Institutional Research. (2014) University of central missouri fact book-2014: 
Five-year trends of institutional and academic profiles. Retrieved from http://www.ucmo.edu/ir/documents/factbook.pdf

Sage. (2015). Journal of Teacher Education. Retrieved from https://us.sagepub.com/enus/nam/journal-of-teacher- education/journal200961\#submission-guidelines

Tschannen-Moran, M., \& Woolfok Hoy, A. (2001). Teacher efficacy: Capturing an elusive construct. Teaching and Teacher Education 17, 783-805.

University of Central Missouri. College of Education. (2015). Retrieved from https://www.ucmo.edu/ced/

University of Central Missouri College of Education. Fast facts. Retrieved from https://www.ucmo.edu/ir/documents/factbook.pdf

University of Kansas (1968) An examination of standards and evaluative criteria for the accreditation of teacher education: Report presented at the Nineteenth Annual Kansas College Conference and Teacher Education and Professional Standards Conference on Teacher Education. Kansas Advisory Council on Education; Kansas State Dept. of Public Instruction, Topeka; Kansas State Teachers Association.

Vasquez-Montilla, E., Spillman, C., Elliott, E. \& McGonney, A. (2007). Co- teaching in teacher education: Expectations, inspirations and limitations. Florida Educational Leadership. 7(2). 47-51).

Vaughn, S., Schumm, J.S., \& Arguelies, M. E. (1997). The ABCDE's of co- teaching. Teaching Exceptional Children, 30(2), 8.

Villa, R., Thousand, J., \& Nevin, A. (2008). A guide to co-teaching: Practical tips for facilitating student learning ( $2^{\text {nd }}$ ed.). Thousand Oaks, CA: Corwin Press. 
Vogler, K. E., \& Long, E. (2003). Team teaching two sections of the same undergraduate course: A case study. College Teaching, 51(4), 122-126.

Vygotsky, L. S. (1978). Mind in society: Development of higher psychological processes. Cambridge, MA: Harvard University Press

York-Barr, J. Bacharach, N., Salk, J., Hinz Frank, J., \& Benick, B. (2004). Team teaching in teacher education: General and special education faculty experiences and perspectives. Issues in Teacher Education, Spring 2004. 13(1), 73-94.

University of Kansas (1968) A Report of the Nineteenth Annual Kansas College Conference and Teacher Education and Professional Standards Conference on Teacher Education; An Examination of Standards and Evaluative Criteria for the Accreditation of Teacher Education, Kansas Advisory Council on Education; Kansas State Dept. of Public Instruction, Topeka.; Kansas State Teachers Association. 
Appendix A

\section{Consent Form}

Identification of Researchers: This research is being conducted by doctoral student Abby Volmer. I am with the Educational Leadership and Policy Analysis Department at the University of Missouri in conjunction with the University of Central Missouri.

Purpose of the Study: The purpose of this study will be to collect data on perceptions of how well the co-teaching student teaching model prepares student teachers for their first year of teaching.

Request for Participation: I am inviting you to participate in a survey and an interview. It is up to you whether you would like to participate. If you decide not to participate, you will not be penalized in any way. You can also decide to stop at any time without penalty. If you do not wish to answer any of the questions, you may simply skip them. You may withdraw your data at the end of the study. If you wish to do this, please tell me before you turn in your materials.

Exclusions: To participate in this study you must be a student teacher using the co- teaching model, a cooperating teacher who has used the co-teaching model of student teaching, a university supervisor who has supervised both traditional and co-teaching models of student teaching, first-third year teacher who used the co-teaching model of student teaching, or a principal who has been administrator to student teachers in both the traditional and co-teaching models of student teaching.

Description of Research Method: This study involves completing a 31 item survey taking approximately 10 minutes to complete. It will be followed up by either a 
one-on- one interview or focus group taking approximately 30-45 minutes.

Privacy: All of the information we collect will be confidential. We will not record your name with the data that is collected.

Explanation of Risks: The risks associated with participating in this study are similar to the risks of everyday life.

Explanation of Benefits: You will benefit from participating in this study by adding to the continual data of leadership research and the benefits of effective leadership.

Questions: If you have any questions about this study, please contact my advisor Dr. Sandy Hutchinson. She can be reached at hutchinson@ucmo.edu or at (816) 405-9306.

If you have any questions about your rights as a research participant, please contact the IRB at (573) 882-3181.

If you would like to participate, please sign a copy of this letter and return it to me. The other copy is for you to keep.

I have read this letter and agree to participate. Signature:

Date:

Reviewed 10/2010 JP 


\section{Appendix B}

Survey and Interview Questions and Prompts as They Relate to Research

Questions

RQ1. What are the perceptions of University of Central Missouri current and former student teachers on the co-teaching student-teaching model's ability to prepare student teachers for their first year of teaching?

RQ2. What are the perceptions of University of Central Missouri university supervisors on the co-teaching student-teaching model's ability to prepare student teachers for their first year of teaching?

RQ3. What are the perceptions of cooperating teachers on the co-teaching student- teaching model's ability to prepare student teachers for their first year of teaching?

\begin{tabular}{|c|l|l|l|l|}
\hline Quantitative Survey & RQ & RQ2 & RQ3 \\
\hline & & 1 & & \\
\hline & $\begin{array}{l}\text { Current and Former Student Teacher Beliefs } \\
\text { Regarding How Well the Co-Teaching Model of } \\
\text { Student Teaching Prepared Him or Her for His } \\
\text { or Her First Year of Teaching }\end{array}$ & $\mathrm{X}$ & & \\
\hline $\begin{array}{l}\text { Supervising and Cooperating Teachers' Beliefs } \\
\text { on How Well the Co-Teaching Model of Student } \\
\text { Teaching Prepares Student Teachers for First } \\
\text { Year of Teaching }\end{array}$ & & $\mathrm{X}$ & $\mathrm{X}$ \\
\hline
\end{tabular}

\begin{tabular}{|l|l|l|l|}
\hline Qualitative Interview Survey & RQ & RQ2 & RQ3 \\
\hline$\bullet \quad \begin{array}{l}\text { What comes to your mind first when } \\
\text { thinking about your student-teaching } \\
\text { experience and how well it has prepared you } \\
\text { to begin a class of your own for your first } \\
\text { year of teaching? }\end{array}$ & $\mathrm{X}$ & & \\
\hline
\end{tabular}




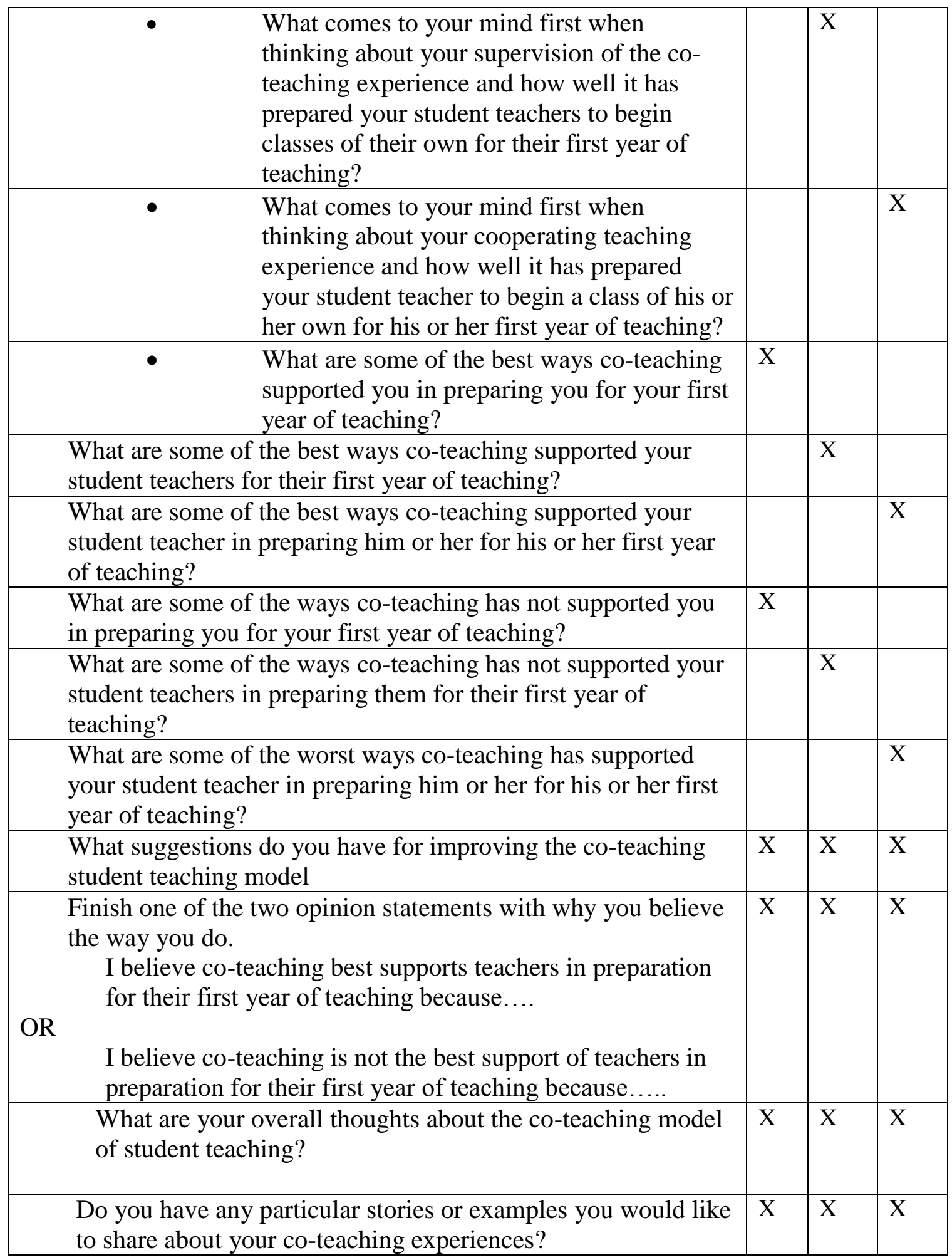




\section{Appendix C}

\section{Quantitative Surveys}

\section{Supervising and Cooperating Teachers' Beliefs on How Well the Co-Teaching}

\section{Model of Student Teaching Prepares Student Teachers for First Year of Teaching}

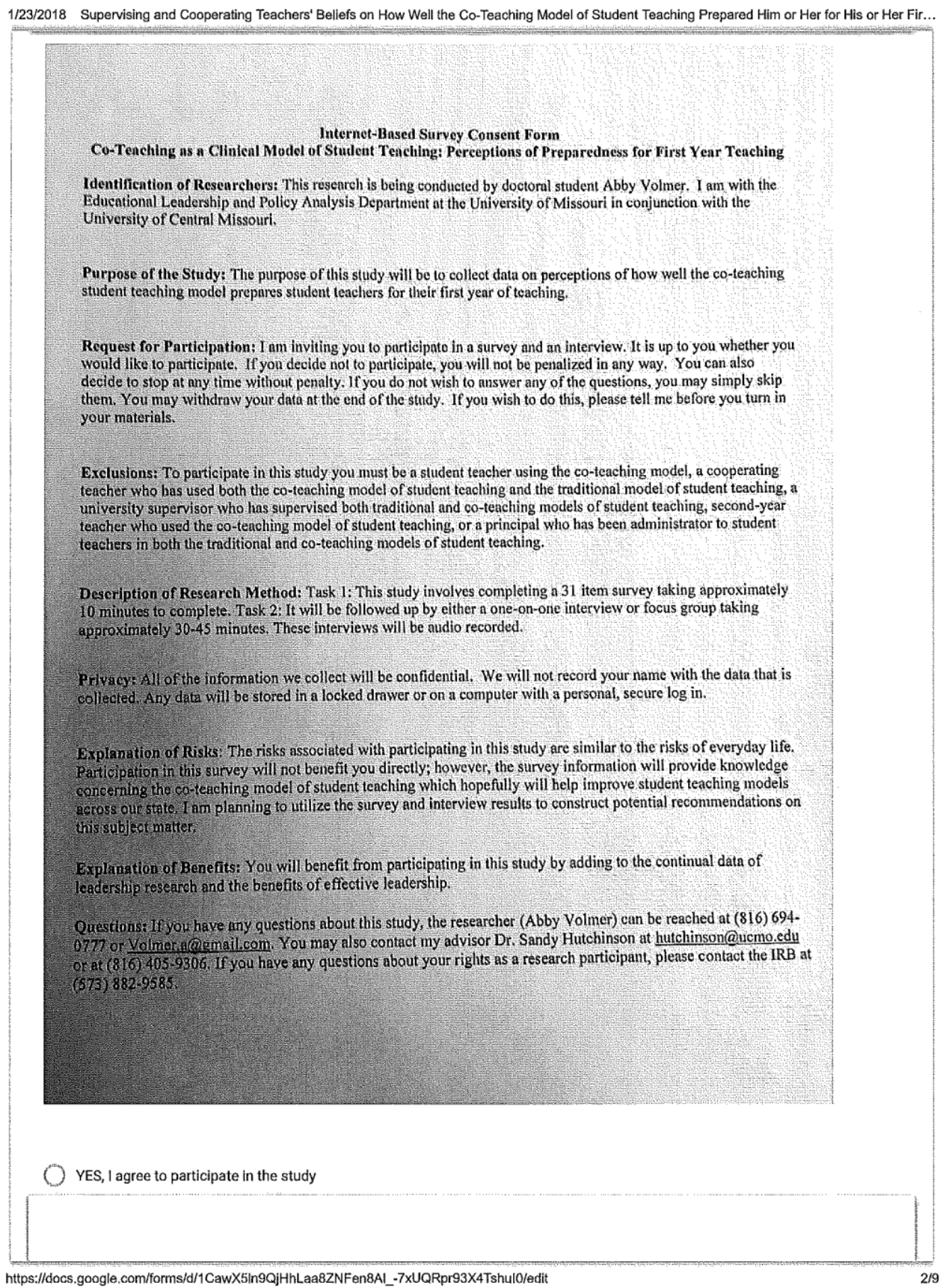


1/23/2018 Supervising and Cooperating Teachers' Beliefs on How Well the Co-Teaching Model of Student Teaching Prepared Him or Her for His or Her Fir...

Supervising and Cooperating Teachers' Beliefs on How Well the Co-Teaching Model of

$\begin{array}{lll}\text { QUESTIONS } & \text { RESPONSES } & 19\end{array}$

Section 1 of 2

Supervising and Cooperating Teachers' Beliefs on How Well the CoTeaching Model of Student Teaching Prepares Student Teachers for First Year of Teaching

Directions: This questionnaire is designed to help us gain a better understanding of the how well the co-teaching model prepares student-teacher for their first year of teaching. Please indicate your opinion about each of the statements below. Your answers are confidential.

Email address *

Valid email address

This form is collecting email addresses. Change settings

Question 


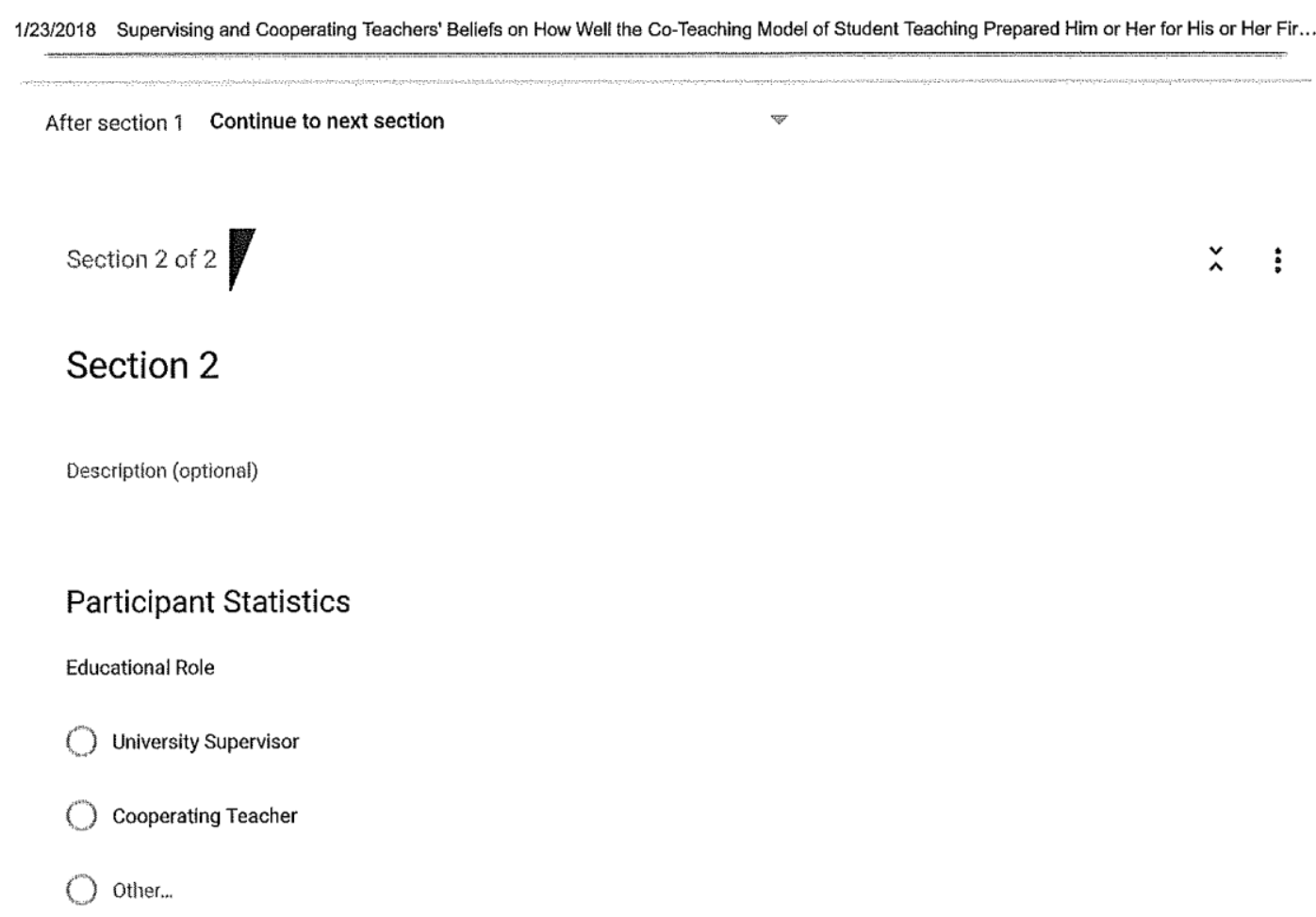

The co-teaching model supports student teacher and first year teacher independence 1

https://docs.google.com/forms/d/1CawX5In9QjHhLaa8ZNFen8AI_-7xUQRpr93X4Tshul0/edit 
1/23/2018 Supervising and Cooperating Teachers' Beliefs on How Well the Co-Teaching Model of Student Teaching Prepared Him or Her for His or Her Fir...

The co-teaching model supports student teacher and first year teacher independence * in knowing how to address misbehavior promptly and effectively with the least disruption of instruction.

$\begin{array}{lllllllllll} & 1 & 2 & 3 & 4 & 5 & 6 & 7 & 8 & 9 & \\ \text { Not at all } & \bigcirc & 0 & 0 & 0 & 0 & 0 & 0 & 0 & 0 & \text { A great deal }\end{array}$

The co-teaching model supports student teacher and first year teacher independence * in knowing how to manage time, space, transitions, and activities.

$\begin{array}{lllllllllll} & 1 & 2 & 3 & 4 & 5 & 6 & 7 & 8 & 9 & \\ \text { Not at all } & 0 & 0 & 0 & 0 & 0 & 0 & 0 & 0 & 0 & \text { A great deal }\end{array}$

The co-teaching model supports student teacher and first year teacher independence * in knowing how to develop a positive classroom and school culture.

$\begin{array}{lllllllllll} & 1 & 2 & 3 & 4 & 5 & 6 & 7 & 8 & 9 & \\ \text { Not at all } & 0 & 0 & 0 & 0 & 0 & 0 & 0 & 0 & 0 & \text { A great deal }\end{array}$

The co-teaching model supports student teacher and first year teacher independence * in knowing how to better understand the subject/s they teach

$\begin{array}{lllllllllll} & 1 & 2 & 3 & 4 & 5 & 6 & 7 & 8 & 9 & \\ \text { Not at all } & 0 & 0 & 0 & 0 & 0 & \bigcirc & 0 & 0 & 0 & \text { A great deal }\end{array}$

The co-teaching model supports student teacher and first year teacher independence * in knowing how to use specific instructional strategies to engage students.

https://docs.google.com/forms/d/1CawX5in9QjHhLaa8ZNFen8Al_-7xUQRpr93X4Tshul0/edit 
1/23/2018 Supervising and Cooperating Teachers' Beliefs on How Well the Co-Teaching Model of Student Teaching Prepared Him or Her for His or Her Fir...

The co-teaching model supports student teacher and first year teacher independence * in knowing how to work in teams to share and analyze data to inform gradedepartment level and/or school-wide decisions.

$\begin{array}{lllllllllll} & 1 & 2 & 3 & 4 & 5 & 6 & 7 & 8 & 9 & \\ \text { Not at all } & 0 & 0 & 0 & 0 & 0 & 0 & 0 & 0 & 0 & \text { A great deal }\end{array}$

The co-teaching model supports student teacher and first year teacher independence * in knowing how to use formative and summative assessments to gauge learner progress.

$\begin{array}{lllllllllll} & 1 & 2 & 3 & 4 & 5 & 6 & 7 & 8 & 9 & \\ \text { Not at all } & 0 & 0 & \bigcirc & 0 & 0 & \bigcirc & 0 & 0 & 0 & \text { A great deal }\end{array}$

The co-teaching model supports student teacher and first year teacher independence * in knowing how to use assessment data to plan instruction.

$\begin{array}{lllllllllll} & 1 & 2 & 3 & 4 & 5 & 6 & 7 & 8 & 9 & \\ \text { Not at all } & 0 & 0 & 0 & 0 & 0 & 0 & 0 & 0 & 0 & \text { A great deal }\end{array}$

The co-teaching model supports student teacher and first year teacher independence * in knowing how to create learning experiences aligned to state and district curriculum and assessments.

$\begin{array}{lllllllllll} & 1 & 2 & 3 & 4 & 5 & 6 & 7 & 8 & 9 & \\ \text { Not at all } & 0 & 0 & 0 & 0 & 0 & 0 & 0 & 0 & 0 & \text { A great deal }\end{array}$

The co-teaching model supports student teacher and first year teacher independence * in knowing how to apply instructional techniques that require students to think critically and problem-solve.

https://docs.google.com/forms/d/1CawX5In9QjHhLaa8ZNFen8AI_-7xUQRpr93X4Tshul0/edit 
1/23/2018 Supervising and Cooperating Teachers' Beliefs on How Well the Co-Teaching Model of Student Teaching Prepared Him or Her for His or Her Fir... Not at all
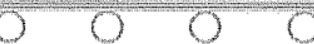

The co-teaching model supports student teacher and first year teacher independence * in knowing how to enhance student technological literacy.

$\begin{array}{lllllllllll} & 1 & 2 & 3 & 4 & 5 & 6 & 7 & 8 & 9 & \\ \text { Not at all } & 0 & 0 & 0 & 0 & 0 & 0 & 0 & 0 & 0 & \text { A great deal }\end{array}$

The co-teaching model supports student teacher and first year teacher independence * in knowing how to use a variety of learning structures, such as independent, small group, and whole class.

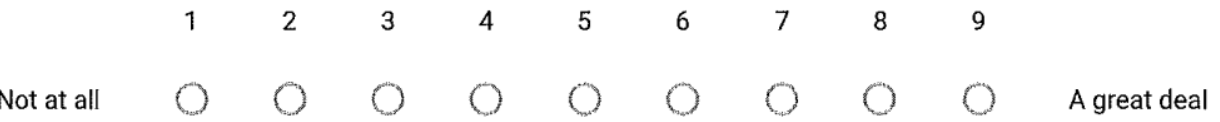

The co-teaching model supports student teacher and first year teacher independence * in knowing how to effectively communicate with students including students whose first language is not Standard English or whose disability requires specific forms of communication.

$\begin{array}{lllllllllll} & 1 & 2 & 3 & 4 & 5 & 6 & 7 & 8 & 9 & \\ \text { Not at all } & 0 & 0 & 0 & 0 & 0 & 0 & 0 & 0 & 0 & \text { A great deal }\end{array}$

The co-teaching supports student teacher and first year teacher independence in knowing how to facilitate student expression in speaking, writing, listening, and other media ensuring it adheres to district policy.

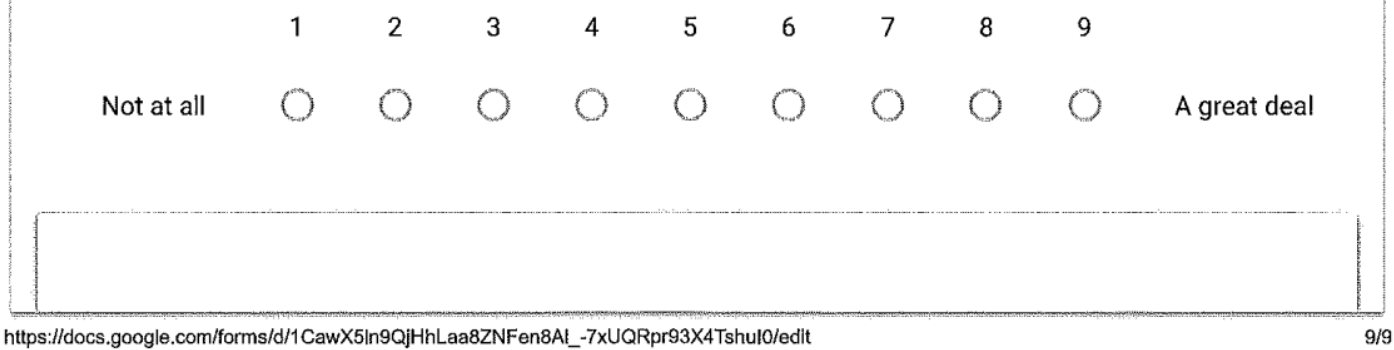




\section{Supervising and Cooperating Teachers Beliefs on How Well the Co- Teaching Model of}

\section{Student Teaching Prepares Student Teachers for Their First Year of Teaching}

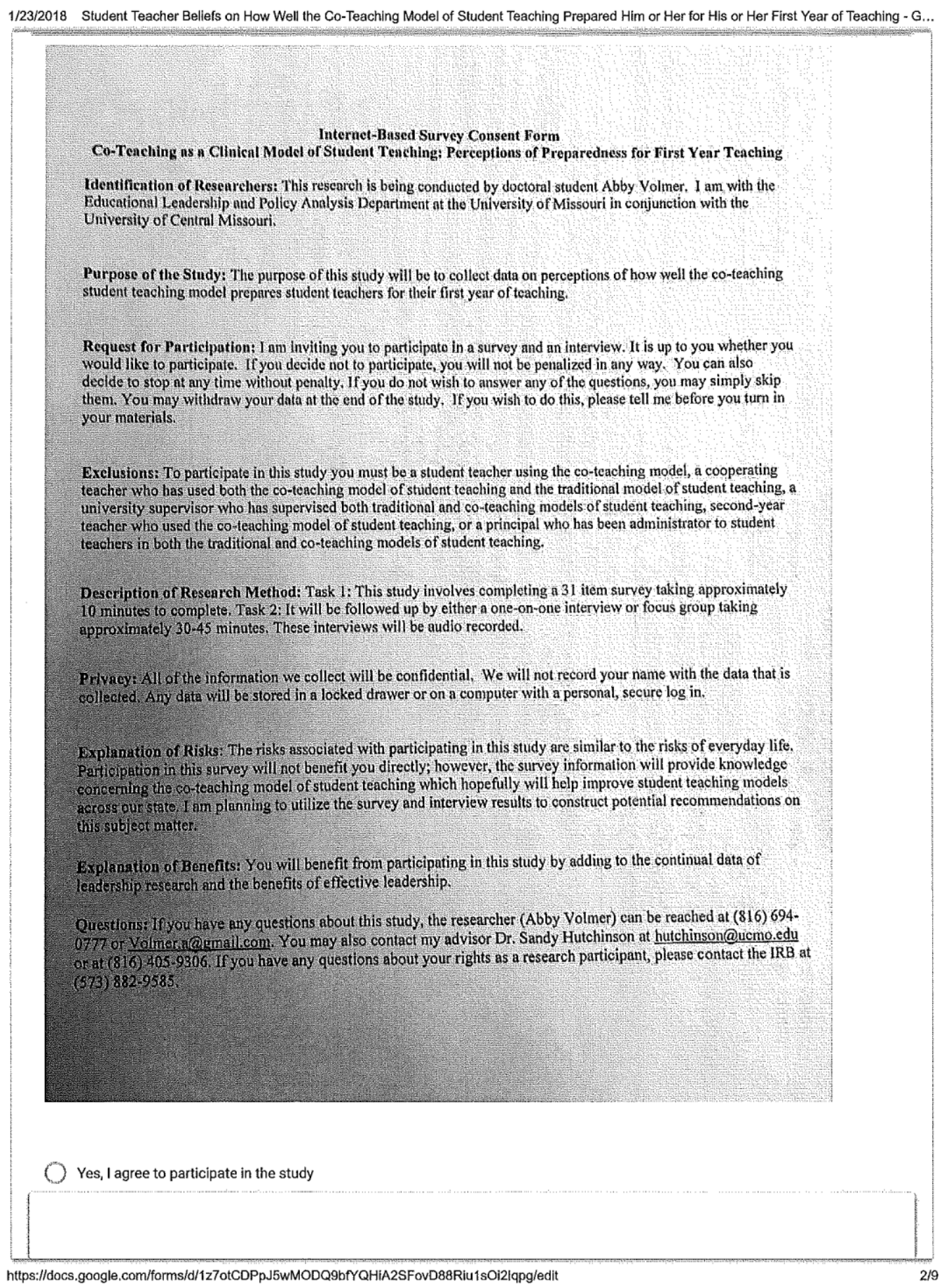


1/23/2018 Student Teacher Beliefs on How Well the Co-Teaching Model of Student Teaching Prepared Him or Her for His or Her First Year of Teaching - G...

After section 1 Continue to next section

\section{Section 2}

Description (optional)

Question

Long answer text

\section{Participant Statistics *}

Educational Role

Q Student Teacher

Q First-Year Teacher

S Second-Year Teacher

() Other...

\section{Participant Statistics *}

Grade level currently teaching

$\mathrm{K}-2$

3-5

6-8

9-12

https://docs.google.com/forms/d/1z7otCDPpJ5wMODQ9bFYHiA2SFovD88Riu1sOi2lqpg/edit 
1/23/2018 Student Teacher Beliefs on How Well the Co-Teaching Model of Student Teaching Prepared Him or Her for His or Her First Year of Teaching - G...

Other...

The co-teaching model supported my independence in knowing how to reflect on my classroom practice in order to modify future instruction.

$\begin{array}{lllllllllll} & 1 & 2 & 3 & 4 & 5 & 6 & 7 & 8 & 9 & \\ \text { Not at all } & 0 & 0 & 0 & 0 & 0 & 0 & 0 & 0 & 0 & \text { A great deal }\end{array}$

The co-teaching model helped me learn to use many resources for professional learning and enabled me to apply my new knowledge in the classroom.

$\begin{array}{lllllllllll} & 1 & 2 & 3 & 4 & 5 & 6 & 7 & 8 & 9 & \\ \text { Not at all } & 0 & 0 & 0 & 0 & 0 & 0 & 0 & 0 & 0 & \text { A great deal }\end{array}$

The co-teaching model supported me in knowing how to demonstrate professional and ethical behavior.

$\begin{array}{lllllllllll} & 1 & 2 & 3 & 4 & 5 & 6 & 7 & 8 & 9 & \\ \text { Not at all } & 0 & 0 & 0 & 0 & 0 & 0 & 0 & 0 & 0 & \text { A great deal }\end{array}$

The co-teaching model supported me in knowing how to build effective working relationships with students, families, school colleagues, and community members.

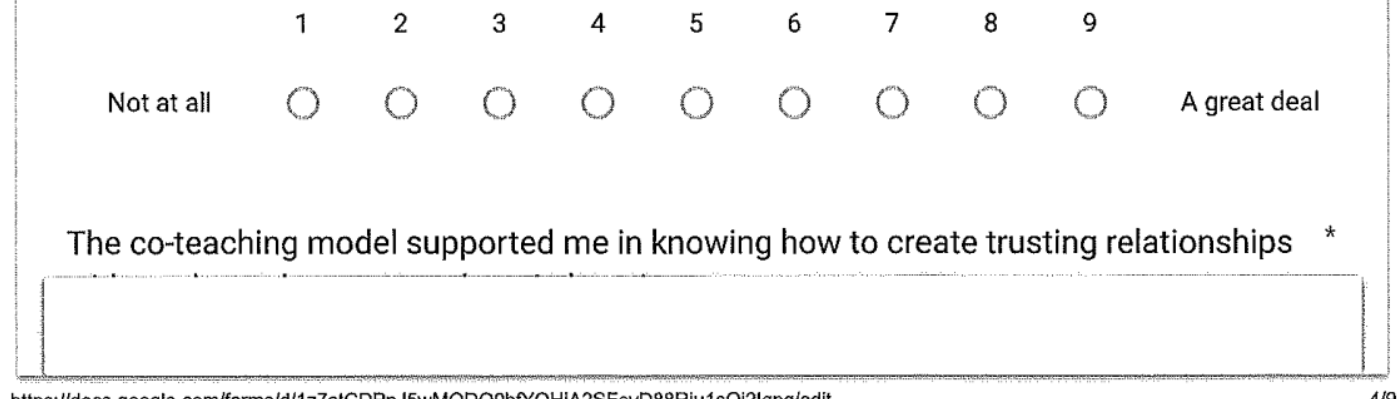

https://docs.google.com/forms/d/1z7otCDPpJ5wMODQ9bfYQHIA2SFovD88Riu1sOi2/qpg/edit 
1/23/2018 Student Teacher Beliefs on How Well the Co-Teaching Model of Student Teaching Prepared Him or Her for His or Her First Year of Teaching - G...

\begin{tabular}{|c|c|c|c|c|c|c|c|c|c|c|c|}
\hline & 1 & 2 & 3 & 4 & 5 & 6 & 7 & 8 & 9 & & \\
\hline Not at all & 0 & 0 & 0 & 0 & 0 & 0 & 0 & 0 & 0 & \multicolumn{2}{|l|}{ A great deal } \\
\hline \multicolumn{12}{|c|}{$\begin{array}{l}\text { The co-teaching model supported my independence in knowing how to address } \\
\text { misbehavior promptly and effectively with the least disruption of instruction. }\end{array}$} \\
\hline & 1 & 2 & 3 & 4 & 5 & 6 & 7 & 8 & 9 & & \\
\hline Not at all & 0 & 0 & 0 & 0 & 0 & 0 & 0 & 0 & 0 & \multicolumn{2}{|l|}{ A great deal } \\
\hline \multicolumn{12}{|c|}{$\begin{array}{l}\text { The co-teaching model supported my independence in knowing how to manage my * } \\
\text { time, classroom space, daily transitions, and activities. }\end{array}$} \\
\hline & 1 & 2 & 3 & 4 & 5 & 6 & 7 & 8 & 9 & & \\
\hline Not at all & 0 & 0 & 0 & 0 & 0 & 0 & 0 & 0 & 0 & A great deal & \\
\hline \multicolumn{12}{|c|}{$\begin{array}{l}\text { The co-teaching model supported my independence in knowing how to develop a } \\
\text { positive classroom and school culture. }\end{array}$} \\
\hline & 1 & 2 & 3 & 4 & 5 & 6 & 7 & 8 & 9 & & \\
\hline Not at all & 0 & 0 & 0 & 0 & 0 & 0 & 0 & 0 & 0 & A great deal & \\
\hline \multicolumn{12}{|c|}{$\begin{array}{l}\text { The co-teaching model supported me in knowing how to better understand the } \\
\text { subject/s I teach. }\end{array}$} \\
\hline & 1 & 2 & 3 & 4 & 5 & 6 & 7 & 8 & 9 & & \\
\hline Not at all & 0 & 0 & 0 & 0 & 0 & 0 & 0 & 0 & 0 & A great deal & \\
\hline \multicolumn{12}{|c|}{ The co-teaching model my independence in knowing how to use specific instructional * } \\
\hline
\end{tabular}




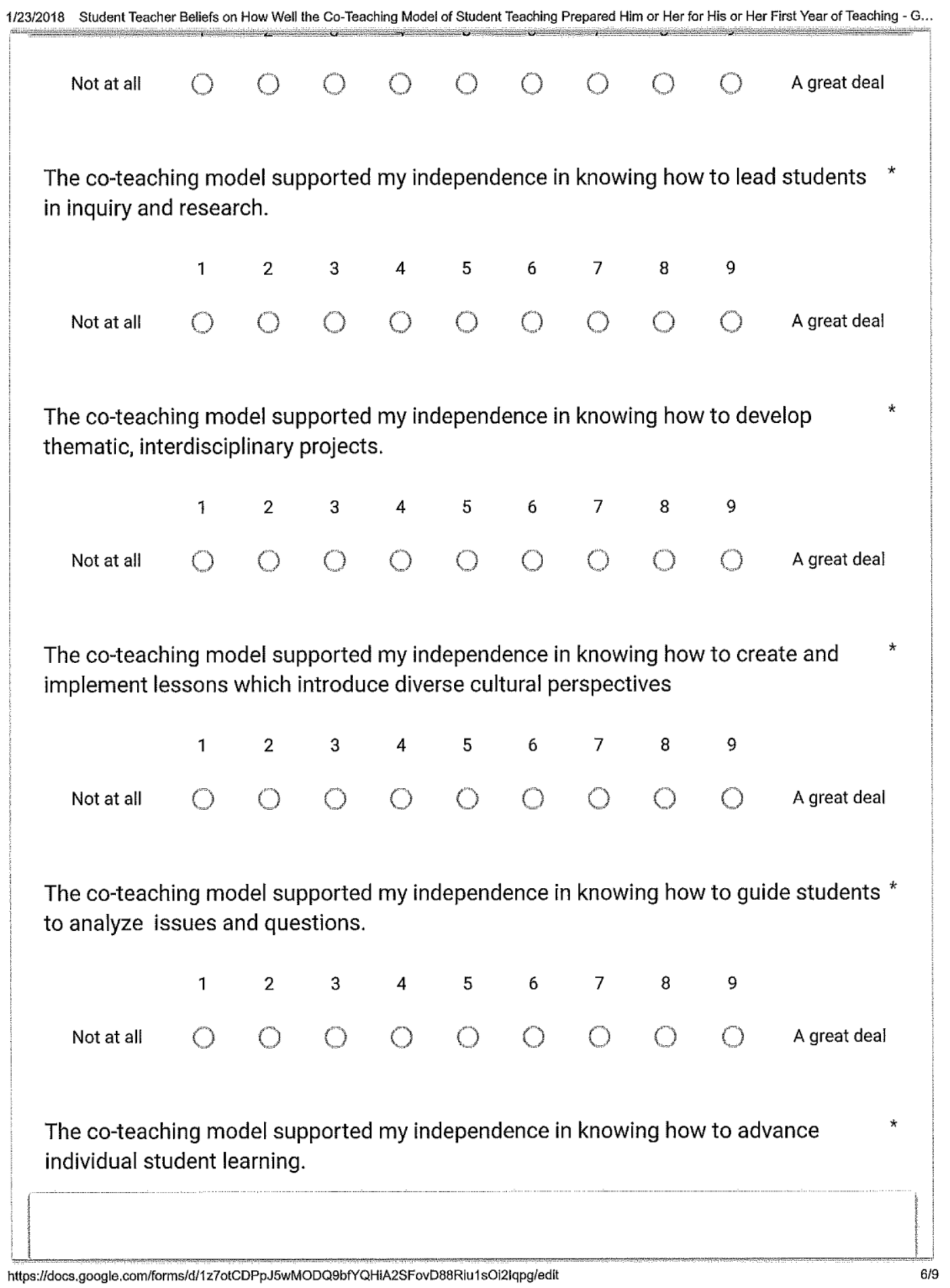




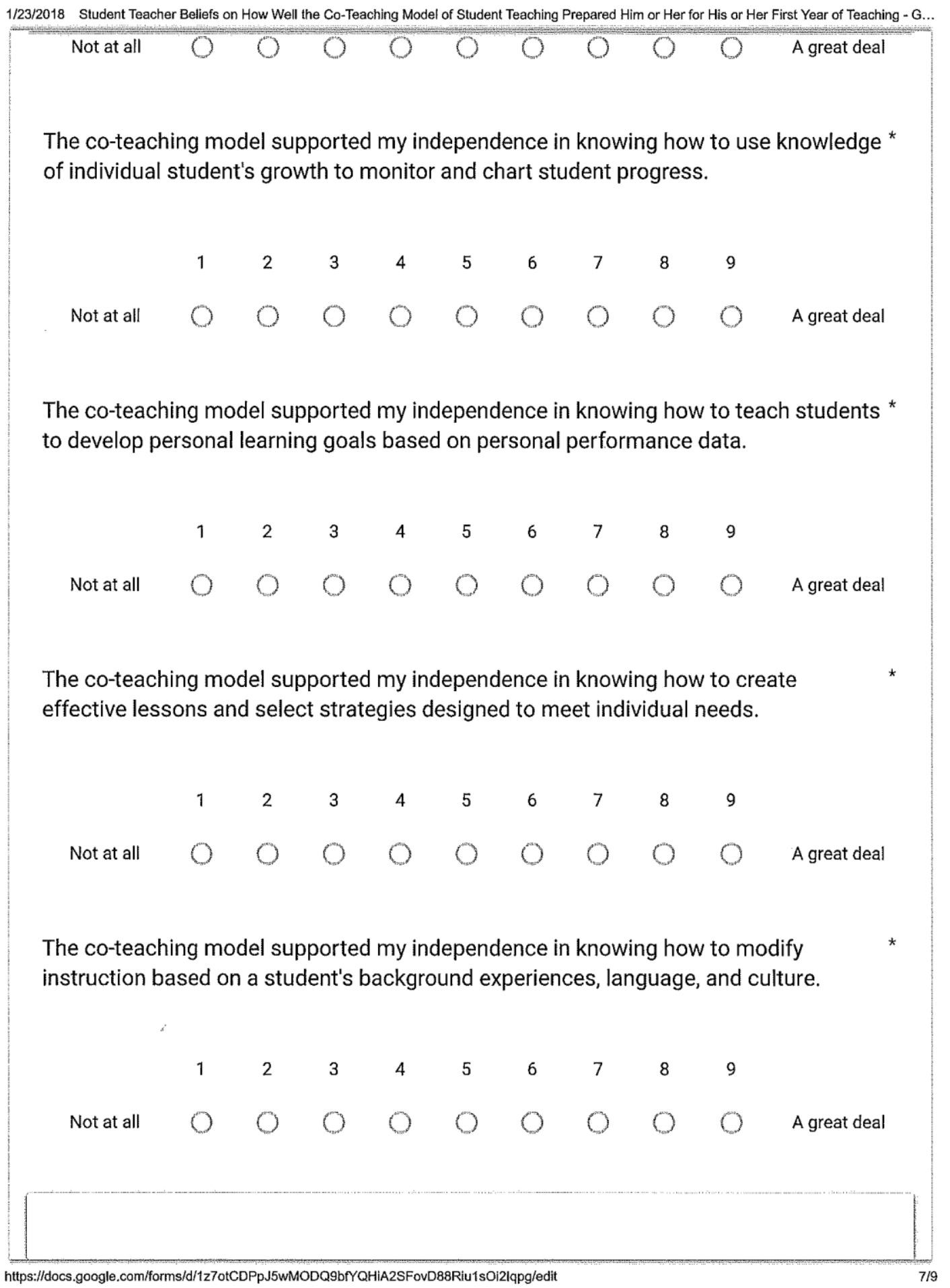


1/23/2018 Student Teacher Beliefs on How Well the Co-Teaching Model of Student Teaching Prepared Him or Her for His or Her First Year of Teaching - G...

to share and analyze data to inform grade-department level and/or school-wide

$\begin{array}{lllllllllll} & 1 & 2 & 3 & 4 & 5 & 6 & 7 & 8 & 9 & \\ \text { Not at all } & 0 & 0 & 0 & 0 & 0 & 0 & 0 & 0 & 0 & \text { A great deal }\end{array}$

The co-teaching model supported my independence in knowing how to use formative * and summative assessments to gauge learner progress

$\begin{array}{lllllllllll} & 1 & 2 & 3 & 4 & 5 & 6 & 7 & 8 & 9 & \\ \text { Not at all } & 0 & 0 & 0 & 0 & 0 & 0 & 0 & 0 & 0 & \text { A great deal }\end{array}$

The co-teaching model supported my independence in knowing how to use assessment data to plan instruction.

$\begin{array}{lllllllllll} & 1 & 2 & 3 & 4 & 5 & 6 & 7 & 8 & 9 & \\ \text { Not at all } & 0 & 0 & 0 & 0 & 0 & 0 & 0 & 0 & 0 & \text { A great deal }\end{array}$

The co-teaching model positively supported my independence in knowing how to create learning experiences aligned to state and district curriculum and assessments.

$\begin{array}{lllllllllll} & 1 & 2 & 3 & 4 & 5 & 6 & 7 & 8 & 9 & \\ \text { Not at all } & 0 & 0 & 0 & 0 & 0 & 0 & 0 & 0 & 0 & \text { A great deal }\end{array}$

The co-teaching model supported my independence in knowing how to apply instructional techniques that require students to think critically and problem-solve.

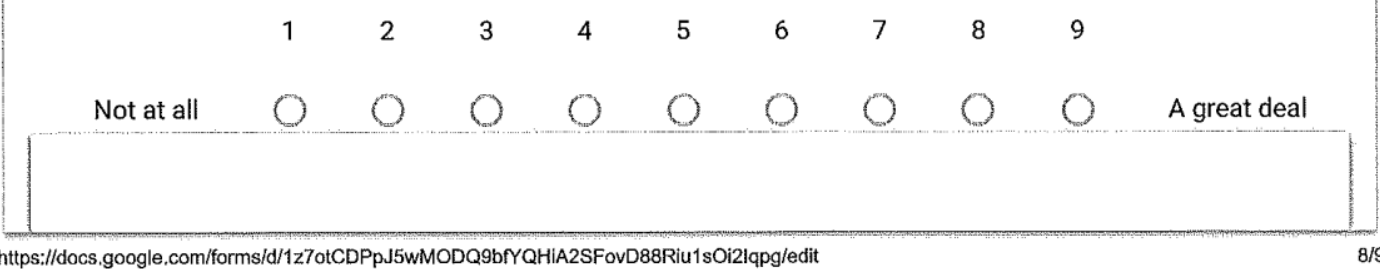


1/23/2018 Student Teacher Beliefs on How Well the Co-Teaching Model of Student Teaching Prepared Him or Her for His or Her First Year of Teaching - G... The co-teaching model supported my independence in knowing how to enhance student technological literacy.

$\begin{array}{llllllllll}1 & 2 & 3 & 4 & 5 & 6 & 7 & 8 & 9\end{array}$

Not at all 000000000000 A great deal

The co-teaching model supported my independence in knowing how to use a variety of * learning situations, such as independent, small group, and whole class.

$\begin{array}{lllllllllll} & 1 & 2 & 3 & 4 & 5 & 6 & 7 & 8 & 9 & \\ \text { Not at all } & 0 & 0 & 0 & 0 & 0 & 0 & 0 & 0 & 0 & \text { A great deal }\end{array}$

The co-teaching model supported my independence in knowing how to effectively communicate with students including students whose first language is not Standard English or whose disability requires specific forms of communication.

$\begin{array}{lllllllllll} & 1 & 2 & 3 & 4 & 5 & 6 & 7 & 8 & 9 & \\ \text { Not at all } & 0 & 0 & 0 & 0 & 0 & 0 & 0 & 0 & 0 & \text { A great deal }\end{array}$

The co-teaching model supported my independence in knowing how to facilitate student expression in speaking, writing, listening, and other media, ensuring it adheres to district policy.

It supported my independence in knowing how to facilitate student expression in speaking, writing, listening, and other media, ensuring it adheres to district policy.

$\begin{array}{lllllllllll} & 1 & 2 & 3 & 4 & 5 & 6 & 7 & 8 & 9 & \\ \text { Not at all } & 0 & 0 & 0 & 0 & 0 & 0 & 0 & 0 & 0 & \text { A great deal }\end{array}$

The co-teaching model supported my independence in knowing how to model and

https://docs.google.com/forms/d/1z7otCDPpJ5wMODQ9bfYQHiA2SFovD88Riu1sOi2lqpg/edit 


\section{Appendix D}

\section{Qualitative Interview Prompts/Questions}

\section{Current and Former Student Teachers}

\section{Background/Demographic Questions}

1. What is your major? Was your school district in which you taught urban, suburban, town, or rural? Suburban/urban

2. In what grade level and/or subject area did you do your student teaching?

3. About how many students did you teach a day? Descriptive History:

4. Explain how your personal role in the co-teaching student-teaching experience began and how it changed throughout the semester.

5. Explain the how the role of your cooperating teacher in co-teaching began and how it changed throughout the semester.

\section{Thoughts and Opinions}

6. What comes to your mind first when thinking about your student-teaching experience and how well it has prepared you to begin a class of your own for your first year of teaching?

7. What are some of the best ways co-teaching supported you in preparing you for your first year of teaching?

8. What are some ways co-teaching has not supported you in preparing you for your first year of teaching

9. What suggestions do you have for improving the co-teaching student teaching model?

10. Finish one of the two opinion statements with why you believe the way 
you do.

a. I believe co-teaching best supports teachers in preparation for their first year of teaching because....

OR

b. I believe co-teaching is not the best support of teachers in preparation for their first year of teaching because.....

11. What are your overall thoughts about the co-teaching model of student teaching?

12. Do you have any particular stories or examples you would like to share about your co-teaching experiences?

13. Is there anything else you would like to share? 


\section{Appendix E \\ Qualitative Interview Prompts/Questions \\ Cooperating Teachers}

Background/Demographic Questions

1. What grade level or content area do you teach?

2. Is the school district in which you teach urban, suburban, town, or rural?

3. How many years have you been teaching?

4. About how many students do you teach a day?

5. Have you had a student teacher other than your latest from UCM? If so, have you had any who have not used the co-teaching model?

Descriptive History:

6. Explain how your personal role in the co-teaching student-teaching experience began and how it changed throughout the student teacher in coteaching began and how it changed throughout the semester.

Thoughts and Opinions

7. What comes to your mind first when thinking about your cooperating teaching experience and how well it has prepared your student teacher to begin a class of his or her own for his or her first year of teaching?

8. What are some of the best ways co-teaching supported your student teacher in preparing him or her for his or her first year of teaching?

9. What are some of the worst ways co-teaching has supported your student teacher in preparing him or her for his or her first year of teaching?

10. What suggestions do you have for improving the co-teaching student 
teaching model?

11. Finish one of the two opinion statements with why you believe the way you do.

a. I believe co-teaching best supports teachers in preparation for their first year of teaching because....

OR

b. I believe co-teaching is not the best support of teachers in preparation for their first year of teaching because.....

12. What are your overall thoughts about the co-teaching model of student teaching?

13. Do you have any particular stories or examples you would like to share about your co-teaching experiences?

14. Is there anything else you would like to share? 


\section{Appendix F}

Qualitative Interview Prompts/Questions

$$
\text { University Supervisors }
$$

\section{Background/Demographic Questions}

1. What grade levels have you supervised in the co-teaching model?

2. Are the school districts in which you supervised urban, suburban, town, or rural?

3. How many years have you been supervising student teachers?

4. About how many student teachers do you supervise a semester?

5. Have you ever supervised a student teacher who has not used the coteaching model?

Descriptive History:

6. Explain your personal history in the co-teaching student-teaching experience at UCM.

7. Explain your role now in the co-teaching student-teaching experience at UCM.

8. Explain your perception of the student teacher's role in the co-teaching student-teaching experience at UCM.

9. Explain your perception of cooperating teacher's role in the co-teaching student -teaching experience at UCM.

\section{Thoughts and Opinions}

10. What comes to your mind first when thinking about your supervision of the co- teaching experience and how well it has prepared your student 
teachers to begin classes of their own for their first year of teaching?

11. What are some of the best ways co-teaching supported your student teachers for their first year of teaching?

12. What are some of the ways co-teaching has not supported your student teachers in preparing them for their first year of teaching?

13. What suggestions do you have for improving the co-teaching student teaching model?

14. Finish one of the two opinion statements with why you believe the way you do.

a. I believe co-teaching best supports teachers in preparation for their first year of teaching because....

OR

b. I believe co-teaching is not the best support of teachers in preparation for their first year of teaching because.....

15. What are your overall thoughts about the co-teaching model of student teaching?

16. Do you have any particular stories or examples you would like to share about your co-teaching experiences?

17. Is there anything else you would like to share? 


\section{Appendix G}

\section{Findings}

\section{Quantitative Survey Data Analysis}

Descriptive statistics, One-Way ANOVA, One-Way Repeated Measures

ANOVA, and $t$-Tests were used to analyze the quantitative survey results. The Likerttype responses were treated as continuous (Fink, 2013) and each participant group's (current and former student teachers, cooperating teachers, university supervisors) set of data were entered into a spreadsheet. The median, mode, and mean were determined in the frequency distribution of the data (Field, 2013).

\section{Respondent Group Perceptions of Effectiveness}

To determine if the respondent groups of student teachers, cooperating teachers, university teachers, and the total response group perceived the co-teaching model as effective in preparing the student teacher for first year teaching, the researcher ran a Single Sample $t$-Test. The labeling of the Likert-style scale named a (5) as "somewhat effective." A (5) and above was considered the range for perceiving the co-teaching model as effective. The (5) mean was then compared to each group member's means. If the test found the results Significant, the group results were determined to be high enough to perceive the co-teaching model of student teaching as effective in preparing student teachers for first year teaching. The results were as follows: 


\begin{tabular}{|l|l|l|l|l|}
\hline \multicolumn{5}{|l|}{ Table G1 } \\
$\begin{array}{l}\text { Respondent Groups' Perceptions of Effectiveness of Co-Teaching Model of Student } \\
\text { Teaching }\end{array}$ & & & & \\
\hline & t-Value & p-Value & Significant & Effective \\
\hline Respondent Group & 4.80 & $9.6 \mathrm{E}-05$ & $\mathrm{Y}$ & $\mathrm{Y}$ \\
\hline Student Teachers & 8.57 & .00001 & $\mathrm{Y}$ & $\mathrm{Y}$ \\
\hline Cooperating Teachers & -0.12 & 0.91 & $\mathrm{~N}$ & $\mathrm{~N}$ \\
\hline University Supervisors & 5.64 & .00001 & $\mathrm{Y}$ & $\mathrm{Y}$ \\
\hline Total Respondent Group & & & & \\
\hline
\end{tabular}

Comparing Respondent Group (Roles) Perceptions: To compare the overall perceptions between three independent respondent groups in how well the co-teaching model of student teaching prepares teaching candidates for their first year of teaching, the One-Way ANOVA statistical analysis was used. The three respondent groups were composed as such:

Group one roles (ST). Current and former student teachers who completed their student teaching experience using the co-teaching clinical model of student teaching.

Group two role $(\boldsymbol{C T})$. Cooperating teachers who have used the co-teaching model of student teaching with their student teachers in their classroom

Group three role (US). University supervisors who supervise student teachers who have used the co-teaching model in their student teaching experience.

The first data set entered was the overall survey mean values for respondent Group One members (current and former student teachers). The second data set consisted of the overall mean values for respondent Group Two members (cooperating teachers), 
and the third data set entered was composed of the overall mean values for respondent Group Three members (university supervisors).

Table G2

Respondent Group (Roles) Perceptions One-Way ANOVA Descriptives Table

\begin{tabular}{|ccccc|}
\hline & $1(S T)$ & $2(C T)$ & $3($ US $)$ & Total \\
\hline $\mathrm{N}$ & 22 & 14 & 5 & 41 \\
$\mathrm{x}$ & 147.47 & 103.58 & 24.03 & 275.08 \\
Mean & 6.70 & 7.40 & 4.81 & 6.71 \\
$\sum \mathrm{x}^{2}$ & 1046.79 & 780.60 & 168.97 & 1996.36 \\
Std. Dev. & 1.67 & 1.05 & 3.66 & 1.94 \\
\hline
\end{tabular}

Table G3

Respondent Group (Roles) Perceptions One-Way ANOVA Result Details Table

\begin{tabular}{|lccc|c|}
\hline Source & $\begin{array}{c}\text { SS (Sum of } \\
\text { Squares })\end{array}$ & $\begin{array}{c}\text { Df(Degrees of } \\
\text { Freedom) }\end{array}$ & MS (Mean Square) & \\
\hline $\begin{array}{l}\text { Between- } \\
\text { treatments }\end{array}$ & 24.76 & 2 & 12.38 & $F=3.73$ \\
$\begin{array}{l}\text { Within- } \\
\text { treatments }\end{array}$ & 126.01 & 38 & 3.31 & \\
Total & 150.77 & 40 & & \\
\hline
\end{tabular}

ANOVA Test results showed an $f$-value (variation between sample means) of 5.73 and a significance value ( $p$-value) of .033 indicating a significant difference across the three groups of respondents in perceptions of how well the co-teaching model of student teaching prepares teaching candidates for their first year of teaching.

\section{Comparing Two Respondent Group Perceptions for Significant Differences:}

The ANOVA results prompted the use of three $t$-Tests to explain what the group differences were in relation to the ANOVA result of significant differences. The $t$-Tests 
were used to compare the averages (means) of the perceptions of two respondent groups on how well the co-teaching model of student teaching prepares student teachers for their first year of teaching.

Student teachers/Cooperating teachers group perceptions $t$-Test: The first set of values was the overall numeric means for current and former student teachers. The second set of values was overall numeric means for cooperating teachers.

Table G4

Student Teachers/Cooperating Teachers Group Perceptions $t$-Test Descriptive Table

\begin{tabular}{|lcccccc|}
\hline & $N$ & $d f$ & $M$ & $S S$ & $S^{2}$ \\
\hline Student Teachers & 22 & 21 & 6.7 & 58.27 & 2.77 \\
Cooperating Teachers & 14 & 13 & 7.4 & 14.25 & 1.1 \\
\hline The $t$-value is -1.39 . The $p$-value is .086. The result is not significant at $p<.05$. & \\
\hline
\end{tabular}

Student teacher/University supervisor group perceptions t-Test: The first set of values was the overall numeric means for current and former student teachers. The second set of values was overall numeric means for cooperating teachers.

Table G5

Student Teachers/University Supervisors Group Perceptions t-Test Descriptive Table

\begin{tabular}{|c|c|c|c|c|c|}
\hline & $N$ & $d f$ & $M$ & $S S$ & $S^{2}$ \\
\hline Student Teachers $/ 1^{\text {st }} 3^{\text {rd }}$ Year Teachers & 22 & 21 & 6.7 & 58.27 & 2.77 \\
\hline University Supervisors & 5 & 4 & 4.81 & 53.48 & 13.37 \\
\hline
\end{tabular}

The $t$-value is 1.81116 . The $p$-value is .041075 . The result is significant at $p<.05$. 
Cooperating teachers/University supervisors group perceptions t-Test: The first set of values was the overall numeric means for cooperating teachers. The second set of values was overall numeric means for university supervisors.

\section{Table G6}

Cooperating Teachers/University Supervisors Group Perceptions t-Test Descriptive Table

\begin{tabular}{|llllll|}
\hline & $N$ & $d f$ & $M$ & $S S$ & $S^{2}$ \\
\hline Cooperating Teachers & 14 & 13 & 7.4 & 14.25 & 1.1 \\
University Supervisors & 5 & 4 & 4.81 & 53.48 & 13.37
\end{tabular}

The $t$-value is 2.49294 . The $p$-value is .011641 . The result is significant at $p<05$.

The $t$-Test results showed no significant difference between the student teachers and cooperating teachers' perceptions of how well the co-teaching model of student teaching prepares student teachers for their first year of teaching. The $t$-Tests did show, however, a significant difference between the student teachers' perceptions compared to the university supervisors' perceptions with the university supervisors scoring a mean score lower than the student teacher by 1.89 , a $p$-value of .041075 . There was also a significant difference between the cooperating teachers' perception compared to the university supervisors' perceptions. The greatest difference was found between the cooperating teachers' perceptions and the university teachers' perception with the $p$-value of .011641 , the university supervisors scoring a mean score lower than cooperating teachers by 2.59 . 


\section{Comparing Respondents' Perceptions by Grade Level Groups: To compare}

the overall perceptions of how well the co-teaching model of student teaching prepares teaching candidates for their first year of teaching between three independent respondent groups divided into the grade levels with which they work, the One-Way ANOVA statistical analysis was used. The respondents were divided into three groups:

Group One (K-8): Works within the grade levels K-8.

Group Two (9-12): Works within the grade levels 9-12.

Group Three (K-12): Works within the grade levels K-12.

Set one data set was the overall survey mean values for respondent Group One (K-8). Set two data set consisted of the overall mean values for respondent Group Two (9-12), and set three data set was composed of the overall mean values for respondent Group Three (K-12).

Table G7

Respondents' Perceptions by Grade Level One-Way ANOVA Descriptives Table

\begin{tabular}{|c|c|c|c|c|}
\hline & $\begin{array}{c}\text { Group } \\
1 \\
(K-8)\end{array}$ & $\begin{array}{c}\text { Group } \\
2 \\
(9-12)\end{array}$ & $\begin{array}{c}\text { Group } \\
3 \\
(K-12)\end{array}$ & Total \\
\hline $\mathrm{N}$ & 17 & 7 & 6 & 30 \\
\hline$\sum x$ & 131.12 & 35.62 & 34.13 & 200.87 \\
\hline Mean & 7.71 & 5.09 & 5.69 & 6.70 \\
\hline$\sum \mathrm{x}^{2}$ & 1027.13 & 210.70 & 241.60 & 1479.44 \\
\hline $\begin{array}{l}\text { Std. } \\
\text { Dev. }\end{array}$ & 0.99 & 2.22 & 3.08 & 2.15 \\
\hline
\end{tabular}




\begin{tabular}{|l|l|l|}
\hline \multicolumn{3}{|l|}{ Table G8 } \\
Respondents' Perceptions by Grade Level One-Way ANOVA Result Details Table
\end{tabular}

\section{Comparing Two Respondent Grade Level Group Perceptions for Significant}

Differences: The ANOVA results prompted the use of three $t$-Tests to explain what the group differences were in relation to the ANOVA result of significant differences. The $t$ Tests were used to compare the averages (means) of the perceptions of two grade level respondent groups on how well the co-teaching model of student teaching prepares student teachers for their first year of teaching.

Grades $K-8 / K-12$ respondents $t$-Test: The first set of values was the overall numeric means for respondents who worked with grade levels K-8. The second set of values was overall numeric means for respondents who worked with grade levels K-12. 
Table G9

Grades K-8/K-12 Respondents t-Test Descriptive Table

\begin{tabular}{|llllll|}
\hline & $N$ & $d f$ & $M$ & $S S$ & $S^{2}$ \\
\hline K-8 & 17 & 16 & 7.71 & 15.81 & 0.99 \\
K-12 & 6 & 5 & 5.69 & 47.46 & 9.49 \\
\hline
\end{tabular}

The $t$-value is 2.45627 . The $p$-value is .011415 . The result is significant at $p<.05$.

Grades K-8/9-12 Respondents $t$-Test: The first set of values was the overall numeric means for respondents who worked with grade levels K-8. The second set of values was overall numeric means for respondents who worked with grade levels 9-12.

Table G10

Grades K-8/9-12 Respondents t-Test Descriptive Table

\begin{tabular}{|l|c|c|c|c|c|}
\hline \multicolumn{1}{|c|}{} & $N$ & $d f$ & $M$ & $S S$ & $S_{2}$ \\
\hline K-8 & 17 & 16 & 7.71 & 15.81 & 0.99 \\
\hline $9-12$ & 7 & 6 & 5.09 & 29.45 & 4.91 \\
\hline
\end{tabular}

The $t$-value is 4.07438 The $p$-value is .000252 . The result is significant at $p<.05$.

Grades 9-12/K-12 t-Test: The first set of values was the overall numeric means for respondents who worked with grade levels 9-12. The second set of values was overall numeric means for respondents who worked with grade levels K-12. 
Table G11

Grades 9-12/K-12 t-Test Three Descriptive Table

\begin{tabular}{|cccccc|}
\hline & $N$ & $d f$ & $M$ & $S S$ & $S^{2}$ \\
\hline $9-12$ & 7 & 6 & 5.09 & 29.45 & 4.91 \\
$\mathrm{~K}-12$ & 6 & 5 & 5.69 & 47.46 & 9.49 \\
\hline
\end{tabular}

The $t$-value is -0.4077 . The $p$-value is .345658 . The result is not significant at $p<.05$.

The $t$-Tests did show a significant difference between those who worked with grades K-8 perceptions compared to those who worked with grades K-12 perceptions with the $p$-value of .011415 and a mean difference of 2.02. The greatest significant difference was found between the K-8 group perceptions and the 9-12 group perception with the $p$-value of .000252 and a mean difference of 2.62. The $t$-Test results, however, showed no significant difference between those who worked with grade levels 9-12 and those who worked with grade levels K-12 of how well the co-teaching model of student teaching prepares student teachers for their first year of teaching.

\section{Comparing Respondents' Perceptions by Educational Concepts Categories:}

Finally, a comparison was made between the respondents' perceptions of the ability to prepare student teachers for their first year of teaching in relation to five overarching educational concepts addressed in the survey. The five overarching concepts were as follows:

Group One (PR): Professionalism and Collaboration Group Two (CM): Classroom Management Group Three (CK/IS): Content Knowledge and Instructional Strategies 
Group Four (SLG): Student Learning Goals

Group Five (CR/LP): Curriculum and Lesson Planning

The One-Way Repeated Measures ANOVA statistical analysis was used. The same data set of all respondents' means were used in each treatment.

Table G12

Respondents' Perceptions by Educational Concepts Summary of Data

\begin{tabular}{|c|c|c|c|c|c|c|}
\hline & \multicolumn{6}{|c|}{ Treatments } \\
\hline & (PR) & $(\mathrm{CM})$ & $(\mathrm{CK} / \mathrm{IS})$ & (SLG) & (CR/LP) & Total \\
\hline $\mathrm{N}$ & 41 & 41 & 41 & 41 & 41 & 205 \\
\hline$\sum x$ & 283.5 & 280.5 & 268.95 & 272 & 280.14 & 1385.09 \\
\hline Mean & 6.91 & 6.84 & 6.56 & 6.63 & 6.83 & 6.76 \\
\hline$\sum \mathrm{x}^{2}$ & 2133.25 & 2103.88 & 1919.97 & 1953.76 & 2059.84 & 10170.69 \\
\hline Std. Dev. & 2.08 & 2.15 & 1.97 & 1.93 & 1.91 & 2.0 \\
\hline
\end{tabular}

\section{Table G13}

Respondents' Perceptions by Educational Concepts: One-Way Repeated Measures ANOVA Results Details

\begin{tabular}{|c|c|c|c|c|}
\hline Source & $S S$ & $d f$ & $M S$ & \\
\hline $\begin{array}{l}\text { Between } \\
\text { Treatments }\end{array}$ & 3.76 & 4 & 0.94 & $F=0.58024$ \\
\hline Within-treatments & 808.51 & 200 & 4.043 & \\
\hline Error & 259.20 & 160 & 1.62 & \\
\hline
\end{tabular}


The data revealed that each respondent generally rated the items closely across educational concepts and thus did not show a significant difference on how they perceived the co-teaching student teaching model prepares the first year teacher in any particular educational concept. The means of the respondents' ratings by educational concept, however, were as listed in the table below:

Table G14

Respondents' Perceptions by Educational Concepts Means

\begin{tabular}{|l|c|c|c|c|}
\hline & $\begin{array}{l}\text { Overall } \\
\text { Mean }\end{array}$ & $\begin{array}{l}\text { Student } \\
\text { Teacher } \\
\text { Means }\end{array}$ & $\begin{array}{l}\text { Cooperating } \\
\text { Teachers }\end{array}$ & $\begin{array}{l}\text { University } \\
\text { Supervisors }\end{array}$ \\
\hline $\begin{array}{l}\text { Professionalism } \\
\text { and } \\
\begin{array}{l}\text { Collaboration } \\
\text { (PR) }\end{array}\end{array}$ & 6.91 & 7.03 & 7.43 & 4.95 \\
\hline $\begin{array}{l}\text { Classroom } \\
\text { Management } \\
\text { (CM) }\end{array}$ & 6.84 & 6.90 & 7.20 & 5.00 \\
\hline $\begin{array}{l}\text { Content } \\
\text { Knowledge and } \\
\text { Instructional } \\
\begin{array}{l}\text { Strategies } \\
\text { (CK/IS) }\end{array}\end{array}$ & 6.56 & 6.55 & 7.32 & 4.47 \\
\hline $\begin{array}{l}\text { Student } \\
\text { Learning Goals } \\
\text { (SLG) }\end{array}$ & 6.63 & 6.45 & 7.57 & 4.84 \\
\hline Assessment/Data & 6.20 & 6.18 & 7.57 & 4.87 \\
\hline $\begin{array}{l}\text { Curriculum and } \\
\text { Lesson Planning } \\
\text { (CR/LP }\end{array}$ & 6.83 & 6.94 & 7.37 & 4.86 \\
\hline
\end{tabular}


Overall, professionalism and collaboration educational concepts were ranked the most positively influenced by the co-teaching model in preparing student teachers for their first year of teaching. Student teachers also ranked professionalism and collaboration as the highest preparation factor. University supervisors found classroom management to most positively influenced by the co-teaching model in preparing student teaches for their first year of teaching. Cooperating teachers ranked both Student Learning Goals use as most positively influenced by the co-teaching model in preparing student teachers for their first year of teaching.

Summary of Quantitative Data: In summary, the quantitative data revealed that current and former student teachers, cooperating teachers, and the overall respondent group total perceive the co-teaching student teaching model as effective. In contrast, the university supervisors do not perceive the model as effective in preparing student teachers for first year teaching.

Additionally, the quantitative data revealed that current and former student teachers and cooperating teachers significantly scored co-teaching higher than did university supervisors in the co-teaching model's ability to support first year teachers. The student teachers' overall mean for the co-teaching model's ability to support first year teachers was 6.70 out of 9 and the cooperating teachers' overall mean was 7.40 out of 9. The university supervisors' overall mean was 4.80 out of 9 . The cooperating teachers' and student teachers' means proved to be significantly higher than the university supervisors' means in rating the co-teaching model's ability to support first year teachers. 
K-8 respondents significantly scored co-teaching higher in its ability to support first year teachers than did K-12 or 9-12 respondents. The K-8 respondents' overall mean was 7.71 out of 9 while the $9-12$ respondents' mean was 5.09 out of 9 and the K-12 respondents mean was 5.69 out of 9 . The K-8 overall mean proved to be significantly higher than the 9-12 or K-12 respondents' overall means in rating the co-teaching model's ability to support first year teachers.

In relation to the Missouri Learning Standards educational concepts categories of professionalism and collaboration, classroom management, content knowledge and instructional strategies, student learning goals, and curriculum and lesson planning, there was no significant difference in how these item categories were scored by any respondent group. However, the overall means for these educational concept categories were ordered from most positively influenced by co-teaching to least positively influenced by coteaching as follows: professionalism and collaboration; classroom management; curriculum and lesson planning; student learning goals; content knowledge and instructional strategies; and assessment/data.

\section{Qualitative Interview Data Analysis}

The qualitative data were coded for patterns, generalizations, and themes (Creswell, 2014). Upon analysis, the researcher followed the six step coding process for qualitative data (Creswell, 2014, pp. 197-201) to review data. Step 1: The researcher organized and prepared the noted. Step 2: The researcher looked for data consistency within and across the groups. Step 3: The researcher began to group common observations into generalization categories. Step 4: The researcher generated a descriptive theme or themes based on generalizations. Step 5: The researcher created a 
narrative passage to describe the themes represented in the data. Step 6: The researcher interpreted the qualitative data couched in personal understandings and comparisons to literature and known theories.

Qualitative and quantitative data were triangulated to identify overarching themes between the qualitative and quantitative data. The triangulation of data also identified any disparate data. The researcher interpreted the overall data within the context of personal understandings and comparisons to literature and known theories.

\section{Finding One}

The co-teaching student teaching model provides a structure that closely aligns to the theoretical framework of Gradual Release of Responsibility (GRR), thus providing the first year teacher the guided learning experience needed to support his or her first year of teaching. The GRR model of instruction theorizes that the more skilled peer or, as

Vygotsky (1978) termed, More Knowledgeable Other (MKO), leads the learner through explicit instruction and guidance. The MKO gradually releases the responsibility of the determined skill or strategy until the learner is capable of independently applying the skill to new situations. Vygotsky stresses the fundamental role of social interaction in learning as he believed that community plays a central role in the process of making meaning. According to Vygotsky's cognitive development theory, cognitive development follows social interaction and learning is guided by a MKO.

Fisher and Frey (2008) define four phases of the GRR model based upon Vygotsky's theory. The first phase provides the learner with explicit instruction from the MKO. Fisher and Frey (2008) refer to this stage as a Focused Lesson or the "I do it" portion of instruction in which "I" refers to the MKO. The next stage of GGR is Guided 
Instruction or the "We do" phase of learning. This stage is based heavily on Vygotsky's idea of instructional scaffolding in which the lesson provides adult and peer support for performing the skill or strategy. During instructional scaffolding, the MKO works with the learner/s in a place of learning in which the novice must rely on support from the MKO or collaboration with peers to perform the targeted skill. Vygotsky refers to this place of learning as the Zone of Proximal Development (ZPD). The next phase of the GRR model is the collaborative phase or "You do it, together" phase. This stage is the beginning of the transfer of learning in which the MKO pulls away from a central role and becomes an observer of the learning. The learner must independently apply the skill or strategy while still engaged with peers. The last phase of the GRR model is the independent phase in which the learner applies his or her new learning to a new situation. The role of the MKO is to observe the independent work of the learner.

As the qualitative data were analyzed, some general categories emerged.

- The student teacher is provided extensive modeling of various educational concepts by the cooperating teacher.

- $\quad$ The co-teaching model provides a structure whereby there is the chance to have a singular focus, allowing baby steps to be taken in a Gradual Release of Responsibility.

- $\quad$ The co-teaching model provides a comfort level for the student teacher that is often termed as a "safety net" or "security blanket."

- The co-teaching model provides extensive amount of time for reflection and immediate feedback between the student teacher and cooperating teacher.

- $\quad$ The student teacher and cooperating teacher become equal partners. 
In the co-teaching model of student teaching, the cooperating teacher is always in the room providing extensive modeling. This structure aligns to the first stage of the Gradual Release of Responsibility called the "I do it" stage. The student teacher is able to observe the cooperating teacher in all daily student, parent, and teacher interactions, transitions, and instructional methods. As Student Teacher Seven noted in reflection of the modeling of the Missouri Teaching Standards, "Yes, you can observe (the Missouri Teacher Standards) through the traditional teaching aspect, but with co-teaching you are constantly seeing (the standards) in action. They are being modeled and you are learning from that." Student Teacher Seven also said, "My cooperating teacher modeled it by showing me what it should look like beforehand...seeing how (the cooperating teacher) handled situations, and having a good base of what it should look like and then being able to kind of mimic that and take those things and then tweak them and turn them into my own, really prepared me." Student Teacher Eight said, "The best way was just seeing how someone else taught, like taking ideas away from someone who does it every single day." Student Teacher Four referencing classroom discipline noted, "Being able to observe how (the cooperating teacher) handled situations kind of taught me to give a little benefit of the doubt to students. I was kind of a 'stick to the rules' kind of person and not all kids work off of that, so watching her helped me create a variety of classroom management strategies." University Supervisor Three said, "When (the cooperating and student teachers) are co-teaching, the student teacher can see (instructional strategies) in action whereas the opposed traditional cooperating teacher would have been out of the room." University Supervisor One noted in regards to the extensive modeling provided in the co-teaching model, "I feel that the student teacher that co-teaches develops more skills, more strategies, more confidence to be a better teacher than that teacher who is just catapulted in the classroom." 
Student Teacher Four noted the following:

I was one-on-one working with someone, getting her stuff and seeing the observation of it all. I think I worked better working with someone like that. I am a hands-on, visual person, so seeing it done and doing it with her is more memorable to me probably for me to be able to use in my classroom next time. But also it was nice to observe someone to see how they handled a situation differently than I probably would have and it gave me a better viewpoint on the situation.

Student Teacher One said the co-teaching model best supports teachers in preparation for their first year of teaching.

It gives the student teacher a model. At the beginning (the cooperating teacher) would teach the classes, and I would observe and it was really, really helpful to think, okay, this is what I should be doing. He had a great rapport with the kids and he was very interactive. I really appreciated that...I learned to be engaging and to work with the kids to keep them interested. I found that just incredibly helpful as a modeling kind of thing.

Student Teacher Two remarked, "I was able to see how my teacher within the classroom, how SHE did things. And then I was able to apply them in what I was doing, and I was also able to feel like I had more of a responsibility within the classroom. Student Teacher Nine said,

I think (co-teaching) prepared me very well because I was able to see so many things that I have come in contact with this first year of my teaching...I feel like I got a really good idea for what planning looks like, for what management looks 
like, the administrative side of things like how the day is done, how everything is turned in that needs to be turned in on my side, and parent communication. I'm so glad I was able to sit in on all the conferences...So I think that I was pretty well prepared. I don't feel like there were many things that caught me off guard this year."

Student Teacher Nine also said about her cooperating teacher, "She was a good role model as a teacher but also as a professional to show, like, this is how you behave in an educational environment." Cooperating Teacher 2 noted, "(Student Teacher) told me several times that she felt really well prepared going into teaching. And it wasn't just classroom discipline. It was also setting things up more efficiently in your classroom with your teaching or with your transitions. It was that she had the organizational skills to be more successful with transitions or doing different daily tasks." Student Teacher Five, who is now a second year teacher, noted,

I mean there are just several management and behavior management type things that I was able to mold into my own. The biggest parts of student teaching that I came out with was how to talk to kids in a way that they feel respected but also know what they did wrong and how to fix it later. And so I can just think of one student that my mentor teacher basically talked through this whole situation and she did not scold him. She did not talk down to him in any way, shape, or form, but she still got her message across, and he still learned a lesson from that experience. So that one memory is the thing that I kind of base how I talk to my student now.

Student Teacher Seven shared a similar story. "By seeing (the cooperating 
teacher) really kind of care and nurture those kids in the way that they needed it, whether it was the same way other students were cared for, I realized that was okay." The coteaching model of student teaching provided a structure that allowed for extensive modeling, or the "I do it" stage of GRR.

The second phase of GRR, described as the Guided Instruction or "We do" stage, is also closely aligned to the benefits of the co-teaching student teaching model. Data support the philosophy that the learner is eased into teaching with heavy support by the MKO. As Student Teacher Six noted, "I definitely feel (co-teaching) provides a lot more of the expectation of easing in and easing out." Cooperating Teacher Two noted,

(Co-teaching) helps on being able to focus on one thing as you're learning instead of everything at the same time. So for instance, we would do things like, 'Okay (student teacher), this week you are taking over the responsibility of spelling,' but we still shared the ideas and the teaching of it, although I would let her take the lead of it, and she would do the lesson plans while I watched. So I think that it probably helped with narrowing your focus instead of being so overwhelmed. You feel like there is a shared responsibility in the class, more like they are our students instead of mine or just hers. Co-teaching allows the student teacher to focus on more specific things they are trying to improve on or learn about instead of the whole thing at once."

Cooperating Teacher Three said, Co-teaching makes the experience like baby steps...I think when I had a traditional student teacher, it was, 'Okay, now this is all you. I'll come talk to you at the end of the day.' I think that the ability to do a little bit at a time, even if it's 
like starting off with Bell Work, that becomes her thing in the beginning. She designed it. She used our assessments to figure out what it needed to be, all that kind of stuff. And then it turned into, now we are going to plan on what to do based on what our formative data said, and so on and so forth. I didn't do that with traditional student teaching. With traditional student teaching, (the student teacher) just walked around and helped kids while I gave instruction, and then all the sudden had to fill my shoes.

The co-teaching model of student teaching provides a structure for guided instruction.

The co-teaching model continued to scaffold the student teacher learning in the "We do" phase of the GRR model of instruction by allowing the MKO to provide a comfort level of support for the student teacher often termed a safety net or security blanket. This is a part of the "We do" phase whereby the student teacher receives needed support from the MKO. As Cooperating Teacher one noted,

I think one of the things that new teachers struggle with is behavior management. So I think it is good in that case where they're not necessarily having to focus on that as much as content and how to teach the lessons. You know when there's two people in here, it's easier to monitor that type of stuff. And if something's happening, I'm always here to kind of guide her through and say, 'You might want to try this,' like in math where it's difficult."

University Supervisor Three said, "It gives (the student teachers) a safety net there. If they get handed off to classes a few weeks in then there is a lot of failing that goes on until they sort it out. It smoothens the transition." Student Teacher Nine said, "So 
(having the cooperating teacher there) was like having a safety net there, and it was comforting." University Supervisor One stated,

I think it provides (the student teacher) a comfort level that might not have been there previously. It also gives a security blanket because they know that the teacher is going to remain in the room. They're not going to fall on their face because the cooperating teacher is not going to let them. That gives them a personal boost. Like I've said, sort of a security blanket.

The "You do, together" phase of the GRR model is heavily supported by the coteaching model of student teaching due to the amount of immediate feedback and collaborative reflection the cooperating teacher can provide the student teacher. In the "You do, together" phase of GRR, the learner is responsible for the learning, but the MKO is closely watching and monitoring to provide feedback and reflection. The interview participants frequently mentioned immediate feedback and collaborative reflection as strong benefits of the co-teaching model. "By co-teaching, both the teacher and the co-teacher are able to assess pretty much immediately how things are going. And they are helping in small increments of time in the beginning so changes can be made and improvements can be made after reflections right away," noted Collaborative Teacher Six. Collaborative Teacher Three said,

I think if it was a traditional student teaching model, then we couldn't have gone back and forth with her practicing on things as much. If it was traditional and I just walked away, she would have had to figure things out. I think the fact that we could go back and forth and that I could take over part of a class and then she take over part of a class, or if we split the class and I took half and she took half, then we could talk about 
the experience. 'How did yours go and why?' So I think if we did it traditionally, she wouldn't have grown as much as she did."

Student Teacher Seven explained the "You do, together" phase this way. As I slowly began taking things over, once everything was mine, than I lesson planned with her, and I told her why I was going to do the things I was doing. Then she would offer suggestions or say, 'I've done those sort of things. It didn't really work out,' or 'That's a great ida. I think that will go really well.' And then if I was stuck or struggling to come up with things as a new teacher, she offered some insight and suggestions and really made it a team effort."

Student Teacher Five said, "You have someone there that you can lean on to guide you, because it is a learning experience. You're still learning and (co-teaching) provides several, actually not even several, TONS of coachable moments." Collaborative Teacher One noted, "Somebody is there to monitor, to bounce things off of, to process with...There's just somebody always there as a resource." Student Teacher Five noted, "(The cooperating teacher) really guided me and took me under her wing. I mean she was honest. If she thought something I was doing wasn't good, she had no problem telling me about it or telling me that I was doing really great. She was good at both." Student Teacher One explained how the "You do, together" feedback worked for her. "(The collaborative teacher) would say, "I saw you do this, this, and this and that was great. But you might think about doing this differently. Or maybe you shouldn't do this because it's not really that effective." Collaborative Teacher Five noted that because she was there in the room, she could hear the co-teacher giving lessons even when she was with another group. It gave the collaborating teacher the opportunity to guide the reflection, asking 
questions that she felt would pull out things she had seen or heard when they were reflecting how the lesson went, how they would change it, and what they would do differently. Cooperating Teacher Five shared the same sentiment.

I think co-teaching provides an opportunity for a lot of conversation about what is being taught and if it is working. Reflection. I think conversations came up as to what didn't work well. 'I should have done this instead which would have engaged them more.' I think a lot comes from the conversations and reflections. Would those opportunities be there if it was a traditional model of student teaching? I don't know, but I was here to witness the stuff. So when I was saying, 'How did you think that went?' I was looking for something in response, if she saw the same thing that I was kind of thinking. The important idea is that in the co-teaching experience, the most important vehicle is the conversations you have around planning your lessons and reflecting on the lessons. Those conversations are richer because you're both so involved in the process." Cooperating Teacher Four remarked,

I would think that (co-teaching) allows the cooperating teacher to be much more involved in the feedback process. I was always in here to say, 'This worked really well, or, if you tried it this way'...You're around them more to process. If I would have left her for two weeks straight, I wouldn't have known what was going on. I don't know that I would have been able to help a ton."

Student Teacher Three said, "I LOVED the reflection at the end of the day on daily decisions and what could be done differently. It was effective, made sense, and I loved that I got that."

Student Teacher Two shared a moment of feedback that strongly influenced her. There 
were certain things I began to notice behaviorally that I was able to pick out and address right there, and I specifically remember the cooperating teacher saying, 'That was good. Not many first-year teachers notice those type of things. I can tell you are becoming more perceptive of those type of things the students need or what corrections are needed.

Whenever I was the sole person in charge and took over the lesson and she was the guide, then she was able to give me tips afterwards, or she was able to jump in and add something that maybe I missed or helped me explain something I was having trouble explaining. So that was nice to have a person there to give their two cents or advice occasionally."

Student Teacher Six explained how immediate feedback supported him in classroom behavior.

I mean that classroom management experience was probably the greatest. And I lay a lot of that with my cooperating teacher who was very good at observing how I was managing classroom behavior or how I was not in some cases managing classroom behavior and kind of providing that supportive feedback throughout. So that was kind of the biggest thing."

Student Teacher Five sums up the reflection and feedback element of co-teaching and GRR with the following. "More than anything, my student teaching experience coached me."

The last phase of the GRR model is the independent phase in which the learner applies his or her new learning to a new situation. The role of the MKO is to observe the independent work of the learner. Where the traditional and co-teaching student teaching models differ is that in the traditional model, the MKO is gone and in the co-teaching 
model, the MKO remains as a collaborative partner. Respondents frequently mentioned the benefits of this final phase of GRR when the co-teachers are seen more as equal partners collaborating. Cooperating Teacher Four provides her view of the benefits of the collaboration. "I definitely think it was a mentorship. I think she learned a lot. I learned a lot. So I don't want to say that she was the only one learning. I learned a lot." Cooperating Teacher Four said of her student teacher, "She just did everything I did. We were PARTNERS. We both knew what we needed to do. She would bring ideas and we just knew what we needed to do and we would do it." Cooperating Teacher Three supported that idea.

When we planned it was like, 'Here's what we need to do,' and then we'd come back and say what each thought the best way to do this was. If her idea was awesome, we'd go with that. I mean it was just nice. The planning and the team work would be the best part of co-teaching."

University Supervisor 1 said of the equal partner relationship that builds, They'll always be part of each other's professional network. The cooperating teacher learns as well as the student teacher because of what they share with one another. They work as a team and that is what we want them to do. I've seen some marvelous examples of where it's like, 'Wow, you just finish one another's sentences.' One picks up where the other drops off in the middle of a sentence."

Student Teacher Four mentioned the positives of bringing her own ideas.

(The cooperating teacher) was really good at kind of showing me how SHE did things...but she also let me experiment with things. So I brought some things into her classroom that she hadn't really done that she LIKED and the vice versa." 
Student Teacher Nine said,

By the end, I felt like a colleague, like we were able to discuss things on the same level and communicate the same way, and were able to sort of handle the classroom the same way. I didn't really feel like a student at the end. I felt more like a professional and was treated like one."

Student Teacher Five said,

In the end, I was just as responsible for teaching as the lead teacher was. While she was the one I would go to if I had questions, I knew that we were both the same. I knew that the kids had to do exactly what they did for HER for ME. From day one I felt like I was just as responsible as she was for much of the day. And so just being that equal from day one really helped me.

The first theme that emerged from the qualitative data analysis was the coteaching student teaching model provides a structure that closely aligns the theoretical framework of Gradual Release of Responsibility (GRR). Participant responses supported this theme with statements that aligned to the phases of GRR.

The quantitative data that reflects the overall mean ordering of the educational concepts categories supports the qualitative data. Professionalism and Collaboration was the highest scoring category in how well the co-teaching model supports professionalism and collaboration for first year teachers.

\section{Finding Two}

Another finding supporting the first year teacher that emerged from the qualitative data was that co-teaching as a student teaching model provided the student teacher with confidence in his or her teaching early in the process. When asked how the 
co-teaching model best supported her first year of teaching, Student Teacher Two said, "Confidence. It really helped me to feel confident as a teacher because I saw myself as one of the teachers in the classroom, and so I built up confidence. I built up experiences through that confidence." She added, "I just remember that I did gain confidence throughout the semester even as a co-teacher, which I did appreciate in the model and didn't feel lacking because of it." Student Teacher Eight stated, "Co-teaching helped me to feel confident even when the kids were taller than me." Student Teacher Nine mentioned,

Co-teaching kind of helped me get over my self-consciousness of being in front of everybody. It was also kind of comforting to know that I had somebody there so if I tripped over my vocabulary or I missed a step, or was using the wrong algorithm, she could pipe in, because my biggest fear is teaching something incorrectly."

University Supervisor One also noted the idea of confidence building by the coteaching model.

I think (the student teachers) gain confidence more quickly because they know that someone has got their back. I see their confidence level growing and I know their cooperating teacher does too. There are plenty of times that I see One-Teach-One-Assist because they have that much confidence in the student teacher and the student teacher has enough content knowledge and self-confidence in their ability to handle the classroom that the classroom teacher just sort of takes a secondary role and the student teacher is the lead teacher throughout most of the semester.

\section{Finding Three}

By not completely and independently taking over the classroom, the student 
teacher does not get a fully realistic experience of teaching. While the participants report the co-teaching experience as building a strong base of knowledge and confidence, many reflect on the need to completely take over the planning, curriculum, delivery, and management of the classroom for a period of time to prepare the student teacher for time alone his or her first year of teaching. As Student Teacher Five said, "It would have been HELPFUL to have had the opportunity to plan EVERYTHING rather than being a coplanner, because then I would have had an idea of what it was like before I became a teacher. Co-teaching does not give student teachers the opportunity to be in charge of an entire class for all subjects, ever." Cooperating Teacher Two noted that one barrier to coteaching for the first year teacher, "May be feeling overwhelmed when it comes time for you to be responsible for your whole class and all things that encompasses, because we really didn't do that where I just left and it was just (the student teacher)." Student Teacher Five stated,

The only thing that I didn't like was that I always had somebody else in there with me. So then my first year of teaching I never had anybody in there with me, so I didn't have someone to lean on. I would have liked to have had two or three weeks of just me, solely me, making the decisions, making the plans, making the decisions about management. Those kinds of things. I would have liked to have had a couple of weeks of being solely responsible. I feel like I didn't get that from the co-teaching experience.

Cooperating Teacher Five believed that the traditional student teaching experience provided more of an opportunity for the student teacher to think through the whole day and take ownership because it was their class at that point. She believed that using the co-teaching models throughout the experience does not allow the student 
teacher to fit all the thematic pieces of the school day together into a unified whole. University Supervisor One mentioned,

Having $100 \%$ control authority over planning, over the curriculum, the delivery, the classroom management, all of the record keeping, everything, that is going to be a rude awakening for (first year teachers). And so that's why I feel (cooperating teachers) should back off at some point and let the student teachers have it all. The more (the student teachers) can be integrated into the whole load, the better off they are.

In addition to the planning and delivery, not having the opportunity to completely manage behaviors alone is seen as a barrier to preparing the student teacher for his or her first year of teaching. As Student Teacher Two reported,

I still feel like I had decent classroom management my first year of teaching. My principal said that, too. He can tell I had more experience in the classrooms as well, because I came in with some management techniques, but I do wish I would have had some opportunity to be the sole teacher in the classroom, because then it would have helped me to have that classroom management over the whole group without the other teacher there.

Cooperating Teacher One said,

Because, with two people in here, that certainly made sure there wasn't a lot of behavior issues. I think that since (behavior management) is probably something that you have to navigate on your own and figure out how to do, she probably didn't have as much of a chance to try her own thing and see what worked and kind of fall and have to figure it out on her own."

Student Teacher Nine noted, 
I do kind of wish I had that other time on my own, because I think it really impaired my classroom management experience, because (classroom management) was sink or swim this whole (first) year. It's the end of the year, and I feel like I'm finally getting ahold of what that looks like. I wish I had had more time with them, let them get more comfortable with JUST me, let them test my limits, and then have that experience with correcting and redirecting. If I were to go back and do it again, I would ask to just let me take them for a day or two."

Cooperating Teacher Five stated that even though she tried to encourage her students go to the co-student teacher, the students would instinctively come to her simply because she was in the room. She felt the student teacher missed out on the opportunity to work her way out of management situations. University Supervisor Two noted that,

When you have a (student teacher) that is actually trying to co-teach often the cooperating teacher takes over. I also feel like it is detrimental to the disciplinary part of classroom management. I feel like they get zero of that because the teacher is present and the kids won't try the student teacher. So they have no idea what they're about to step into by themselves."

Because of this lack of an extended period of solo teaching, it was noted that the co-teaching model may not completely prepare teachers for their first year of teaching because it does not give a fully realistic teaching experience. Cooperating Teacher One told the story of having a student who needed a lot of support. The student teacher would present a math lesson and then was to give a short, mini-lesson to this one particular student. However, the student loved working with the student teacher, so the student teacher would sit with her beyond the amount of time allotted for extra help. 
The student teacher's time was eaten up so nobody else could come to her. I did have to have a lot of conversation of, 'That isn't realistic. You can spend time with her, but you also have to be there with the other 24.' So when there are two of you in there, you are able to meet the needs of more students, but I don't know if that gives a real clear picture of what it's really like when you are the only one and you are having to meet the needs of everyone and monitor if everybody is getting what they need."

Student Teacher Eight explains, "Well, you simply just don't have somebody else with you (your first year of teaching). Right? I mean when you actually teach, you're on your own. I mean you have your mentors and stuff like that, but in your room you are on your own." University Supervisor Two noted,

It gives (the student teachers) a false sense of what teaching really is. It gives them a false sense of, 'I'm going to have someone catch me when I fall, and I'm going to have someone to take over that has more knowledge than me, and when I mess up, someone is going to fix it.' I can only speak for secondary. I can't speak to elementary. But from what I've seen in 7-12 is that co-teaching is just not real. There's no way a principal or superintendent is going to hire two teachers per class."

University Supervisor Three was of the same opinion.

I had an experience once where the principal said he would not hire a student teacher who had gone through co-teaching because his school does not co-teach...Unless (the first year teacher) has a Class-Within-a-Class, they don't have an extra teacher in the room.

University Supervisor Three then spoke to the cooperating teacher and the use of the co-teaching models. "I just think that some of these really experienced teachers sort 
of say, 'Is this the hot new thing on the market now?' They'll use what rings true to them and they'll skip over the part that seems artificial."

Finally, not having the opportunity to completely take over the class may develop a dependency of the student teacher on the cooperating teacher. Student Teacher Five said,

There are times now where I'm like, 'Oh, I really wish I had someone to lean on right now. Someone who could kind of coach me through this, right now in this moment. I know that I can always go to other teachers across the hall or to other teachers in the building, but it might not be right at that moment that I need them in my classroom. So that is the only reason why I feel co-teaching might not have supported my first year of teaching."

Student Teacher Seven noted,

In the real setting, I mean I have grade level partners, but I don't really have anyone else's opinion...I don't have anyone to run things by, so I'm kind of on my own. As long as I cover the standards, it's up to me how I want to teach it. In co-teaching, I always had support. I always had someone to bounce ideas off of. So that is one way I feel like I was kind of babied with co-teaching."

Cooperating Teacher Three said,

I think because I was so much of a support, I think sometimes she leaned on me. And even her first year of teaching, she still would come and want me to help her do some things, where I think if she were a traditional first year teacher, she would have had to learn on her own...She relied on me a lot and that might be a detriment in some ways." University Supervisor One spoke of the cooperating teacher as a safety net being 
both a positive and a negative.

It can be both. In the early weeks, it's positive, but at some point, and nearly every cooperating teacher tells me, (cooperating teachers) have to be able to walk out of the room and the student teacher has to take it. They're not prepared for their own classroom if they don't. They can't do complete co-teaching the whole semester. And I think that's a fallacy if they believe that they should because otherwise the student teachers are unprepared to go under contract. They've got to have full responsibility of the classroom. And so, that is why I say I have mixed feelings about co-teaching as a student teaching model. I think it's great for the first three or four weeks, and then as the cooperating and student teacher feel comfortable, there should be time alone.

University Supervisor Two said,

I think (co-teaching student teaching) enables (the student teacher). I think it gets them off the hook of what real teaching is like and how stressed you are when you're there seven hours a day on your feet. And I think that it gives them a sense that they're going to have someone to fall back on when they actually go out and get a job, and they're not. They're there by themselves."

So a barrier to the co-teaching student teaching model in preparing the first year teacher for his or her first year of teaching is that, by not completely and independently taking over, the student teacher does not get a fully realistic experience of teaching.

\section{Finding Four}

Participants suggest that student teachers would benefit from a structured time for the student teacher to totally take over the classroom based upon the professional decision of the cooperating teacher. Student Teacher Five said, 
I think that there should be a couple of weeks where the student teacher is having to make all the decisions. The co-teaching experience helped me more than it did not help me, but I do think that there should be a couple of weeks where the mentor teacher should kind of be phased out completely and the student teacher becomes $100 \%$ the teacher, BECAUSE in our district where I am, the majority of teachers are on their own for the day. I think that would have better prepared me by having just a few weeks of just me.

Student Teacher Two said,

I definitely like the idea of the co-teaching model, but I still think it is important that the student teacher has an opportunity, even if it is just one week, to be the sole planner of the lessons. And to be the sole person in charge of the lessons for the entire week so they have an idea of what it's really like when they become a teacher."

Cooperating Teacher One noted,

I think they need to have a time where it's just them. I mean, what if they hate being the only one in the classroom? I think they need some of that. Maybe it's just half day, maybe it's full days, maybe it's a week, maybe it's two, but I think that would give them more of an immersion in teaching, maybe. The safety net felt like it could be taken away. And I don't know if that's right, but you don't know until you do it. But the cooperating teacher has to understand that there also has to be processing daily if they're doing that.

University Supervisor One suggested a blend of co-teaching and solo teaching. I think (the university) needs to encourage (the cooperating and student teachers) to make a gradual release process, sort of a learning curve, where you start up high and 
the line would descend with less classroom teacher support and control from the middle to end of the semesters. Say three weeks or so the student teacher is the lead teacher. He or she has full responsibility. But along with that, $100 \%$ of the time the cooperating teacher needs to be engaged in the curriculum planning with the student teacher. So coteaching maintains throughout on that piece. The planning and reflection and all of that are still cooperative, but it's like a bubble where the student teachers maximize their classroom control about week six to twelve of their student teaching experience. That solo time should last at least three weeks.

University Supervisor Two's suggestions are much more limiting with the coteaching experience,

Co-teaching would be great the first three weeks for the teacher to model for the student and then they leave. So the co-teaching would actually be a limited type situation and it's modeling, it's coaching, it's modeling, it's coaching and then at the end of this...the cooperating teacher is outta there."

University Supervisor Three, however, believed a time schedule of release should fall more fully on the shoulders of the cooperating teacher.

I think there is no beating the wisdom of an experienced teacher as a guiding hand... When I get a very experienced cooperating teacher, I don't question what they do. They may fudge the rules of co-teaching because they believe that will help prepare this student teacher for his or her own classroom. So I trust the wisdom that comes with years of teaching...Use an experienced teacher's wisdom as one of the guides to help structure co-teaching.

The fourth theme that unfolded was the recommendation that student teachers 
would benefit from a structured time for the student teacher to totally take over the classroom based upon the professional decision of the cooperating teacher. 
VITA

Abby Elizabeth Volmer was born in Independence, Missouri, on September $10^{\text {th }}$, 1963, the second daughter of Mary Louise and James Bryson Pulley. After completing her work at Truman High School, Independence, Missouri, she entered Northwest Missouri State University in Maryville, Missouri. In May of 1985 she completed a Bachelor of Science degree in Elementary Education. During the following years she was employed as a teacher in Edmonton, Texas, and Tuloso-Midway, Texas. She returned to Missouri and worked as a teacher for eight years in the Kansas City Missouri School District. She entered graduate school at the University of Missouri, Kansas City in 1990 and graduated with a Master's Degree in Curriculum and Instruction (Elem Ed). In 1995 she worked with Parents as Teachers and in 1996 she was employed as a teacher in Odessa, Missouri. She has worked in Odessa, Missouri as a teacher, a middle school literacy coach, and the Director of Curriculum and Instruction, Assessment, Professional Development, and Federal Programs. In July of 2013 Abby entered the Graduate School at The University of Missouri a Doctor of Education Degree in Educational Leadership and Policy Analysis. 